MICHELI ZANOTTI GALON

\title{
Influência da composição da placa aterosclerótica nos resultados da angioplastia com stent coronariano
}

\author{
Tese apresentada à Faculdade de Medicina da \\ Universidade de São Paulo para obtenção do título \\ de Doutor em Ciências \\ Programa de Cardiologia \\ Orientador: Prof. Dr. Roberto Kalil Filho \\ Coorientador: Prof. Dr. Pedro Alves Lemos
}

São Paulo 
Dados Internacionais de Catalogação na Publicação (CIP)

Preparada pela Biblioteca da

Faculdade de Medicina da Universidade de São Paulo

Creproduçăo autorizada pelo autor

\section{Galon, Micheli Zanotti}

Influência da composição da placa aterosclerótica nos resultados da angioplastia com stent

coronariano / Micheli Zanotti Galon. -- São Paulo, 2017.

Tese (doutorado)--Faculdade de Medicina da Universidade de Săo Paulo.

Programa de Cardiologia.

Orientador: Roberto Kalil Filho.

Coorientador: Pedro Alves Lemos Neto.

Descritores: 1. Doença da artéria coronariana 2. Placa aterosclerótica 3. Vasos coronários 4 . Stents farmacológicos 5. Neointima 6.Tomografia de coerência óptica 7. Processamento de imagem assistida por computador

USP/FM/DBD-469/17 
Dedicatória 
Aos meus pais Suely e José Durval, por me apoiarem nas minhas escolhas, acreditando sempre na minha capacidade ao longo de todos esses anos.

Às minhas irmãs Camilla e Sabrina, das quais me orgulho por serem pessoas íntegras e verdadeiras. 
Agradecimentos 
Ao meu orientador, Prof. Dr. Roberto Kalil Filho pelos ensinamentos e incentivo para o meu ingresso na vida acadêmica. Seu exemplo de trabalho incansável e contínua busca pela excelência profissional me marcaram ao longo desse convívio.

Ao meu co-orientador, Prof. Dr. Pedro Alves Lemos exemplo de pesquisador comprometido com a ética e com a qualidade científica. Agradeço pelo tempo e empenho dedicados a essa pesquisa. Seu envolvimento e apoio neste projeto foram imprescindíveis e muito valiosos para o meu crescimento profissional.

Aos médicos assistentes do Setor de Hemodinâmica do Incor $\mathrm{Dr}$ Luiz Kajita, Dr Antônio Esteves, Dr Pedro Horta, Prof. Dr. Marco Perin, Prof. Dr. Expedito Ribeiro, Dr Marcos Gama, Dr Gilberto Marchiori, Dr André Spadaro, Dr José Mariani, Paulo Soares e Silvio Zalc pela e colaboração na realização dos procedimentos relacionados a essa tese.

Aos mestres e amigos Prof. Dr. Marco Costa, Dr. Hiram Bezerra, Dr. Guilherme Attizzani e Audrey Schnell pelo treinamento recebido nos meses que permaneci no Cardiovascular Imaging Core Laboratory, Harrington Heart \& Vascular Institute, University Hospitals, Case Medical Center em Cleveland nos Estados Unidos. O intenso intercâmbio de ideias e aprendizado científico moldaram a base técnica necessária para o meu desempenho neste projeto.

Aos médicos e amigos Dr. George Ximenes Meireles, Dr. Gilberto Marchiori e Dr. Sérgio Kreimer pelo apoio e incentivo constantes, viabilizando tempo para a minha dedicação a essa tese quando 
precisei me ausentar do Serviço de Hemodinâmica do Hospital do Servidor Público Estadual. Agradeço em especial ao Dr. George por ter tornado possível o meu afastamento junto ao Hospital do Servidor para o estágio em Cleveland, nos Estados Unidos.

À Profa. Dra. Ludhmila Abrahão Hajjar pelo exemplo de compromisso com a medicina e pelo incentivo durante os anos como médica assistente na Enfermaria de Pacientes Críticos do Incor. Agradeço também à Fernanda S. Feitosa e Cristiane M. Zambolim, colegas de pós-graduação e de trabalho na enfermaria, pela parceria e disponibilidade em ajudar.

À Patrícia, pela dedicação e empenho em todos os aspectos administrativos desse trabalho, desde a submissão desse projeto junto aos comitês, agendamento e atendimento dos pacientes.

Às Sras. Paula e Silvana pelo apoio administrativo e no agendamento dos procedimentos para estudo e reestudo angiográficos e por tomografia de coerência óptica necessários para esta tese.

Às enfermeiras Irinéia, Vera e Margarete e em especial aos técnicos de enfermagem da hemodinâmica do Incor pela ajuda na realização dos procedimentos desta tese.

Aos técnicos de radiologia Ivo, Fernando, Roberto, João Batista, João Arnoni e Nilson pela ajuda na realização dos procedimentos dessa tese. Agradeço em especial ao Ivo e Fernando pelo envolvimento direto nos exames de tomografia de coerência óptica. 
Aos amigos e colegas de trabalho na Hemodinâmica do Incor, Breno Falcão, Rafael Cavalcante e Carlos Campos pelo incentivo, generosidade e intercâmbio científico durante esses anos.

Aos membros participantes da minha banca de qualificação Prof. Dr. Roberto Rocha Giraldez, Dr. Adriano Caixeta e Dr. Celso Takimura pelas críticas e sugestões que contribuíram para a finalização desta tese.

À Comissão de Pós-graduação e a Sra Neusa Dini, Juliana e Valdecira pela atenção e orientação durante esta tese.

Aos pacientes envolvidos, pela confiança em mim depositada e pela colaboração com esta pesquisa. 
Normatização adotada 
Esta tese está de acordo com as seguintes normas, em vigor no momento de sua publicação:

Referências: adaptado de InternationalCommitteeof Medical JournalsEditors (Vancouver).

Universidade de São Paulo. Faculdade de Medicina. Divisão de Biblioteca e Documentação. Guia de apresentação de dissertações, teses e monografias. Elaborado por Anneliese Carneiro da Cunha, Maria Julia de A.L.Freddi, Maria F.Crestana, Marinalva de Souza Aragão, Suely Campos Cardoso, Valéria Vilhena. $3^{a}$ ed. São Paulo: Divisão de Biblioteca e Documentação; 2011.

Abreviatura dos títulos e periódicos de acordo com ListofJournalsIndexed in Index Medicus. 
Sumário 


\section{Lista de símbolos, siglas e abreviaturas}

\section{Lista de figuras}

\section{Lista de tabelas}

\section{Resumo}

\section{Abstract}

1 INTRODUÇÃO.

01

1.1 Intervenção coronária percutânea: balanço entre injúria vascular e ganho luminal

1.2 A composição da placa aterosclerótica e a pressão ideal para o implante do stent.

1.3 Tomografia de coerência óptica: princípios físicos e aplicações práticas no laboratório de cateterismo.

1.3.1 A tomografia de coerência óptica e seu papel na caracterização da placa aterosclerótica...

1.3.2 A tomografia de coerência óptica e o seu papel na avaliação dos stents coronários.

1.3.2.1 Aposição das hastes e expansão aguda do stent...

1.3.2.2 Lesão vascular periprocedimento e cobertura incompleta da lesão.

1.3.2.3 Avaliação da resposta vascular ao stent no seguimento tardio

1.4 Justificativas para este estudo

2 OBJETIVOS.

2.1 Objetivo primário

2.2 Objetivo secundário.

3.1 Desenho do estudo e considerações éticas......................... 17

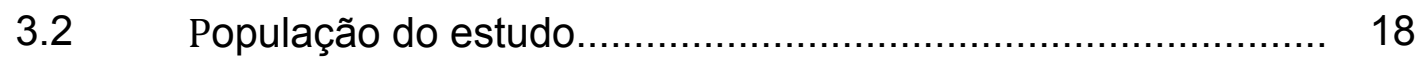


3.2.1 Critérios de Inclusão......................................................... 18

3.2.2 Critérios de Exclusão............................................................ 19

3.3 Procedimento Índice ...................................................... 21

3.3.1 Preparo dos pacientes..................................................... 21

3.3.2 Cuidados durante o procedimento.......................................... 21

3.3.3 Aquisição da imagem............................................................ 22

3.3.4 Tomografia de coerência óptica basal e após as dilatações sequenciais com balões...................................................... 24

3.3.5 Implante de stent guiado por Tomografia de Coerência Óptica. 25

3.3.6 Tomografia de Coerência Óptica após a angioplastia................ 30

3.4 Análise das imagens........................................................ 30

3.4.1 Medidas Quantitativas e Qualitativas da luz do vaso e da placa aterosclerótica na tomografia de coerência óptica basal do procedimento índice.

3.4.1.1 Medidas Quantitativas................................................... 32

3.4.1.2 Medidas Qualitativas.......................................................... 33

3.4.2 Medidas Quantitativas e Qualitativas do stent no

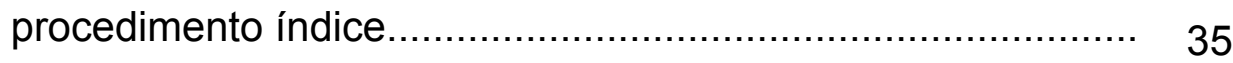

3.4.2.1 Medidas Quantitativas....................................................... 35

3.4.2.2 Medidas Qualitativas..................................................... 38

3.4.3 Medidas Quantitativas e Qualitativas do stent no reestudo

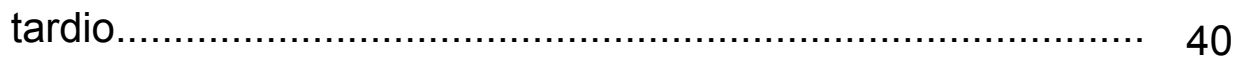

3.4.3.1 Medidas Quantitativas........................................................ 40

3.4.3.2 Medidas Qualitativas....................................................... 41

3.5 Evolução intra-hospitalar e acompanhamento ambulatorial..... 42

3.6 Considerações estatísticas.................................................... 43 
4. RESULTADOS

4.1 População do estudo......................................................... 46

$4.2 \quad$ Procedimento Índice....................................................... 47

4.2.1 Angiografia e Tomografia de coerência óptica: medidas quantitativas das imagens basais e do procedimento índice....

4.2.2 Efeitos agudos do implante do stent visibilizados pela tomografia de coerência óptica.

4.2.3 Medidas semi-quantitativas e quantitativas dos componentes da placa aterosclerótica

4.2.4 Composição da placa e seu impacto nos resultados agudos do implante do stent.

4.3 Resultados tardios do reestudo por tomografia de coerência óptica

4.3.1 Análise do stent haste a haste.

4.3.2 Relação entre os resultados do procedimento-índice e do reestudo avaliados pela tomografia de coerência óptica.

4.3.3 Injúria vascular no procedimento índice e seu efeito na formação do tecido neointimal.

4.4 Evolução intra-hospitalar e acompanhamento a longo prazo..... 69

$5 \quad$ DISCUSSÃO................................................................... 70

5.1 Maior área mínima do stent versus lesão vascular no procedimento índice.

5.2 Propriedades mecânicas da placa aterosclerótica e sua interação com o stent.

5.3 Tecido neointimal e sua relação com a composição basal da placa.

5.4 Limitações do estudo. 
CONCLUSÕES........................................................................ 81 


\section{Listas}




\begin{tabular}{|c|c|}
\hline$\%$ & porcentagem \\
\hline$<$ & menor que \\
\hline$=$ & igual \\
\hline$>$ & maior que \\
\hline \pm & mais ou menos \\
\hline $\mathrm{cm}$ & centímetro \\
\hline$g$ & grama \\
\hline $\mathrm{kg}$ & quilograma \\
\hline $\mathrm{h}$ & hora \\
\hline $\mathrm{m}$ & metro \\
\hline $\mathrm{mg}$ & miligrama \\
\hline $\mathrm{mm}$ & milímetro \\
\hline $\mathrm{mm}^{3}$ & milímetro cúbico \\
\hline $\mathrm{ml}$ & mililitro \\
\hline $\min$ & minuto \\
\hline $\mathrm{s}$ & segundo \\
\hline ug & micrograma \\
\hline$\mu \mathrm{m}$ & micrômetro \\
\hline Atm & Atmosferas \\
\hline CKMB & Creatina quinase $\mathrm{MB}$ \\
\hline DAC & Doença arterial coronariana \\
\hline $\mathrm{F}$ & French \\
\hline ICP & Intervenção coronária percutânea \\
\hline NC & Não complacente \\
\hline
\end{tabular}


OCT Optical Coherence Tomography

SCA Síndrome coronariana aguda

SC Stent convencional

SF Stents farmacológicos

UI unidade internacional

USIC Ultrassom intracoronário 
Figura 1

Imagem de seções transversas de tomografia de coerência óptica em sépia que ilustram os diferentes componentes da placa aterosclerótica baseado nas diferentes propriedades ópticas de cada tecido. A. Componente Fibrótico: sinal luminoso rico e homogêneo com espessura intimal $\geq 300 u m$. B. Componente lipídico: sinal luminoso pobre sobreposto por borda luminal com sinal rico, com limites difusos devido à alta atenuação ao sinal luminoso. C. Componente Calcificado: regiões heterogêneas com bordas bem delimitadas

Figura 2 Diagrama ilustrativo do desenho do estudo. OCT = optical coherence tomography, NC = não complacente

Figura 3 Dispositivos utilizados para a aquisição das imagens de Tomografia de coerência óptica. TCA: tempo de coagulação ativado, ICP: intervenção coronária percutânea.

Figura 4 Imagem ilustrativa das etapas do protocolo do estudo. A. Imagens da angiografia no momento basal em projeções ortogonais (à esquerda, imagens em escala de cinza) e imagens de secções transversas da tomografia de coerência óptica basal (à direita, imagens em sépia) com as respectivas medidas: A.1 área de referência (AR) do segmento distal; $A .2$ área luminal mínima (ALM); $A .3$ área de referência $(A R)$ do segmento proximal. B. Imagens da angiografia (à esquerda, imagens em escala de cinza) e subsequentes imagens de secções transversas da tomografia de coerência óptica (à direita, imagens em sépia) nas etapas sequenciais do implante do stent $\mathrm{e}$ pós-dilatações: B.1 implante do stent com 10 atm; B.2 
pós-dilatação com balão não complacente com 14 atm e B.3 pós-dilatação com balão não complacente com 20 atm. Observa-se neste exemplo o aumento na área do stent (AS) em todas as etapas do protocolo: basal para implante do stent a 10atm (ALM=0.96 $\mathrm{mm}^{2} \rightarrow \mathrm{AS}=3.79 \mathrm{~mm}^{2}$, aumento de $74.6 \%$ ), do implante do stent a $10 \mathrm{~atm}$ para a pós-dilatação a 14 atm (AS=3.79 $\mathrm{mm}^{2} \rightarrow 4.84 \mathrm{~mm}^{2}$, aumento de $21.7 \%$ ) e da pós-dilatação a 14 atm para $20 \mathrm{~atm}$ ( $A S=4.84$ $\mathrm{mm}^{2} \rightarrow 5.62 \mathrm{~mm}^{2}$, aumento de 13.8\%). Atm: atmosferas

Figura 5 Imagem esquemática do corregistro das imagens offline das diferentes etapas do estudo no procedimento índice (basal, 10atm, 14-16 atm, alta pressãoe/ou balão maior) e no reestudo. Para o corregistro das imagens foram usados marcadores anatômicos como ramos laterais

Figura 6 Imagem representativa de cortes transversais e longitudinal da tomografia de coerência óptica durante a avaliação qualitativa. As seções transversas foram avaliadas a cada $0,6 \mathrm{~mm}$ e divididas em 4 quadrantes. Cada quadrante foi classificado conforme a presença do componente de placa predominante: normal, lipídico, fibrótico ou calcificado

Figura 7 Imagem ilustrativa de seções transversas de tomografia de coerência óptica com as medidas quantitativas realizadas no procedimento índice. A. Seção transversa no ponto da área luminal mínima (ALM); visualizam-se pequenos pontos com sinal intenso de luz emitida e sombreamento em direção à 
parede do vaso correspondentes às hastes metálicas do stent recém implantado (seta amarela). B. Mesma seção transversa após a segmentação automática da área do stent (AS: em azul) e da área da luz ( $A L$ : em verde). Notam-se as hastes recém implantadas e sobrepostas à superfície da luz do vaso. Correções manuais foram feitas quando o algoritmo do software não reconhecia corretamente o contorno da luz do vaso, sendo traçado manualmente a delimitação da luz posterior à haste do stent. C. Corte longitudinal correspondente à aquisição das imagens pelo recuo automático do cateter de tomografia de coerência óptica, com a identificação da ALM e comprimento do stent (linha vermelha)

Figura 8 Figura ilustrativa da quantificação da malaposição das hastes do stent. Uma haste foi considerada malaposta quando a distância da superfície luminal do reflexo da haste do stent até o contorno luminal foi maior que a espessura da haste acrescida da espessura do polímero e do fármaco, acrescida de um fator de correção de $20 \mu \mathrm{m}$. Para o stent deste estudo este valor foi de $100 \mu \mathrm{m}$

Figura 9 Imagens ilustrativas de seções transversas de tomografia de coerência óptica representativas de prolapso tecidual durante o procedimento índice (setas amarelas). Identificado tecido projetado para dentro da luz do vaso entre as hastes do stent após seu implante e quantificado como distâncias haste-luz e áreas com valores positivos no procedimento índice. 
Figura 10 Imagem ilustrativa de seções transversas de tomografia de coerência óptica com as medidas quantitativas realizadas no reestudo. Painel da esquerda: A. Área da luz, B. Área do stent, C. Área do tecido neointimal; Painel da direita: análise da espessura do tecido neointimal (distância hasteluz).

Figura 11 Áreas luminais mínimas nas diferentes etapas do procedimento índice (basal, após o implante do stent a 10 atm, após a pós-dilatação com 14-16 atm e ao final do procedimento). Os gráficos mostram o comportamento mecânico das placas com pouco ou muito componente lipídico (painéis superiores), pouco ou muito conteúdo de vaso normal (painéis do meio), e pouco ou muito componente fibrocalcificado (painéis inferiores). As lesões foram divididas em 2 grupos usando a mediana de cada tipo de tecido como valores de corte para categorizar as lesões. Os valores de $\mathrm{P}$ se referem às comparações da área luminal mínima entre placas com pouco ou muito componente tecidual no mesmo momento do protocolo. Atm = atmosferas; barras de erro são intervalos de confiança 95\%; úmeros são medianas (intervalos interquartis)

Figura 12 Área total de prolapso de placa nas diferentes etapas do procedimento índice (após o implante do stent a 10 atm, após a pós-dilatação a 14-16 atm, e ao final do procedimento). Os gráficos mostram a quantidade de prolapso de placa dentro do stent na placa-alvo com pouco ou muito componente fibrocalcificado (painel 
superior), pouco ou muito componente lipídico (painel do meio), e pequeno ou grande arco de vaso normal (painel inferior). O valor de $\mathrm{P}$ refere-se à comparação da área luminal mínima entre placas com pouco ou muito componente tecidual na mesma etapa do procedimento. atm = atmosferas; as barras de erro são 95\% dos intervalos de confiança; números são medianas (intervalo interquartil).

Figura 13 Achados da tomografia de coerência óptica no seguimento tardio. Os gráficos mostram as medidas da área neointimal, percentual de obstrução neointimal e espessura da neointima na placa-alvo com com pouco ou muito componente fibrocalcificado $(A)$, pouco ou muito componente lipídico (B), e pequeno ou grande arco de vaso normal $(\mathrm{C})$. O valor de $\mathrm{P}$ referese às comparações entre a área luminal mínima das placas com pouco ou muito componente tecidual na mesma etapa do procedimento. Barras de erro são 95\% dos intervalos de confiança; números são medianas (intervalo interquartil).

Figura 14 Correlação entre as medidas da área de protrusão tecidual no procedimento índice e a área da neoíntima no reestudo com tomografia de coerência óptica.

Figura 15 Correlações entre índices de lesão vascular após o implante de stent (mudanças na área luminal mínima entre o pré-procedimento e o resultado final - painéis da esquerda; área de prolapso de placa ao final do procedimento índice - painéis da direita) versus os parâmetros de crescimento neointimal. 
Tabela 1 Características basais dos pacientes.

Tabela 2 Medidas quantitativas basais obtidas pela tomografia de coerência óptica - análise por artéria.

Tabela 3 Medidas quantitativas obtidas pela angiografia no procedimento índice.

Tabela 4 Achados sequenciais da tomografia de coerência óptica na região do stent durante 0 procedimento índice.

Tabela 5 Componentes da placa aterosclerótica no segmento da lesão tratada e nas referências: medidas semiquantitativas e quantitativas basais obtidas pela tomografia de coerência óptica - análise por artéria.

Tabela 6 Correlação entre as áreas da luz esperada e obtida e os componentes da placa aterosclerótica com as pressões 10 atm, 14-16 atm e ao final do procedimento - análise por artéria.

Tabela 7 Correlação entre as áreas do stent esperada e obtida e os componentes da placa aterosclerótica com as pressões $10 \mathrm{~atm}, 14-16$ atm e ao final do procedimento - análise por artéria.

Tabela 8 Correlação entre as áreas da luz esperadas e obtidas e componentes da placa aterosclerótica com as pressões 10 atm, 14-16 atm e ao final do procedimento - análise por segmentos.

Tabela 9 Correlação entre as áreas da stent esperada e obtida e componentes da placa aterosclerótica com as pressões $10 \mathrm{~atm}, 14-16 \mathrm{~atm}$ e ao final do procedimento - análise 
por segmento.

Tabela 10 Análise da tomografia de coerência óptica no seguimento tardio- análise haste a haste.

Tabela 11 Medida quantitativa da área luminal mínima nos diferentes momentos pressóricos e no reestudo tardio análise por artéria. 
Galon MZ. Influência da composição da placa aterosclerótica nos resultados da angioplastia com stent coronariano. [tese]. São Paulo: Faculdade de Medicina, Universidade de São Paulo; 2017.

Fundamentos: A caracterização precisa da interação da placa aterosclerótica no momento do implante do stent é crucial para o entendimento da complacência e da cicatrização vasculares. Objetivamos investigar se a composição da placa avaliada pela tomografia de coerência óptica (OCT), influencia as alterações agudas no procedimento índice do implante do stent e na cicatrização vascular no seguimento tardio.

Métodos: Os pacientes tratados com um único tipo de stent eluidor de fármaco (cromo cobalto, eluidor de sirolimus e polímero bioabsorvível) foram incluídos prospectivamente, seguindo um protocolo com etapas de dilatações progressivas do vaso. As imagens de OCT sequenciais foram realizadas no procedimento índice (basal e a cada etapa do protocolo) e no seguimento tardio, co-registradas e analisadas a cada $0,6 \mathrm{~mm}$. A avaliação semiquantitativa da placa foi realizada dividindo-se secções transversas em 4 quadrantes, com cada quadrante rotulado de acordo com o seu componente mais prevalente (fibrótico, calcificado, lipídico, normal). A interação stent-vaso avaliada pela OCT foi utilizada como indicador substituto para lesão e cicatrização vasculares após o implante do stent.

Resultados: Um total de 22 lesões (1stent/lesão) de 20 pacientes e 2298 seções transversas de OCT foram analisadas no procedimento índice. O reestudo com OCT foi realizado em 17 pacientes e 19 lesões (86\%). O 
componente de placa predominante foi fibrótico (fibrótico $=46.84 \pm 16 \%$; lipídico $=17.63 \pm 10.72 \%$; calcificado $=4.63 \pm 5.9 \%$; normal $=29.16 \pm 12.24$; não analizável=1.74 $\pm 5.35 \%$ ). Houve um aumento nas áreas da luz (10atm = $5.5(4.5-7.4) \mathrm{mm}^{2}, 14-16 \mathrm{~atm}=6.0(4.7-7.70) \mathrm{mm}^{2}, 20 \mathrm{~atm}=6.7(5.5-8.2)$ $\mathrm{mm} 2 ; \mathrm{P}<0.001)$ e do stent $\left(10 \mathrm{~atm}=5.2(4.3-7.0) \mathrm{mm}^{2}, 14-16 \mathrm{~atm}=5.7(4.5-\right.$ 7.5) $\left.\mathrm{mm}^{2}, 20 \mathrm{~atm}=6.5(5.3-7.9) \mathrm{mm}^{2} ; \mathrm{P}<0.001\right)$, com um aumento na área do prolapso tecidual $\left(10 \mathrm{~atm}=0.09(0.06-0.12) \mathrm{mm}^{2}, 14-16 \mathrm{~atm}=0.10(0.06-\right.$ $\left.0.15) \mathrm{mm}^{2}, 20 \mathrm{~atm}=0.15(0.08-0.20) \mathrm{mm}^{2} ; \mathrm{P}<0.01\right)$. Segmentos com muito tecido fibrocalcificado tiveram áreas luminais menores ao longo das etapas da intervenção. Por outro lado, placas com muito conteúdo lipídico ou vaso normal tiveram maiores ganhos nas medidas das áreas luminais mínimas ao longo das dilatações sequenciais. Além disso, placas com muito tecido fibrocalcificado no momento basal apresentaram menor crescimento neointimal no seguimento tardio, enquanto que o grau de conteúdo lipídico e de vaso normal não tiveram impacto sobre a formação do tecido neointimal. Os indicadores substitutos de lesão vascular após o implante do stent correlacionaram-se significativamente com o crescimento neointimal no seguimento tardio.

Conclusões: A composição tecidual das placas subjacentes influencia significativamente o comportamento mecânico agudo e a longo prazo dos vasos coronarianos submetidos ao implante de stent. Além disso, a lesão vascular após o implante do stent está potencialmente ligada ao futuro crescimento neointimal no seguimento tardio. 
Descritores: doença da artéria coronariana; placa aterosclerótica; vasos coronários; stents farmacológicos; neointima; tomografia de coerência óptica; processamento de imagem assistida por computador. 
Abstract 
Galon MZ. Influence of atherosclerotic plaque composition on the results of coronary angioplasty with stent implantation [thesis]. São Paulo: Faculdade de Medicina, Universidade de São Paulo; 2017.

Background Accurate characterization of atherosclerotic plaque interaction during stent deployment is crucial to understand vascular compliance and healing. We sought to determine whether plaque composition assessed by optical coherence tomography (OCT), influences acute changes at index procedure and vascular healing at follow up.

Methods Patients treated with a single drug-eluting stent type (cobalt chromium with bioabsorbable polymer eluting sirolimus stent) were prospectively included, following a pre-defined step-by-step progressive vessel dilatation. Sequential OCT imaging were performed at the index procedure (baseline and at each time point of the protocol) and at follow up, co-registered and analyzed every $0.6 \mathrm{~mm}$ for quantitative measurements. Semi-quantitative plaque assessment was performed at baseline by dividing cross-sections into 4 quadrants, with each quadrant labeled according to its most prevalent component (fibrotic, calcific, lipid). OCT assessments of stent-vessel interactions were used as a surrogate for vessel injury and healing after stent implantation.

Results A total of 22 lesions (1stent/lesion) of 20 patients and 2298 OCT crosssections were analyzed at the index procedure. For an average of 19.7 months (591.88 \pm 60.52 days), 17 of the patients and 19 lesions (86\%) underwent OCT imaging at follow up. The predominant percentage plaque component was fibrotic (fibrotic $=46.84 \pm 16 \%$; lipid $=17.63 \pm 10.72 \%$; calcific $=4.63 \pm 5.9 \%$; 
normal $=29.16 \pm 12.24$; non-analyzable $=1.74 \pm 5.35 \%)$. There was an increase in lumen $\left(10 \mathrm{~atm}=5.5(4.5-7.4) \mathrm{mm}^{2}, 14-16\right.$ atm $=6.0(4.7-7.70)$ $\mathrm{mm}^{2}, 20$ atm $\left.=6.7(5.5-8.2) \mathrm{mm}^{2} ; \mathrm{P}<0.001\right)$ and stent $(10 \mathrm{~atm}=5.2(4.3-7.0)$ $\left.\mathrm{mm}^{2}, 14-16 \mathrm{~atm}=5.7(4.5-7.5) \mathrm{mm}^{2}, 20 \mathrm{~atm}=6.5(5.3-7.9) \mathrm{mm}^{2} ; \mathrm{P}<0.001\right)$ areas, with an increase in tissue prolapse area $\left(10 \mathrm{~atm}=0.09(0.06-0.12) \mathrm{mm}^{2}\right.$, 14-16atm $=0.10(0.06-0.15) \mathrm{mm}^{2}, 20$ atm $\left.=0.15(0.08-0.20) \mathrm{mm}^{2} ; \mathrm{P}<0.01\right)$. Segments with high fibrocalcific content tended to have decreased minimal luminal areas along the intervention time-points. Conversely, plaques with high lipid content had increased minimal luminal areas during sequential dilatations. Moreover, plaques with high fibrocalcific tissue at baseline had significantly smaller neointimal growth at follow-up, whereas the degree of lipid content or normal tri-layered vessel had no impact on neointimal formation. OCT surrogates of vessel injury after coronary stenting significantly correlated with neointimal growth at follow-up.

Conclusions: Tissue composition of underlying plaques significantly influences the acute mechanical and the long-term behavior of coronary vessels undergoing stent implantation. In addition, vessel injury after coronary stenting is potentially linked to future neointimal growth at follow-up.

Descriptors: coronary artery disease; atherosclerotic plaque; coronary vessels; drug-eluting stents; neointima; optical coherence tomography; computerassisted image processing. 

1. Introdução 


\subsection{Intervenção coronária percutânea: balanço entre injúria vascular e ganho luminal}

O implante de stent por balão expansível no tratamento da doença arterial coronariana estenótica impõe à parede arterial um estresse não fisiológico. Esta injúria aguda causada pela dilatação do balão e pelo implante do stent resulta em lesões iniciais como desnudação endotelial, deposição de trombos e agregação de monócitos ${ }^{1}$. Subsequentemente, tal injúria desencadeia os processos biológicos associados à reestenose (isto é, inflamação, proliferação das células musculares / fibroblastos e deposição de matriz proteica). Nos casos em que a artéria é incapaz de se adaptar ou remodelar com sucesso a esta situação biomecânica recém-imposta, observase a reestenose. No entanto, sabe-se que a expansão adequada do stent é de importância crucial para otimizar os resultados da intervenção coronária percutânea (ICP). Sua expansão incompleta e aposição inadequada de suas hastes à parede do vaso aumenta o risco de trombose do stent, evento potencialmente catastrófico de especial preocupação na era atual dos stents farmacológicos ${ }^{2-5}$. Além disso, a expansão sub-ótima do stent predispõe à reestenose tanto nos stents convencionais quanto nos farmacológicos ${ }^{6-8}$.

O conceito de que "maior é melhor" há muito tem sido considerado um corolário para a intervenção coronária percutânea. A teoria foi baseada na suposição de que maiores tamanhos finais luminais estariam associados positivamente à melhoria dos resultados clínicos - vários estudos angiográficos e com ultrassom intracoronário (USIC) mostraram que maiores dimensões luminais após a intervenção coronária percutânea cursaram com menores 
riscos de trombose e reestenose tardia, tanto para stents convencionais como para os com eluição de fármacos ${ }^{7-12}$.

Como consequência desta afirmativa, uma grande variedade de estratégias intervencionistas com o objetivo de aumentar as dimensões luminais finais foram investigadas ao longo dos últimos anos. Estudos prévios demonstraram que ao aumentar a pressão de dilatação ocorreria um aumento proporcional no tamanho luminal pós-stent ${ }^{13-15}$. De igual modo, com a utilização de métodos de imagem intravascular para guiar a intervenção

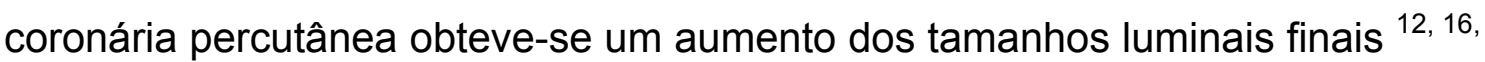
17. Paradoxalmente, contudo, nem implante de stent com alta pressão nem intervenção coronária percutânea guiada por métodos de imagem intravascular foram uniformemente associados a melhores resultados clínicos e angiográficos 14-16,18. Metanálises recentes que englobaram estudos randomizados e observacionais, evidenciaram que a angioplastia guiada por ultrassom intracoronário foi associada a menor risco de morte, infarto do miocárdio, revascularização de lesão-alvo e trombose de stent após o implante de stent farmacológico ${ }^{17,19}$.

Uma das explicações mais citadas para a falta de resultados conclusivos dos estudos é o emprego de estratégias intervencionistas conflitantes utilizadas nos vários estudos. De fato, atualmente, os especialistas ainda buscam estabelecer a melhor forma de usar métodos de imagem intravascular durante a intervenção coronária percutânea - a utilização das informações obtidas préintervenção, a melhor estratégia de dilatação, bem como os melhores parâmetros para guiar a intervenção são temas sob intenso debate ${ }^{16,}$ 20-22. Obstante, independentemente dos parâmetros utilizados ou da estratégia 
adotada, em geral, o uso corrente da imagem intravascular durante a intervenção coronária percutânea é limitado principalmente para a medição de dimensões e de monitoramento de complicações mecânicas (por exemplo, dissecções de borda de stent), com o objetivo de orientar a seleção de balões e tamanhos de stents e avaliar o êxito da dilatação.

\subsection{A composição da placa aterosclerótica e a pressão "ideal“" para o implante do stent}

Placas com composições diferentes podem responder de forma diferente às forças mecânicas que atuam durante a dilatação empregada na intervenção coronária percutânea ${ }^{23,24}$. De fato, um estudo prévio mostrou que as placas com aparência "mole" ao USIC foram associadas com o aumento das taxas de reestenose após a intervenção coronária percutânea "padrão" que emprega altas pressões ${ }^{25}$. Em contraste, placas mecanicamente "duras", ou seja, resistentes à dilatação podem precisar de preparação mais intensa antes do implante do stent, com o objetivo de otimizar os tamanhos luminais pósstent. Este fato pode explicar a proporção relativamente grande de lesões que permanecem com tamanhos luminais finais sub-ótimos, mesmo após o emprego de pós-dilatação agressiva do stent, ainda que guiado por imagem intravascular ${ }^{16}$.

É, portanto, possível que uma caracterização mais refinada da composição da placa, que atualmente não é normalmente considerada quando feito o planejamento da estratégia intervencionista, possa melhorar os resultados da intervenção coronária percutânea. Para analisar tal hipótese é 
desejável o emprego de uma modalidade de imagem intravascular capaz de identificar, classificar e quantificar os diferentes componentes da placa.

\subsection{Tomografia de Coerência Óptica: princípios físicos e aplicações práticas no laboratório de cateterismo}

A tomografia de coerência óptica (optical coherence tomography OCT) é uma tecnologia de imagem intravascular utilizada na prática clínica diária capaz de fornecer imagens tomográficas transversais de estruturas biomédicas com definição superior a qualquer outra modalidade intravascular disponível atualmente ${ }^{26-28}$. A capacidade de resolução da tomografia de coerência óptica é devido à utilização de luz infravermelha como a sua fonte de sinal. Utilizando estas propriedades, a tomografia de coerência óptica é capaz de obter uma resolução espacial de até 10 um, 10 vezes maior que a do ultrassom intravascular ${ }^{26,28}$. Esta resolução aumentada, no entanto, ocorre à custa da menor capacidade de penetração nos tecidos. A absorção e dispersão da luz pelos tecidos biológicos limita a tomografia de coerência óptica para uma profundidade de $2 \mathrm{~mm}$ na parede do vaso.

Atualmente, o sistema fourier domaine de tomografia de coerência óptica está disponível comercialmente no Brasil (St. Jude / LightLab imagem Inc, Westord, MA). A sonda óptica é integrada a um cateter de 2,7-F compatível com cateteres-guia 6-F. O sinal óptico é transmitido por uma fibra de modo único, o qual está equipado com um conjunto de micro prisma com lente integrada para focar o feixe e dirigi-lo para o tecido. A fim de fazer a varredura do vaso no sentido do comprimento, a ponta do cateter de imagem é 
tracionada durante a rotação, dentro de uma bainha transparente, permitindo a obtenção de um conjunto de dados tridimensional da artéria coronária.

Para a obtenção da imagem, o cateter de OCT é avançado distalmente no interior da artéria coronária através de um fio-guia de angioplastia padrão $(0,014$ "). O recuo do cateter de OCT é acionado automaticamente (velocidade de recuo é de habitualmente $20 \mathrm{~mm} / \mathrm{s}$ ) pela injeção do meio de contraste isosmolar através do cateter-guia. Em artérias coronárias, o sangue representa um tecido não transparente causando espalhamento múltiplo e atenuação do sinal. Consequentemente, o sangue deve ser eliminado do campo de visão durante a aquisição da imagem de tomografia de coerência óptica.

À medida que a velocidade da luz é muito maior que a de som, um interferômetro é necessário para medir a luz retrodifundida. O interferômetro divide a fonte de luz em dois "braços": um braço de referência e um braço de amostra, o qual é dirigido para o tecido. A luz de ambos os braços é recombinada com um detector, que registra o chamado interferograma, a soma dos campos de referência e braço de amostra ${ }^{29}$.

\subsubsection{Tomografia de Coerência Óptica e seu papel na caracterização da placa aterosclerótica}

Visto que os vários componentes das placas ateroscleróticas têm diferentes propriedades ópticas, é possível classificá-las em quatro tipos teciduais: lipídico, fibrótico, calcificado e normal ${ }^{30-32}$. Tal identificação dos componentes da placa depende da profundidade de penetração do feixe de luz 
incidente na parede do vaso (figura 1). A profundidade de penetração é maior para o tecido fibroso e menor para trombos, tendo o cálcio e o componente lipídico valores intermediários ${ }^{33}$. Estudos prévios de tomografia de coerência óptica com espécimes de autópsia serviram para a validação dos diferentes componentes da placa aterosclerótica e identificação de critérios objetivos, com elevada sensibilidade e especificidade para a caracterização destes ${ }^{34,35}$.Os componentes da placa aterosclerótica seguem as seguintes definições ${ }^{36}$ :

- Placas fibróticas: são tipicamente ricas em células musculares e colágeno e têm um sinal rico e homogêneo à tomografia de coerência óptica.

- Calcificações no interior das placas: são identificadas como regiões heterogêneas e bordas bem delimitadas.

- Tecidos ricos em lipídios: são menos delimitados do que as calcificações, aparecendo com bordas difusas. Correspondem a regiões com sinal pobre sobrepostas por borda luminal com sinal rico, o que corresponde aos limites fibróticos. A superioridade da tomografia de coerência óptica para a detecção de placa rica em lipídios foi confirmada em outros estudos nos quais comparou-se a OCT com o ultrassom intravascular e técnicas de derivados do USIC para a análise de composição da placa ${ }^{32,37}$. 

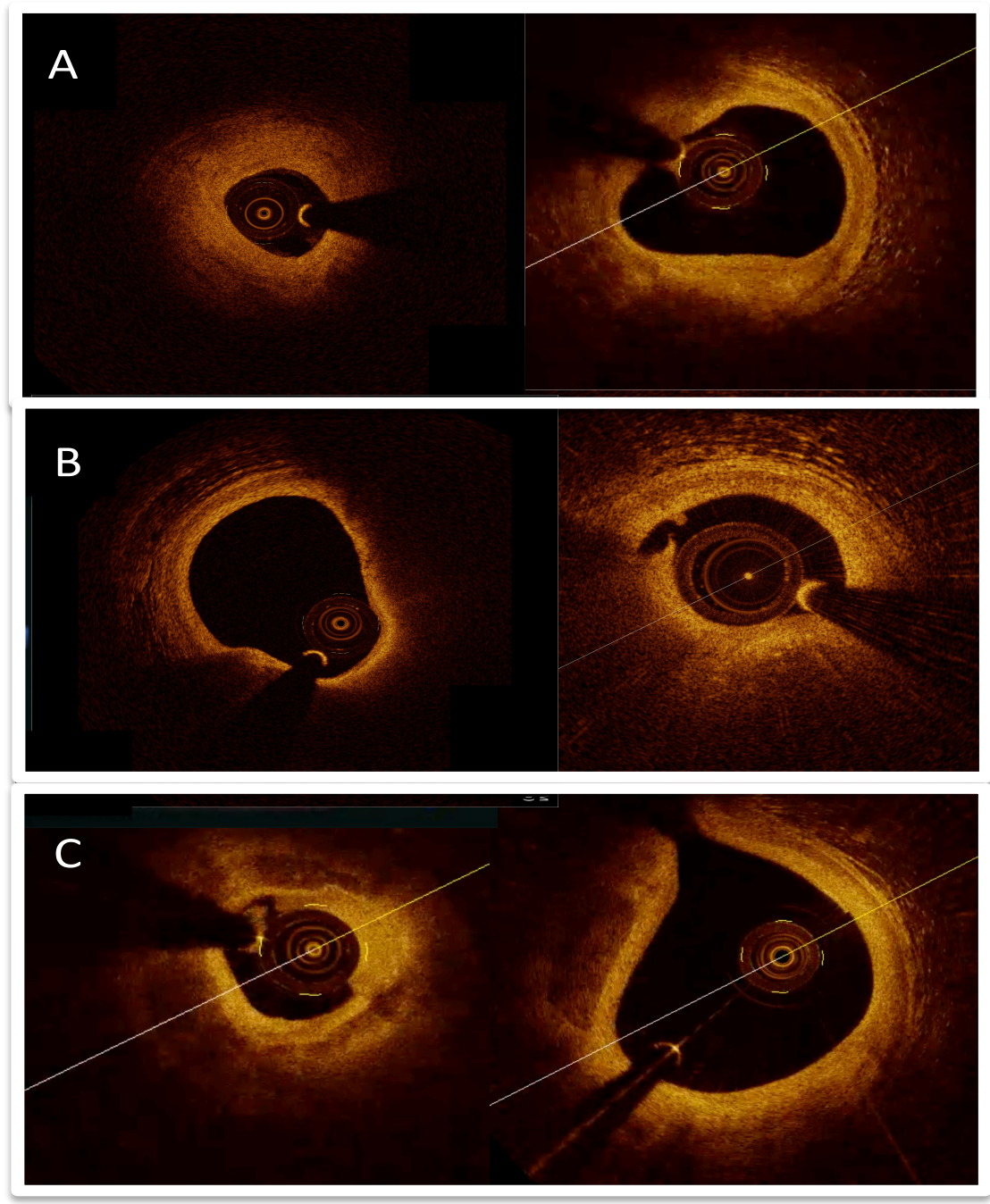

Figura 1 - Imagem de seções transversas de tomografia de coerência óptica em sépia que ilustram os diferentes componentes da placa aterosclerótica baseado nas diferentes propriedades ópticas de cada tecido. A. Componente Fibrótico: sinal luminoso rico e homogêneo com espessura intimal $\geq 300 u m$. B. Componente lipídico: sinal luminoso pobre sobreposto por borda luminal com sinal rico, com limites difusos devido à alta atenuação ao sinal luminoso. C. Componente Calcificado: regiões heterogêneas com bordas bem delimitadas. 


\subsubsection{A tomografia de coerência óptica e o seu papel na avaliação dos stents coronarianos}

Devido ao feixe de luz da tomografia de coerência óptica ser completamente refletido pela haste metálica do stent, a imagem gerada se traduz por um sinal brilhante intenso na sua superfície e sombra em direção à parede do vaso ${ }^{38}$. Desta forma, delimita-se com alta precisão as áreas do stent e da luz, bem como distâncias das haste para a luz do vaso individualmente (análise haste a haste do stent). De forma análoga ao ultrassom intracoronário, estas características fazem da tomografia de coerência óptica uma ferramenta importante na prática intervencionista, uma vez que possibilita a avaliação desde o resultado agudo após o implante de stent, fornecendo informações valiosas sobre a expansão stent, aposição de hastes e sinais de trauma vascular como dissecções e prolapso tecidual, até o resultado da cicatrização do vaso e endotelização do stent ${ }^{39-42}$.

O acúmulo de evidências científicas até o presente momento corroboram para um papel da tomografia de coerência óptica para guiar várias etapas da ICP, bem como para a avaliação de novos dispositivos intracoronarianos, como na verificação dos vasos tratados e na identificação dos mecanismos envolvidos quando da falha do stent $22,36,43,44$.

\subsubsection{Aposição das hastes e expansão aguda do stent}

A OCT permite visibilizar a complexa estrutura da parede arterial coronária após o implante do stent de forma detalhada. Semelhante ao 
ultrassom intracoronariano, a tomografia de coerência óptica permite a avaliação de áreas tanto dentro do segmento arterial com stent, bem como nos segmentos de referência adjacentes, permitindo assim a avaliação da expansão do stent. No cenário pós-implante imediato do stent, estudos com OCT demonstram uma proporção relativamente elevada de hastes não completamente apostas à parede do vaso. Em torno de 62-77\%, para a primeira geração de stents farmacológicos e $74 \%$ para a segunda geração de stents farmacológicos esta malaposição havia resolvido após o seguimento de 8-12 meses ${ }^{45,46}$. Estes estudos demonstraram que o melhor valor de corte para distância da malaposição intra-stent no pós-implante capaz de predizer malaposição tardia persistente aos 8-12 meses variou de 260 a $385 \mu \mathrm{m}$. No entanto, a malaposição do stent no pós-implante imediato não foi associada a um risco aumentado de eventos clínicos relacionados ao stent no seguimento de 1 ano semelhante a outros estudos com seguimento mais curto $39,42,47,48$. Possíveis explicações incluem a melhoria ou resolução da malaposição durante o período de acompanhamento, efetiva prevenção da trombose de stent com o uso de terapia de antiagregação plaquetária dupla e a alta sensibilidade da OCT para a detecção da malaposição ${ }^{39}$.

A área mínima do stent e a área luminal inadequadas estão associadas à reestenose intra-stent, revascularização de lesão-alvo e trombose de stent ${ }^{11}$, 44, 49, 50. Um estudo anterior evidenciou menor área luminal mínima na intervenção coronária percutânea guiada pela tomografia de coerência óptica do que na guiada pelo ultrassom intracoronário, aventando a hipótese de que as medidas luminais aferidas pela tomografia de coerência óptica poderiam potencialmente resultar em diâmetros de referência subestimados e menores 
áreas mínimas intra-stent quando comparados à intervenção coronária percutânea guiada por ultrassom intracoronário ${ }^{51}$. Mais recentemente, uma análise pareada de dois estudos prospectivos mostrou não haver diferença na expansão do stent obtida pelos dois métodos ${ }^{52}$.

\subsubsection{Lesão vascular periprocedimento e cobertura incompleta da lesão}

A expansão adequada do stent muitas vezes requer altas pressões de liberação ou pós-dilatação, ocasionando lesões na parede dos vasos. Gonzalo et al publicou o primeiro estudo sobre os achados pós-implante de stent vistos pela tomografia de coerência óptica e vários estudos subsequentes investigaram o significado clínico destes achados ${ }^{40,45,48}$. Esses estudos, no entanto, foram unicêntricos e com amostras pequenas. Entre estes estudos, a incidência de dissecção de borda de stent e dissecção intrastent variou amplamente: $15 \%$ a $37 \%$ para dissecção de borda e $44 \%$ a $98 \%$ para dissecção intrastent ${ }^{48,53,54}$. Esta variabilidade pode derivar de diferenças nas definições utilizadas em cada estudo. Outro fator associado `a dissecção de borda foi a presença e o tipo de placa nas bordas do stent, sendo a sua ocorrência mais frequente nas placas fibrocalcificadas $(43,8 \%)$ ou ricas em lipídios $(37,5 \%)$ do que na placa fibrosa $(10 \%)(P=0,009)^{55}$.

\subsubsection{Avaliação da resposta vascular ao stent no seguimento tardio}

A tomografia de coerência óptica detecta com segurança a presença de camadas muito finas de cobertura tecidual nas hastes do stent e a sua 
quantificação pode ser realizada com alta reprodutibilidade. Isto a torna a ferramenta ideal para quantificar as diferenças sutis, mas potencialmente relevantes na avaliação dos diferentes tipos de plataformas, polímeros e fármacos constituintes dos stents disponíveis para o uso clínico atualmente ${ }^{46}$, 56, 57. Permite abordar questões clínicas inquietantes tais como a relação entre um stent eluidor de fármaco específico e sua cicatrização, seu verdadeiro tempo de cobertura tecidual e risco de trombose tardia do stent. Tais informações também podem orientar melhor a duração da terapia antiplaquetária dupla.

Apesar de alguns fatores envolvidos no processo de cicatrização dos stents serem relacionados ao próprio stent, como polímero e tipo de fármaco empregado nos stents eluidores de fármacos, outros fatores extrínsecos a ele estão presentes. Um deles é a morfologia da lesão tratada pelo stent.

\subsection{Justificativas para este estudo}

É no contexto do exposto, sumarizado abaixo, que se insere o presente estudo:

1) Tamanhos luminais maiores pós-stent estão relacionados com melhores resultados;

2) No entanto, as estratégias para aumentar o ganho luminal após o implante do stent não melhoraram os resultados. As razões relacionadas com a falta de eficácia dessas estratégias permanecem desconhecidas; 
3) Abordagens técnicas para aumentar o tamanho luminal pós-stent, incluindo intervenção coronária percutânea guiada por ultrassom intracoronário, estão normalmente associadas a uma abordagem com dilatações mais agressivas - o que pode induzir o aumento da lesão do vaso e, finalmente, amplificar a resposta cicatricial local, podendo contrabalançar negativamente o ganho luminal inicial;

4) Além disso, muitos pacientes não atingem dilatação ideal do stent, mesmo depois de dilatações agressivas guiadas por imagem intravascular - nestes casos, os efeitos adversos de lesão adicional ao vaso podem ser ainda mais evidentes, uma vez que não está associada com uma maximização do ganho luminal agudo;

5) A composição das placas pode ser o problema central, modulando os resultados da intervenção coronária percutânea, uma vez que é possível que o tipo de tecido subjacente ao segmento acometido possa:

a. agudamente, influenciar a resposta mecânica às forças de dilatação e

b. posteriormente, influenciar a resposta cicatricial e crescimento do tecido neointimal.

É, portanto, possível que uma caracterização mais refinada da composição da placa, que atualmente não é normalmente considerado quando feito o planejamento da estratégia intervencionista, possa melhorar os resultados da intervenção coronária percutânea. No presente estudo, utilizamos a tomografia de coerência óptica para avaliar a hipótese de que os resultados após o implante do stent coronário sejam significativamente influenciados pela composição da placa aterosclerótica-alvo. 
2. Objetivos 


\subsection{Objetivo primário}

Avaliar a influência da composição tecidual da placa aterosclerótica no segmento alvo coronariano analisado pela tomografia de coerência óptica sobre o implante do stent, empregando uma metodologia predefinida de dilatações progressivas.

\subsection{Objetivo secundário}

Analisar a relação entre a placa aterosclerótica subjacente visibilizada pelo exame de tomografia de coerência óptica pré-implante do stent coronariano e a cicatrização vascular no reestudo tardio. 
3. Métodos 


\subsection{Desenho do estudo e considerações éticas}

Trata-se de um estudo piloto, prospectivo, unicêntrico e aberto, desenhado para avaliar a relação entre a composição da placa ateroscleróticaalvo e os resultados imediatos após o implante do stent coronariano no procedimento índice e resultados no seguimento tardio aos 18 meses utilizando a tomografia de coerência óptica (figura 2).

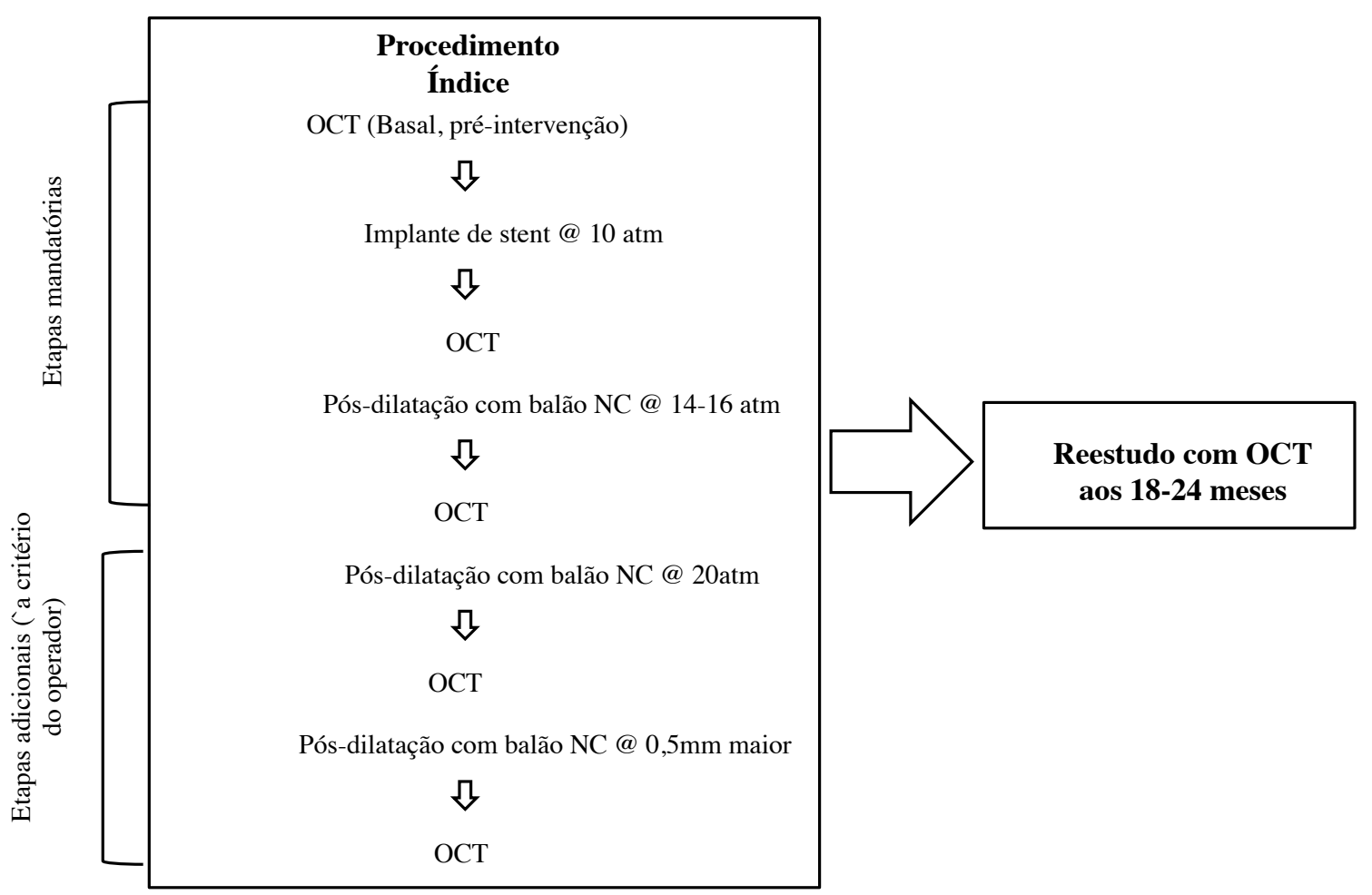

Figura 2 - Diagrama ilustrativo do desenho do estudo. OCT = optical coherence tomography, NC = não complacente.

Esse estudo foi conduzido de acordo com a Declaração de Helsinki. Todos os participantes receberam informações sobre os procedimentos, concordaram de livre arbítrio em participar e assinaram o Termo de Consentimento Livre e Esclarecido, previamente aprovado pelas comissões de ética do Instituto do Coração e do Hospital das Clínicas da Faculdade de 
Medicina da Universidade de São Paulo (HC-FMUSP).

\subsection{População do estudo}

A população desse estudo foi selecionada a partir de uma amostra de pacientes, portadores de doença aterosclerótica coronariana (DAC), que por indicação clínica foram encaminhados para intervenção coronária percutânea, para tratamento de uma ou mais lesões obstrutivas, no período de novembro de 2013 a junho de 2014, no Serviço de Hemodinâmica do Instituto do Coração - HCFMUSP. Foram selecionados todos os pacientes que preencheram os critérios de inclusão estabelecidos e que concordaram em serem submetidos ao estudo, durante o referido período.

\subsubsection{Critérios de Inclusão}

Foram considerados elegíveis para o estudo pacientes que, à angiografia fossem candidatos ao implante de stent direto, ou seja, sem prédilatação como tratamento da lesão coronariana-alvo e cuja anatomia fosse favorável para a realização de estudo intravascular por tomografia de coerência óptica. Foram incluídos apenas aqueles que preenchessem todos os critérios abaixo: 
1. Paciente com doença arterial coronariana obstrutiva significativa (diâmetro de estenose> 50\%), elegíveis para intervenção percutânea com implante de stent de uma ou mais lesões;

2. Lesão coronária de novo no vaso nativo elegível para tratamento com um único stent $\leq 29 \mathrm{~mm}$ de comprimento, entre $2,5-3,5 \mathrm{~mm}$ de diâmetro;

3. Lesão coronária cuja aquisição de imagens de tomografia de coerência óptica tivessem boa qualidade e permitissem a caracterização de placa no segmento-alvo (ou seja, segmento que engloba a lesão-alvo e os 5 $\mathrm{mm}$ da referência proximal e distal);

4. Lesões com pouca evidência angiográfica de calcificação coronariana, a qual fosse possível o tratamento com implante de stent direto, ou seja, sem pré-dilatação;

5. Idade $\geq 18$ anos.

\subsubsection{Critérios de Exclusão}

As seguintes condições foram consideradas critérios de exclusão:

1. Lesões em sequência , com $<10 \mathrm{~mm}$ de segmento angiograficamente normal entre os dois pontos estenóticos;

2. A necessidade de um stent $>29 \mathrm{~mm}$ de comprimento ou stents múltiplos (mais do que uma prótese endovascular) para cobrir todo o segmento alvo acometido;

3. Necessidade de um stent $<2,5 \mathrm{~mm}$ ou $>3,5 \mathrm{~mm}$ de diâmetro; 
4. Extrema heterogeneidade do diâmetro médio do vaso nos segmentos de referência, com mais de $1 \mathrm{~mm}$ de diferença entre diâmetro menor e o maior;

5. Bifurcação envolvendo um ramo lateral significativo (> 2,0 mm) e/ou que precisasse de intervenção (balão ou stent)

6. Enxerto venoso ou arterial ou intervenção percutânea no segmentoalvo

7. Trombos angiograficamente visíveis,

8. Lesão em enxertos venosos ou arteriais (ou seja, vaso não-nativo),

9. Lesão ostial,

10. Infarto agudo do miocárdio $<48$ horas ou angina instável com dor em repouso $<48$ horas precedendo a intervenção coronária percutânea,

11. Clearance de creatinina estimado pelo método de Cockroft-Gault $<60$ $\mathrm{ml} / \mathrm{min}$,

12. Condição clínica que limitasse a expectativa de vida,

13. Doença infecciosa ou inflamatória aguda,

14. Doença inflamatória crônica,

15. Instabilidade hemodinâmica,

16. Fração de ejeção ventricular esquerda $<30 \%$,

17. Distúrbios hemorrágicos,

18. Contra-indicação ao ácido acetilsalicílico ou tienopiridínicos

19. Alergia a contraste iodado conhecida

20. Contagem de leucócitos do sangue total $<3.500$ células $/ \mathrm{mm}^{3}$

21. Contagem de plaquetas $<100.000$ células $/ \mathrm{mm}^{3}$ 


\subsection{Procedimento Índice}

\subsubsection{Preparo dos pacientes}

Todos os pacientes fizeram uso oral de ácido acetilsalicílico e clopidogrel, , conforme a orientação clínica local:

- Ácido acetilsalicílico, $100-300 \mathrm{mg}$, introduzido pelo menos 12 horas antes do procedimento-índice para os pacientes que ainda não estivessem em uso;

- Clopidogrel, $75 \mathrm{mg} / \mathrm{dia}$, introduzido pelo menos 3 dias antes do procedimento. Para pacientes sem uso prévio de clopidogrel, a uma dose de ataque de 300 ou $600 \mathrm{mg}$ foi administrada pelo menos 4 horas antes do procedimento.

Coletou-se amostras de sangue para dosagem de exames laboratoriais préintervenção. Para a angioplastia, recomendou-se período de jejum de $4 \mathrm{~h}$ e obteve-se acesso venoso para hidratação e infusão de medicações. Na sala de procedimento foi instalada monitorização eletrocardiográfica e pressórica invasiva rotineira.

\subsubsection{Cuidados durante o procedimento}

Em todos os casos, realizou-se anestesia local (lidocaína 2\%) na região inguinal ou radial direita sem necessidade de sedação do paciente. Após a obtenção do acesso arterial com introdutor 6 french e a cateterização seletiva 
da artéria coronária, injetava-se vasodilatador intracoronário (nitroglicerina 200 - $400 \mu \mathrm{g}$ ). Antes de iniciar o procedimento de intervenção, administrava-se heparina não-fracionada $(100 \mathrm{Ul} / \mathrm{Kg})$ por via endovenosa e monitorizava-se o tempo de coagulação ativada, com administração de doses adicionais de heparina conforme necessário. Inibidores da glicoproteína Ilb/llla foram utilizados a critério do operador. Após a verificação de tempo de coagulação ativado superior a 250-300s, realizava-se a avaliação intracoronária com tomografia de coerência óptica das artérias com as lesões a serem tratadas, antes da intervenção propriamente dita. Desse modo, a informação gerada pela tomografia de coerência óptica esteve disponível para o operador durante a angioplastia e foi utilizada para guiar o implante dos stents.

Com o objetivo de diminuir o volume de contraste iodado administrado ao paciente durante o procedimento, a aquisição das imagens de tomografia de coerência óptica foram feitas concomitantemente `a aquisição da angiografia. Não foram utilizados cateteres guia com furo lateral e, antes da aquisição das imagens checava-se o alinhamento coaxial do cateter guia `a coronária bem como a posição ideal do cateter de tomografia de coerência óptica na artéria a ser avaliada. Caso houvesse necessidade de realização de imagens angiográficas adicionais, utilizava-se contraste diluído.

\subsubsection{Aquisição da imagem}

A angiografia coronária e os exames de tomografia de coerência óptica foram realizados de forma a proporcionar as melhores condições para a análise 
quantitativa off-line. Todas as imagens de tomografia de coerência óptica foram adquiridas pelo sistema comercial de Fourier Domain (C7-XRTM OCT Intravascular Imaging System, St. Jude Medical, St. Paul, Minnesota) após a administração intracoronária de 200 a 400 ug de nitroglicerina por meio de cateteres guia convencionais. O cateter de tomografia de coerência óptica foi avançado por meio de um fio-guia 0,014 "para o segmento mais distal da artéria. Durante a aquisição da imagem, o sangue foi deslocado empregandose injeção de contraste isoosmolar (iodixanol 370, Visipaque ${ }^{\mathrm{TM}}$, GE Health Care, Irlanda), com o auxilio de uma bomba injetora ou manualmente pelo cateter-guia (figura 3).

O comprimento total da região de interesse foi digitalizado utilizando um dispositivo integrado de recuo automático a $20 \mathrm{~mm} / \mathrm{s}$. Após a aquisição das imagens as mesmas foram armazenadas e processadas. 
AQUISIÇÃO DAS IMAGENS DE TOMOGRAFIA DE COERÊNCIA ÓPTICA

Cuidados no procedimento:

- Heparina não fracionada (TCA>250s)

- Nitroglicerina intracoronária (200-400mcg)

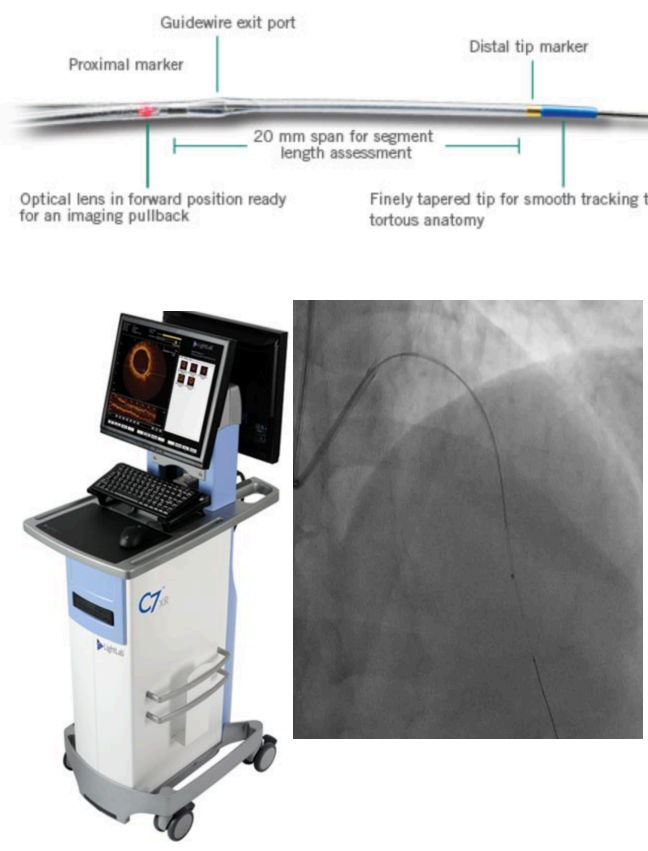

Aquisição das imagens do vaso-alvo:

- Pré-ICP

- Após implante do stent a $10 \mathrm{~atm}$

- Após cada pós-dilatação intra-stent
Cateter C7 Dragonfly: Imagem gerada por luz infra-vermelha

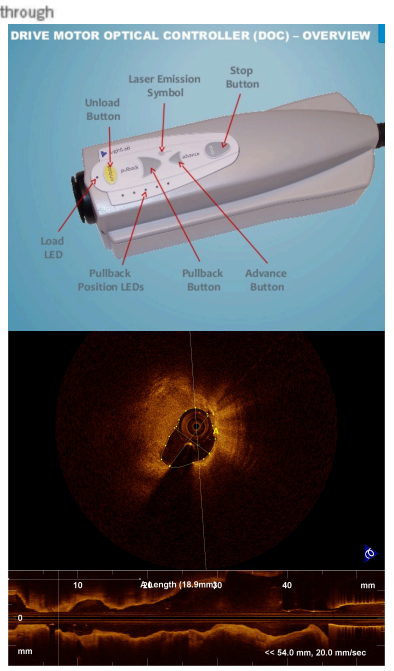

Recuo a $20 \mathrm{~mm} / \mathrm{s}$ $54 \mathrm{~mm}$ de extensão

$100 \mathrm{frames} / \mathrm{s}$

Resolução=10-20 $\mu \mathrm{m}$

Figura 3 - Dispositivos utilizados para a aquisição das imagens de Tomografia de coerência óptica. TCA: tempo de coagulação ativado, ICP: intervenção coronária percutânea.

\subsubsection{Tomografia de coerência óptica basal e após as dilatações sequenciais com balões}

Em todos os pacientes foram obtidas imagens gerada pela tomografia de coerência óptica imediatamente após a passagem da corda-guia 0,014", se possível antes de qualquer dilatação com cateter balão. Na impossibilidade de 
cruzar a lesão com o cateter de tomografia de coerência óptica, uma prédilatação com cateter-balão de $1,5 \mathrm{~mm}$ de diâmetro foi implementada com o intuito de possibilitar a passagem do cateter de OCT.

A angiografia coronária e as imagens de tomografia de coerência óptica, foram adquiridas a partir do vaso-alvo (s), nos seguintes momentos:

1) No início, antes de qualquer intervenção/ dilatação

2) Após a pré-dilatação com balão quando esta fosse necessária

3) Após o implante do stent com pressão nominal (10 atm)

4) Após a pós-dilatação intra-stent com 14-16 atm

5) No final do processo, no caso de dilatações adicionais fossem feitas após o passo 4.

Em todas as etapas foram adquiridas imagens de tomografia de coerência óptica do segmento-alvo (ou seja, o segmento englobando lesãoalvo e as referências proximal e distal). A análise das imagens de tomografia de coerência óptica foram realizadas off-line por um médico analista capacitado, cego para as outras características do paciente.

\subsubsection{Implante de stent guiado por Tomografia de Coerência Óptica}

Apenas o stent coronário Inspiron ${ }^{\circledR}$ eluidor de sirolimus (Scitech, Aparecida de Goiânia, Brasil) foi empregado neste estudo com o intuito de padronizar o desenho do stent e suas características físicas como força radial, espessura das hastes e do polímero. É constituído por plataforma de hastes ultra- 
finas $(75 \mu \mathrm{m})$, eluidor de sirolimus em doses baixas, com revestimento abluminal por polímero bioabsorvível $(5 \mu \mathrm{m})$ e montado em um sistema de balão de baixa complacência.

O implante de stent foi realizado conforme os procedimentos locais já padronizados pela instituição. Todas as insuflações foram mantidas durante 30 segundos para assegurar a equalização da pressão no sistema de dilatação. Foram utilizados apenas balões coronários não complacentes para a pósdilatação.

Os procedimentos foram efetuados de acordo com a seguinte abordagem sequencial:

1) Aquisição da imagem de OCT de base

2) Seleção do comprimento e do diâmetro do stent, com base nos seguintes critérios da OCT:

a. Um único stent utilizado para cobrir todo o segmento coronariano a ser tratado.

b. Stent com diâmetro nominal selecionado para coincidir com o diâmetro médio das referências (proximal e distal) do vaso.

3) Pré-dilatação, quando necessário, com balão de diâmetro 1,5mm e comprimento menor que a extensão da lesão a ser tratada a fim de evitar a lesão vascular em local que não é destinada a ser coberta pelo stent.

4) Aquisição das imagens de OCT após a dilatação.

5) Implante do stent com pressão nominal (10 atm). 
6) Aquisição de imagens de OCT após a liberação do stent com pressão nominal.

7) Pós-dilatação no interior de todo o stent com balão do mesmo diâmetro e de menor comprimento que o stent a 14-16 atm, realizada em todos os casos (etapa obrigatória).

8) Aquisição de imagens de OCT após a pós-dilatação com 14-16 atm e verificação do implante ideal de stent, definido pelos seguintes critérios angiográficos e de tomografia de coerência óptica ${ }^{21,22 .}$

- Ausência de doença residual significativa nas bordas do stent ,

- Ausência de dissecções significativas nas extremidades do stent definida como presença de faixa linear tecidual separada da parede do vaso com distância $>200 \mu \mathrm{m}$,

- Ausência de aposição incompleta do stent significativa considerada como distância entre as hastes do stent e a luz $>200$ $\mu \mathrm{m}$,

- Ausência de protrusão tecidual entre as hastes do stent na direção da luz do vaso $\geq 500 \mu \mathrm{m}$ em espessura,

- Área da seção transversal mínima do stent $>90 \%$ da média das referências ${ }^{21}$,

- Estenose residual com diâmetro <de $20 \%$ na análise visual por angiografia .

9) Caso tenha sido necessária a otimização da expansão do stent, as estratégias que foram implementadas foram: 
a. Doença de borda residual e/ou dissecção com necessidade adicional de stent foram tratados com um stent do mesmo tipo, com uma curta sobreposição com o stent já implantado

b. Stent sub-expandido foi preferencialmente tratado por meio de dilatação com alta pressão (20atm), com o mesmo balão usado no passo anterior

c. Aposição incompleta do stent foi corrigida por meio de dilatação com baixa pressão (<12 atm) por balão com diâmetro maior do que o balão utilizado na etapa anterior

10) Aquisição final de imagens de OCT

11) Após a retirada do fio-guia e a administração intracoronária de nitratos, uma nova angiografia foi obtida nas mesmas projeções selecionados no início do estudo (figura 4). 


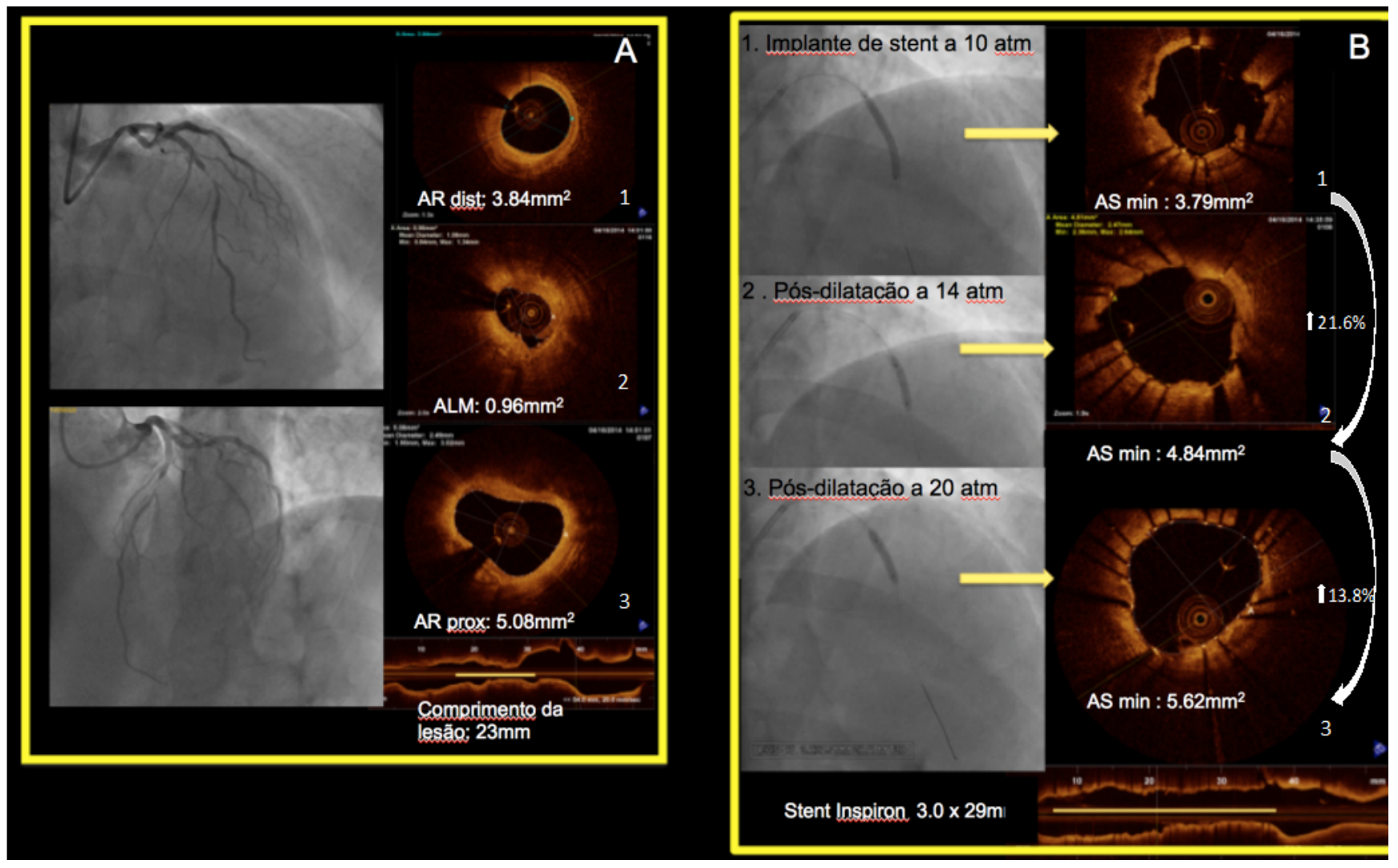

Figura 4 - Imagem ilustrativa das etapas do protocolo do estudo. A. Imagens da angiografia no momento basal em projeções ortogonais (à esquerda, imagens em escala de cinza) e imagens de secções transversas da tomografia de coerência óptica basal (à direita, imagens em sépia) com as respectivas medidas: A.1 área de referência $(A R)$ do segmento distal; $A .2$ área luminal mínima (ALM); $A .3$ área de referência $(A R)$ do segmento proximal. B. Imagens da angiografia (à esquerda, imagens em escala de cinza) e subsequentes imagens de secções transversas da tomografia de coerência óptica (à direita, imagens em sépia) nas etapas sequenciais do implante do stent e pós-dilatações: B.1 implante do stent com 10 atm; B.2 pósdilatação com balão não complacente com 14 atm e B.3 pós-dilatação com balão não complacente com 20 atm. Observa-se neste exemplo o aumento na área do stent (AS) em todas as etapas do protocolo: basal para implante do stent a 10atm $\left(A L M=0.96 \mathrm{~mm}^{2} \rightarrow A S=3.79 \mathrm{~mm}^{2}\right.$, aumento de $\left.74.6 \%\right)$, do implante do stent a 10 atm 
para a pós-dilatação a $14 \mathrm{~atm}\left(\mathrm{AS}=3.79 \mathrm{~mm}^{2} \rightarrow 4.84 \mathrm{~mm}^{2}\right.$, aumento de $21.7 \%$ ) e da pós-dilatação a 14 atm para 20 atm (AS=4.84 mm² $\rightarrow 5.62 \mathrm{~mm}^{2}$, aumento de $13.8 \%$ ). Atm: atmosferas.

\subsubsection{Tomografia de Coerência Óptica após a angioplastia}

O objetivo final dos procedimentos foi a obtenção do implante ótimo do stent. O stent foi considerado otimamente implantado se todos os critérios estivessem presentes:

- Ausência de malaposição significativa de hastes à parede do vaso;

- $\quad$ Ausência de dissecção intimal significativa nas bordas do stent;

- Área luminal mínima intra-stent $>90 \%$ da área média da referência luminal.

O final do procedimento foi considerado como o momento em que o cateter-guia for removido do paciente.

\subsection{Análise das imagens}

As imagens de tomografia de coerência óptica foram armazenadas digitalmente e submetidas à avaliação laboratorial posterior off-line utilizando softwares específicos (com o software da St. Jude Medical para as análises do procedimento índice e com o software Medis Medical Imaging Systems para as análises do reestudo no seguimento tardio). As imagens foram analisadas por dois experientes analistas em OCT. Todas as imagens seccionais foram 
inicialmente testadas para a avaliação da qualidade e excluídas da análise, se qualquer parte da imagem estivesse fora da tela, com um ramo lateral ocupando $>45^{\circ}$ da secção transversal, ou má qualidade devido a presença de sangue residual ou apresentar artefato com distorção da imagem (sew-up) ${ }^{36}$.

\subsubsection{Medidas Quantitativas e Qualitativas da luz do vaso e da placa aterosclerótica na tomografia de coerência óptica basal do procedimento índice}

O primeiro passo na análise off-line após a avaliação de qualidade das imagens foi a calibração da imagem pelo z-offset feita na primeira seção transversa a ser analisada em ambos os softwares específicos empregados (St. Jude Medical para as análises do procedimento índice e software Medis Medical Imaging Systems para as análises do reestudo), seguido do corregistro das imagens (figura 5). A segmentação do contorno luminal foi realizada pelo software empregado no segmento determinado pelo analista e ajustes manuais foram feitos quando necessário. 


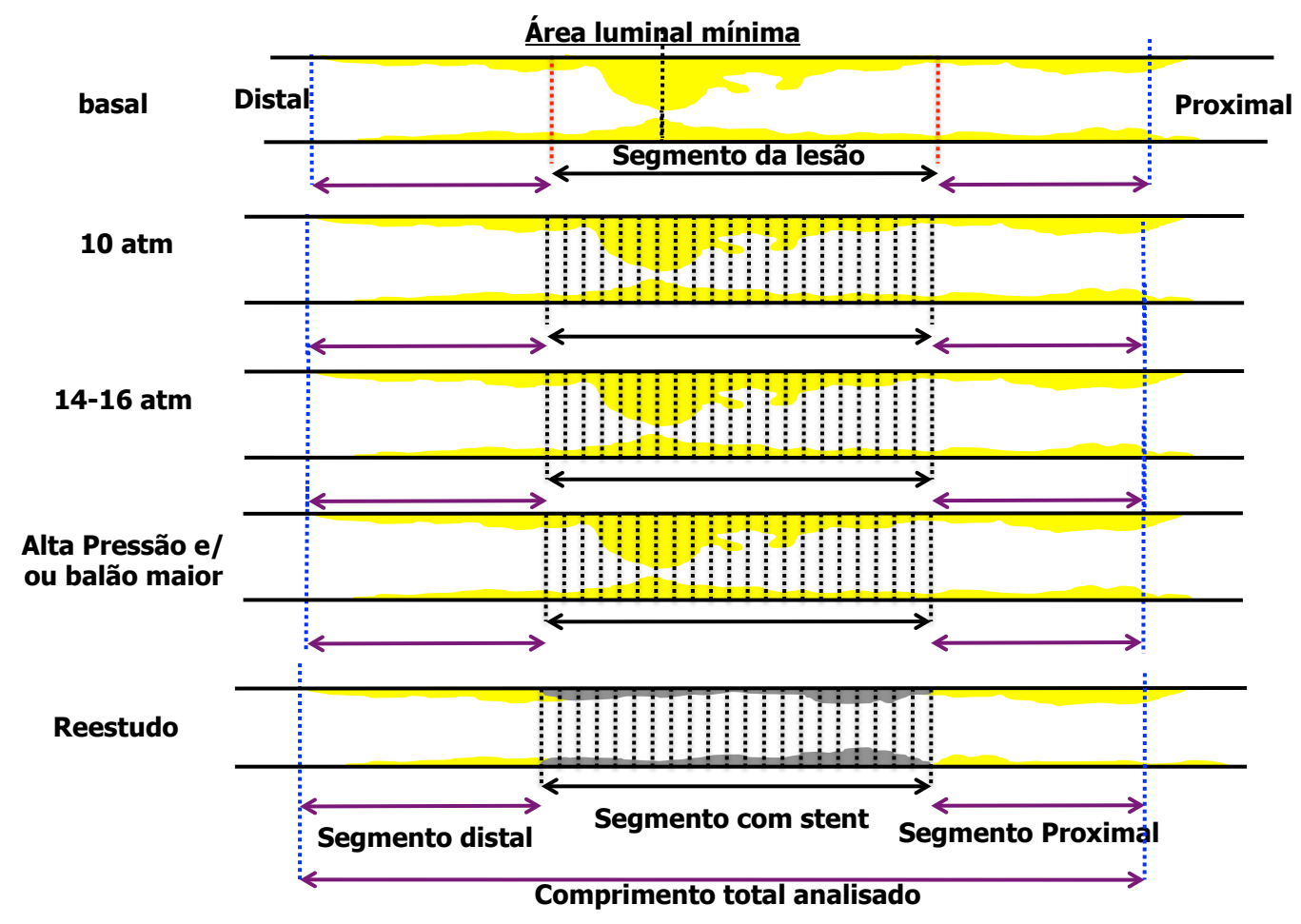

Figura 5 - Imagem esquemática do corregistro das imagens off-line das diferentes etapas do estudo no procedimento índice (basal, 10atm, 14-16 atm, alta pressãoe/ou balão maior) e no reestudo. Para o corregistro das imagens foram usados marcadores anatômicos como ramos laterais.

\subsubsection{Medidas Quantitativas}

Áreas e diâmetros luminais foram medidas a cada 0,6 milímetros no sentido longitudinal, envolvendo as referências proximal e distal e o segmento da lesão ${ }^{36}$.

- Área luminal: área delimitada pela borda luminal.

- Diâmetro luminal mínimo: menor diâmetro delimitado pela borda luminal encontrado no segmento analisado. 
- Diâmetro luminal máximo: maior diâmetro delimitado pela borda luminal encontrado no segmento analisado.

- Excentricidade luminal: diâmetro luminal máximo menos o diâmetro mínimo dividido pelo diâmetro luminal máximo do segmento analisado.

\subsubsection{Medidas Qualitativas}

Os componentes da placa foram quantificados por seção transversa a cada $0,6 \mathrm{~mm}$ e apresentados em percentuais. Cada seção transversa analisada foi dividida em quatro quadrantes e cada quadrante rotulado de acordo com seu componente predominante. Sendo assim, uma avaliação semi-quantitativa das placas foi realizada e expressa em percentual, seguindo as caraterísticas ópticas dos tecidos (figura 6):

- normal: arquitetura vascular em três camadas, compreendendo íntima, média e adventícia,

- componente fibrótico: tecido com sinal rico e homogêneo à OCT, com espessura da íntima $\geq 300$ um,

- componente calcificado: correspondem `as regiões heterogêneas com bordas bem delimitadas. Com o objetivo de quantificar o componente calcificado, as seções transversas analisadas que continham cálcio foram feitas as seguintes medidas: 1. área do cálcio = traçada manualmente a área dos limites do cálcio; 2. distância cálcio-luz do vaso = medida manualmente 3 distâncias da borda superficial da área do cálcio para a luz do vaso; 3. Ângulo de cálcio $=$ medido manualmente o ângulo formado entre o centro do vaso e os limites laterais da área de cálcio. 
- componente lipídico: correspondem a regiões com sinal pobre sobrepostas por borda luminal com sinal rico, região com fronteiras difusas e com grande atenuação do sinal luminoso.

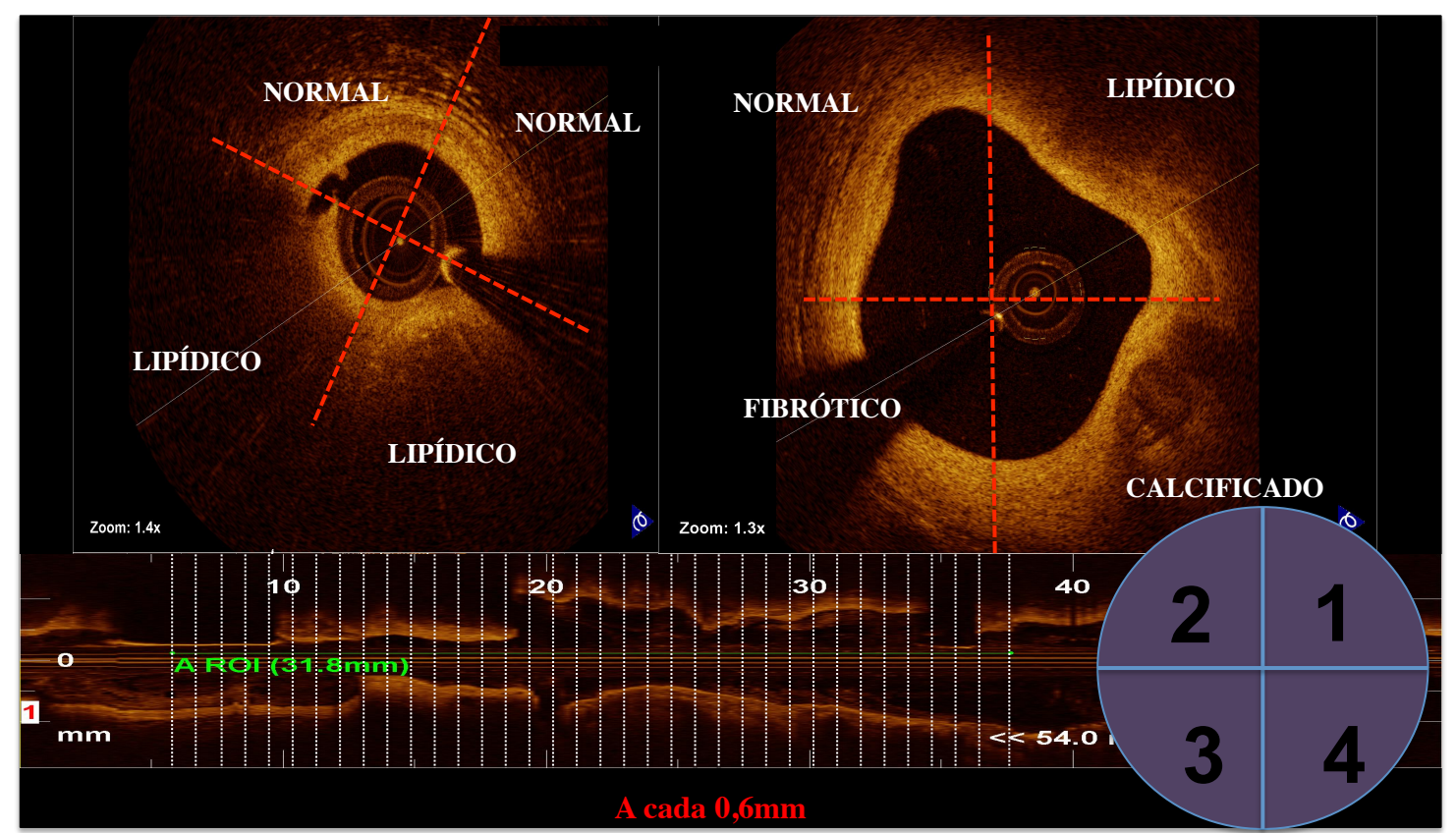

Figura 6 - Imagem representativa de cortes transversais e longitudinal da tomografia de coerência óptica durante a avaliação qualitativa. As seções transversas foram avaliadas a cada $0,6 \mathrm{~mm}$ e divididas em 4 quadrantes. Cada quadrante foi classificado conforme a presença do componente de placa predominante: normal, lipídico, fibrótico ou calcificado.

A reprodutibilidade da metodologia empregada para a avaliação qualitativa da característica da placa foi testada previamente. Dois analistas diferentes analisaram 150 seções transversais com um intervalo de 60 dias e as variabilidades intra e inter-observador e concordância para a avaliação da placa com esta metodologia foram previamente validadas ${ }^{58}$. 


\subsubsection{Medidas Quantitativas e Qualitativas do stent no procedimento índice}

\subsubsection{Medidas Quantitativas}

As hastes metálicas do stent aparecem na tomografia de coerência óptica como pequenos pontos com sinal intenso de luz emitida e sombreamento em direção à parede do vaso. As haste consideradas para análise foram as que apresentavam imagem luminosa do stent $\mathrm{e}$ sombreamento em direção à parede do vaso (figura 7). A detecção automática das hastes foi realizada por um algoritmo e correções para falso-positivos ou falso-negativos foram realizadas manualmente. $O$ número de hastes analisadas em cada corte transversal ao longo do segmento de interesse foi, em seguida, calculado automaticamente.

O contorno traçado ao longo da superfície interna de cada haste foi realizado automaticamente e a delimitação da área do stent em cada seção transversa analisada. Sequencialmente, a distância entre os pontos centrais da face luminal de cada haste e o contorno luminal foi determinado automaticamente por linhas voltadas para o centro de gravidade do vaso. Nas análises das imagens do procedimento índice, ou seja, no pós-implante imediato do stent e após as pós-dilatações intra-stent, os valores esperados para tais distâncias eram negativos, pois as hastes haviam sido recémimplantadas e sobrepostas à superfície da luz do vaso. Correções manuais foram feitas quando o algoritmo do software não reconhecia corretamente o contorno da luz do vaso, sendo traçado manualmente a delimitação da luz 
posterior à haste do stent (figura 7). Obteve-se desta forma as seguintes informações:

- $\quad$ Área do stent: área delimitada pelas hastes do stent.

- Diâmetro do stent: diâmetro delimitado pelas hastes do stent.

- Diâmetro mínimo do stent: menor diâmetro encontrado no segmento com stent.

- Diâmetro máximo do stent: maior diâmetro encontrado no segmento com stent.

- Excentricidade do stent: diâmetro máximo do stent menos o diâmetro mínimo do stent dividido pelo diâmetro máximo do stent.

- Malaposição das hastes do stent: considerada quando a distância da superfície luminal do reflexo da haste do stent até o contorno luminal foi maior que a espessura da haste acrescida da espessura do polímero e do fármaco, acrescida de um fator de correção de $20 \mu \mathrm{m}$, que corrige para a real localização da superfície da haste. Para os stents deste estudo, para distância maior que a soma das espessuras das hastes $(75 \mu \mathrm{m})$, espessura dos polímeros $(5 \mu \mathrm{m})$ e fator de correção $(20 \mu \mathrm{m})$, a haste foi classificada como em malaposição (figura 8). 


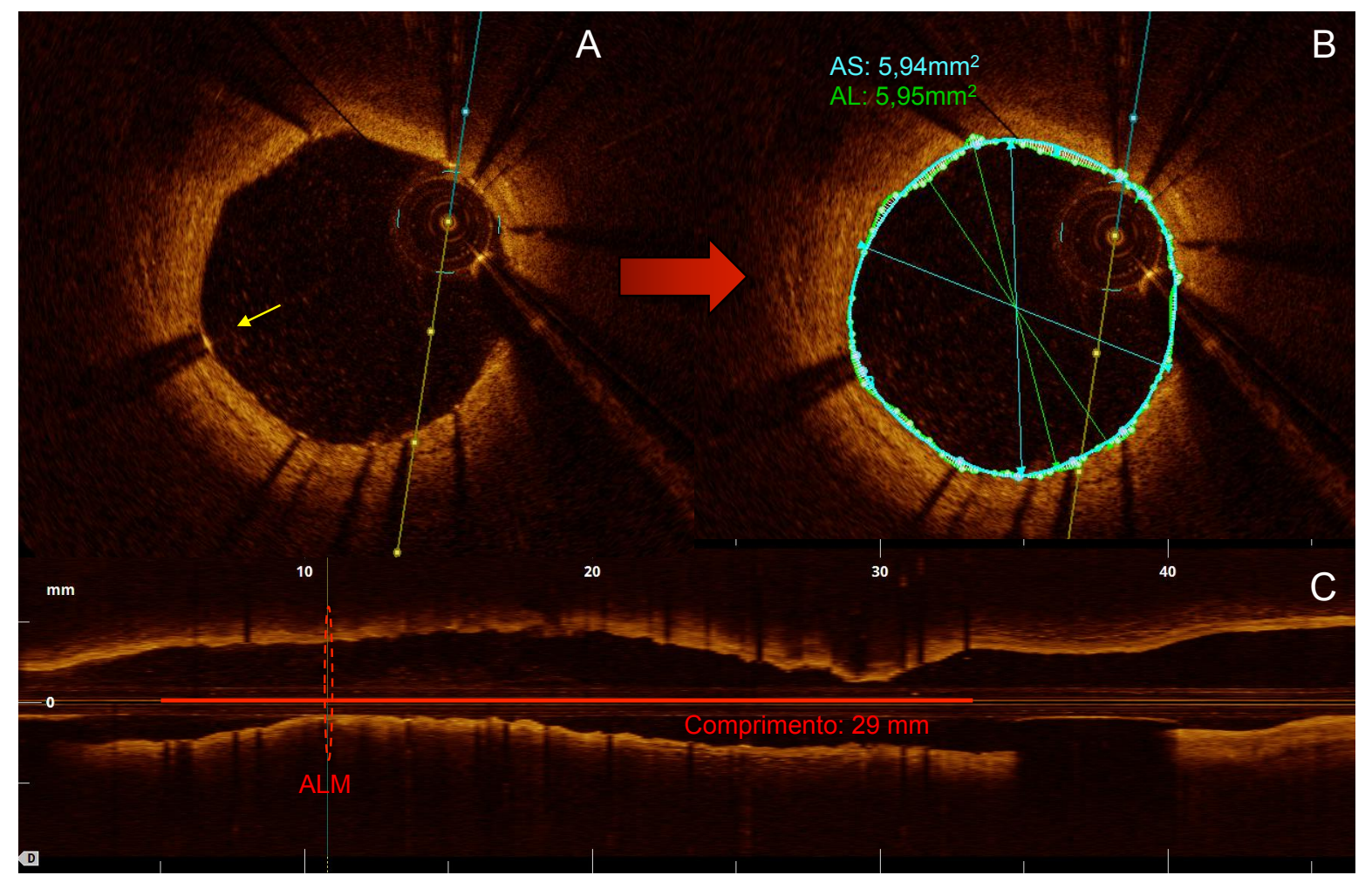

Figura 7 - Imagem ilustrativa de seções transversas de tomografia de coerência óptica com as medidas quantitativas realizadas no procedimento índice. A. Seção transversa no ponto da área luminal mínima (ALM); visualizam-se pequenos pontos com sinal intenso de luz emitida e sombreamento em direção à parede do vaso correspondentes às hastes metálicas do stent recém implantado (seta amarela). B. Mesma seção transversa após a segmentação automática da área do stent (AS: em azul) e da área da luz ( $A L$ : em verde). Notam-se as hastes recém implantadas e sobrepostas à superfície da luz do vaso. Correções manuais foram feitas quando o algoritmo do software não reconhecia corretamente o contorno da luz do vaso, sendo traçado manualmente a delimitação da luz posterior à haste do stent. C. Corte longitudinal correspondente à aquisição das imagens pelo recuo automático do cateter de tomografia de coerência óptica, com a identificação da ALM e comprimento do stent (linha vermelha). 


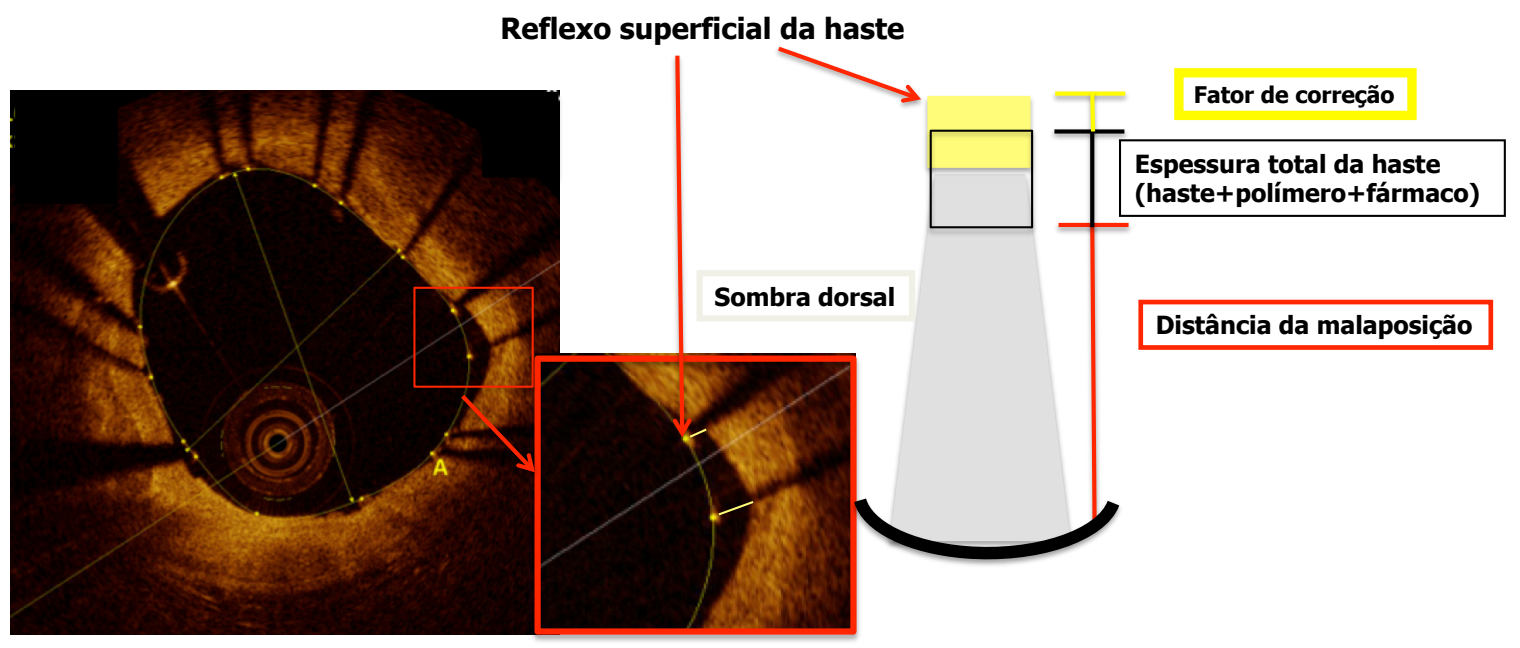

Figura 8 - Figura ilustrativa da quantificação da malaposição das hastes do stent no procedimento índice de cortes transversais de tomografia de coerência óptica. Uma haste foi considerada malaposta quando a distância da superfície luminal do reflexo da haste do stent até o contorno luminal foi maior que a espessura da haste acrescida da espessura do polímero e do fármaco, acrescida de um fator de correção de $20 \mu \mathrm{m}$. Para o stent deste estudo este valor foi de $100 \mu \mathrm{m}$.

\subsubsection{Medidas Qualitativas}

As medidas qualitativas foram feitas a cada $0,6 \mathrm{~mm}$ no segmento das referências distal e proximal e do stent.

- Prolapso tecidual : identificado como a presença de projeção de tecido para dentro da luz do vaso entre as hastes do stent após seu implante. Quantificado como distâncias haste-luz e áreas com valores positivos no procedimento índice (figura 9). 
- Trombo: identificado como massa saliente no lúmen do vaso entre as hastes do stent, classificadas como vermelhos (elevada atenuação do sinal da OCT) ou brancos (baixa atenuação do sinal da OCT).

- Dissecção de borda do stent: definida como uma interrupção da superfície luminal do vaso no segmento que compreende os $5 \mathrm{~mm}$ proximal e distal da região do stent. A dissecção foi considerada importante se a faixa de dissecção apresentasse distância $>200 \mu \mathrm{m}$ da parede do vaso e se estendesse por $>600 \mu \mathrm{m}$ longitudinalmente.

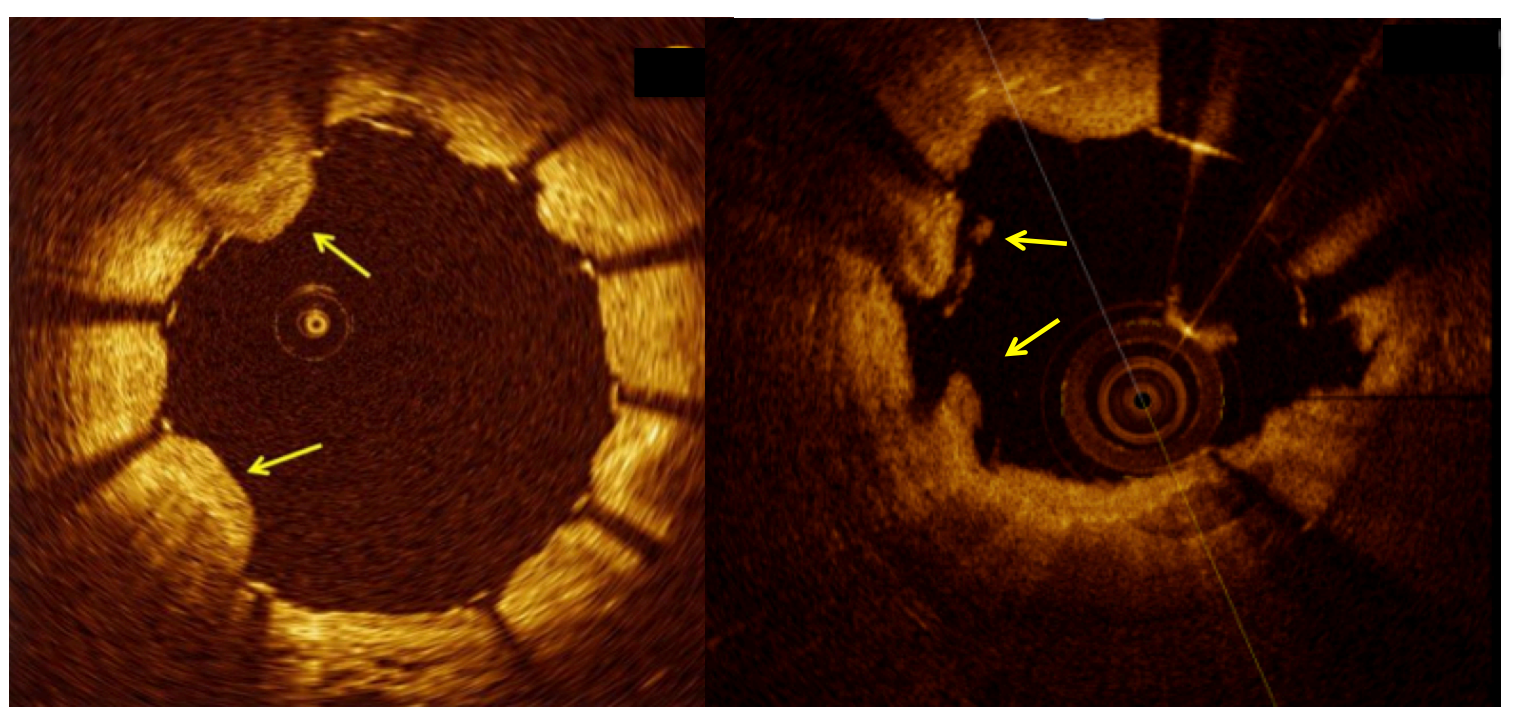

Figura 9 - Imagens ilustrativas de seções transversas de tomografia de coerência óptica representativas de prolapso tecidual durante o procedimento índice (setas amarelas). Identificado tecido projetado para dentro da luz do vaso entre as hastes do stent após seu implante e quantificado como distâncias haste-luz e áreas com valores positivos no procedimento índice. 


\subsubsection{Medidas Quantitativas e Qualitativas do stent no reestudo tardio}

A espessura da neoíntima foi definida como a distância entre a superfície luminal da neointima e a superfície luminal do reflexo da haste do stent no seu ponto médio. Uma haste coberta foi definida como tendo espessura da neointima $>0 \mu \mathrm{m}$. A percentagem de hastes analisadas foi calculada como o número de hastes analisadas $\times 100$ dividida pelo número de hastes totais que eram analisáveis. Malaposição da haste foi definida como uma separação clara entre a haste e a parede do vaso, com uma distância maior do que a espessura da haste do stent acrescida da espessura do polímero e do fármaco, acrescida de um fator de correção de $20 \mu \mathrm{m}$, que corrige para a real localização da superfície da haste ${ }^{59}$.

\subsubsection{Medidas Quantitativas}

A área da neointima foi determinada pelo cálculo da diferença entre a área do stent e a área luminal. Após a determinação da área da neointima, o percentual de obstrução do stent foi calculado para cada seção transversa analisada dividindo a área neointimal pela área do stent (figura 10). 


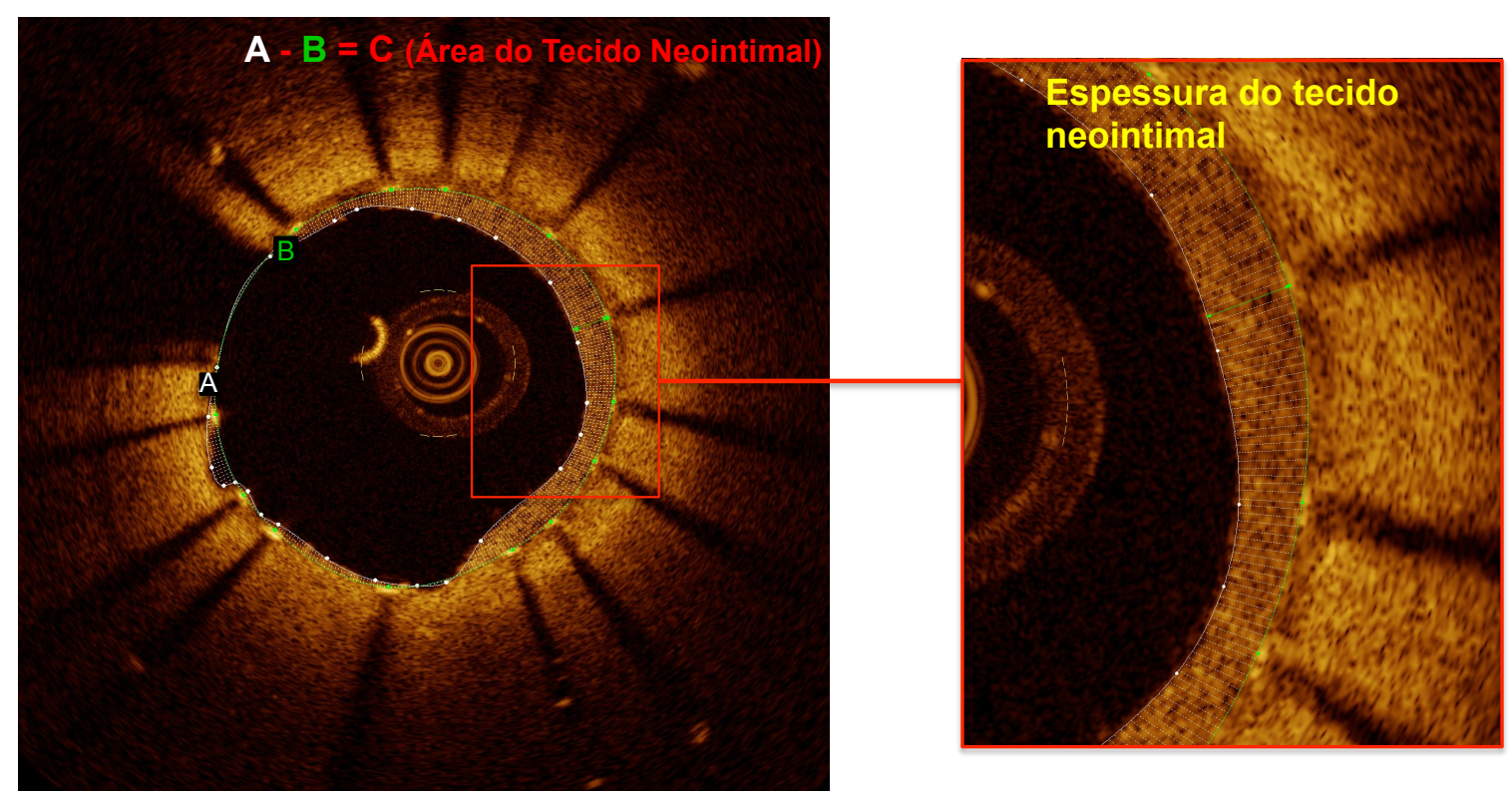

Figura 10 - Imagem ilustrativa de seções transversas de tomografia de coerência óptica com as medidas quantitativas realizadas no reestudo. Painel da esquerda: A. Área da luz, B. Área do stent, C. Área do tecido neointimal; Painel da direita: análise da espessura do tecido neointimal (distância hasteluz).

\subsubsection{Medidas Qualitativas}

Foi realizada uma avaliação qualitativa do tecido neointimal formado ao longo das hastes do stent. Regiões com áreas homogêneas que refletiam o sinal óptico com menos intensidade do que o tecido adjacente, mas sem causar atenuação da luz foram caracterizadas como tecido neointimal anormal ou infiltrativo ${ }^{60}$.

Neoaterosclerose foi definida como a presença de tecido heterogêneo com áreas de baixa intensidade e infiltrado de lipídios e presença de capa fibrosa fina, com ou sem calcificações associadas ${ }^{61}$. 


\subsection{Evolução intra-hospitalar e acompanhamento ambulatorial}

Foram analisados os eletrocardiogramas após a angioplastia e os exames laboratoriais foram solicitados de acordo com a prática local: creatinina e hemoglobina 24 horas após o procedimento e enzimas cardíacas (CKMB [troponina opcional]), sendo a primeira amostra de 6-8 horas após o procedimento. Segunda amostra de 6-8 horas após a primeira amostra, e em caso de elevação enzimática, foram seriadas até a sua normalização.

Informações sobre o seguimento ambulatorial foram coletadas via prontuário eletrônico em 12 meses após o procedimento. Para fins de análise, os seguintes eventos adversos foram considerados desfechos clínicos:

1) morte em geral e de origem cardíaca (qualquer morte a menos que inequivocamente não cardíaca),

2) infarto agudo do miocárdio (sintomas clínicos de infarto com marcadores cardíacos elevados subsequentes, ou qualquer nova onda $Q$ patológica durante o seguimento),

3) Revascularização percutânea ou cirúrgica da lesão-alvo (motivada por uma estenose $>50 \%$ no segmento-alvo),

4) Revascularização percutânea ou cirúrgica do vaso-alvo (motivada por uma estenose $>50 \%$ em qualquer segmento do vaso alvo).

5) Trombose de stent durante o acompanhamento foi classificada de acordo com o grau de certeza como definitiva, provável ou possível, seguindo as definições propostas pelo Academic Research Consortium ${ }^{62}$. 


\subsection{Considerações estatísticas}

O presente estudo é uma análise exploratória, sem cálculo do tamanho da amostra formal. Em vez disso, um tamanho amostral de 20 pacientes foi arbitrariamente selecionado e vários cenários de resultados hipotéticos foram projetados para avaliar o potencial dessa população para fornecer resultados significativos. Para ilustrar, tal tamanho de amostra proporcionaria pelo menos $80 \%$ de poder estatístico para detectar uma correlação entre qualquer tipo de tecido caracterizado pela tomografia de coerência óptica e o resultado agudo final do stent ou a área do tecido neointimal no seguimento tardio durante o reestudo, com um coeficiente de 0,6 ou mais, com um alfa de $0,05^{63}$.

As variáveis categóricas foram expressas como valores absolutos ou proporcões. Diferenças entre grupos foram comparadas por teste de quiquadrado ou por teste exato de Fisher para as variáveis categóricas, conforme apropriado. As variáveis contínuas foram testadas para normalidade e aquelas com distribuição normal foram expressas como média \pm desvio padrão, sendo as demais expressas como mediana e intervalo interquartil. Diferenças entre variáveis contínuas pareadas foram determinadas pelo teste T de Student ou pelo teste de Wilcoxon sign rank, de acordo com a distribuição da variável. Para testar a correlação entre variáveis contínuas de distribuição normal utilizou-se o teste de Pearson e para as variáveis sem distribuição normal o teste de Spearman. A alteração sequencial nos parâmetros da tomografia de coerência óptica foi avaliada pelo teste pareado não paramétrico de Friedman. Os parâmetros quantitativos da tomografia de coerência óptica 
foram comparados entre os tipos de placas pelo teste independente não paramétrico de Mann-Whitney. As correlações bivariadas entre parâmetros quantitativos da tomografia de coerência óptica foram avaliadas pelo teste não paramétrico de Spearman.

Os valores de $\mathrm{P}<0,05$ foram considerados como estatisticamente significativos. As análises estatísticas foram realizadas utilizando o SAS 9.2 (SAS Institute Inc., Cary, NC, EUA) e IBM SPSS Statistics, Versão 21.0.0.0 (IBM Corp .. Armonk, NY, EUA). 
4. Resultados 


\subsection{População do estudo}

Um total de 21 pacientes foram incluídos inicialmente. Desses, um paciente foi excluído devido ao cateter de tomografia de coerência óptica não ultrapassar a lesão após o implante do stent a 10 atmosferas. Não foram excluídos outros pacientes ou lesões devido à qualidade das imagens ou devido a intervenção percutânea sem sucesso. A população final do estudo compreendeu 20 pacientes e 22 lesões (1 lesão por artéria, 1 stent por lesão). A idade média dos pacientes foi de $61,4 \pm 7,8$ anos, $60 \%$ do sexo masculino, $65 \%$ diabéticos, $75 \%$ exibiam padrão coronariano multiarterial e $80 \%$ apresentavam coronariopatia crônica. As demais características clínicas da população, como fatores de risco tradicionais para doença arterial coronária, medicamentos de uso ambulatorial prévios estão descritas na tabela 1.

Tabela 1 - Características basais dos pacientes

Características clínicas basais $(\mathbf{N}=20)$

\begin{tabular}{ll}
\hline Idade (anos) & $61,4 \pm 7,8$
\end{tabular}

Apresentação clínica

Apresentações crônicas (Angina estável/isquemia silenciosa) 16 (80\%)

Equivalente Isquêmico

SCA sem supra de ST

$3(15 \%)$

Padrão arterial

Uniarterial

$5(25 \%)$

Biarterial

$10(50 \%)$

Triarterial

$5(25 \%)$ 
Tabela 1 - Características basais dos pacientes

\begin{tabular}{lc} 
Características clínicas basais (N=20) & (continuação) \\
Circunflexa & $4(18 \%)$ \\
Coronária Direita & $4(18 \%)$ \\
Antecedentes & \\
Diabetes mellitus em uso de medicamentos & $10(50 \%)$ \\
Diabetes mellitus em uso de insulina & $3(15 \%)$ \\
Hipertensão arterial sistêmica & $16(80 \%)$ \\
Tabagismo atual & $10(50 \%)$ \\
História familiar de DAC & $5(25 \%)$ \\
Cirurgia de revascularização miocárdica prévia & $1(5 \%)$ \\
Infarto agudo do miocárdio prévio & $3(15 \%)$ \\
Angioplastia coronária prévia & $3(15 \%)$ \\
Medicações de uso prévio & \\
Estatina & $10(50 \%)$ \\
AAS & $14(70 \%)$ \\
IECA ou ARA & $12(60 \%)$ \\
Betabloqueador & $6(30 \%)$ \\
Bloqueador de cálcio & $3(15 \%)$ \\
Nitrato & $3(15 \%)$ \\
\hline
\end{tabular}

Dados expressos por média \pm desvio padrão para variáveis contínuas ou por freqüência absoluta (percentual) para variáveis categóricas. SCA = síndrome coronariana aguda. $\mathrm{CRM}=$ cirurgia de revascularização miocárdica. $I A M=$ infarto agudo do miocárdio. $D A C=$ doença arterial coronária. IECA = inibidor da enzima de conversão do angiotensinogênio. ARA = antagonista do receptor da angiotensina II.

\subsection{Procedimento Índice}

Após a aquisição das imagens de tomografia de coerência óptica basais dos vasos a serem tratados, as intervenções coronárias percutâneas foram realizadas conforme o protocolo preconizado. Foram tratadas 22 lesões em 22 artérias coronárias, utilizando-se o stent Inspiron ${ }^{\circledR}$ ( 1 stent por artéria), seguindo as etapas do protocolo de pós-dilatações com balões não complacentes. Não ocorreu infarto do miocárdio periprocedimento, definido 
como elevação superior a três vezes o valor de referência da CKMB massa. Todos os pacientes estavam em uso de ácido acetilsalicílico e clopidogrel. $\mathrm{O}$ sucesso angiográfico (definido por estenose $<20 \%$ e fluxo distal TIMI III) foi obtido em $100 \%$ dos casos. A média de volume de contraste utilizado foi de $275 \pm 74 \mathrm{ml}$

\subsubsection{Angiografia e Tomografia de coerência óptica: medidas quantitativas das imagens basais e do procedimento índice}

As imagens de tomografia de coerência óptica basais e do procedimento índice totalizaram 2298 seções transversas analisadas. O segmento do stent foi dividido em subsegmentos de $3 \mathrm{~mm}$ de comprimento com a intenção de tornar a comparação mais acurada entre as diferentes etapas do protocolo.

As medidas quantitativas basais obtidas pela tomografia de coerência óptica estão descritas na tabela 2, tanto para as referências proximais e distais como para o segmento da lesão-alvo. 
Tabela 2- Medidas quantitativas basais obtidas pela tomografia de coerência óptica - análise por artéria

Artérias Analisadas $(\mathrm{n}=\mathbf{2 2})$

\section{Segmento de referência Distal}

Área Luminal $\left(\mathrm{mm}^{2}\right)$

$5,41 \pm 1,51$

Diâmetro luminal $(\mathrm{mm})$

$2,59 \pm 0,38$

\section{Segmento de referência Proximal}

Área Luminal $\left(\mathrm{mm}^{2}\right)$

$7,65 \pm 2,15$

Diâmetro luminal (mm)

Média dos Segmentos de referência

Área Luminal $\left(\mathrm{mm}^{2}\right)$

$6,66 \pm 1,5$

Diâmetro luminal (mm)

$2,86 \pm 0,34$

\section{Segmento da lesão}

Comprimento (mm)

Área luminal mínima $\left(\mathrm{mm}^{2}\right)$

$24,1 \pm 5$

Diâmetro luminal mínimo (mm)

$1,57 \pm 0,51$

$1,38 \pm 0,22$

\section{$\%$ de Estenose}

\% área de estenose

$74,29 \pm 9,77$

\% diâmetro de estenose

Dados expressos por média \pm desvio padrão. OCT = optical coherence tomography. \% área de estenose = área luminal mínima/ área luminal da media das referências $100 . \%$ diâmetro de estenose $=$ diâmetro luminal mínimo/ diâmetro luminal da média das referências * 100 .

Todos os stents $(n=22)$ foram implantados com pressão nominal (10 atm) e pós-dilatados com 14-16 atm (etapas obrigatórias do protocolo). Por tomada de decisão do operador e baseado nas imagens de tomografia de 
coerência óptica durante o procedimento, 11 stents receberam pós-dilatação com alta pressão (20-22atm) e 6 receberam pós-dilatação com balão de diâmetro maior para atingirem os critérios de implante ótimo pela análise no momento do exame. As imagens das angiografias foram adquiridas concomitantemente `as aquisições das imagens de tomografia de coerência óptica e sucesso angiográfico foi considerado na ausência de lesão residual $>20 \%$ e na presença de fluxo TIMI III (tabela 3 ).

\subsubsection{Efeitos agudos do implante do stent visibilizados pela tomografia de coerência óptica.}

O comprimento médio do stent foi de $26,0 \mathrm{~mm}$ (intervalo 13,0 a 29,0 mm, intervalo interquartil [IQR] 22,0 - 29,0 mm) e o diâmetro médio do stent foi de 3,0 mm (intervalo de 2,5 a 3,5 mm, IQR 3,0 - 3,5 mm). Houve um aumento nas médias das áreas da luz e do stent acompanhados do aumento da área de prolapso de placa (tabela 4). Não houve diferença na área de malaposição do stent (tabela 4). Não foi observado o encurtamento longitudinal do stent (10 atm $=24.31 \pm 4.95 \mathrm{~mm} ; 14-16 \mathrm{~atm}=24.65 \pm 4.2 \mathrm{~mm} ; \mathrm{P}=0.58)$. Não houve dissecção considerada importante nas bordas proximal ou distal do stent. 
Tabela 3 - Medidas quantitativas obtidas pela angiografia no procedimento índice

\begin{tabular}{lc}
\hline \multicolumn{1}{c}{ Artérias Analizados $(\mathbf{n = 2 2})$} & \\
\hline Basal & \\
Comprimento da lesão $(\mathrm{mm})$ & $15.16 \pm 5.52$ \\
Diâmetro luminal mínimo $(\mathrm{mm})$ & $0.73 \pm 0.21$ \\
Diâmetro luminal máximo $(\mathrm{mm})$ & $3.14 \pm 0.55$ \\
Diâmetro luminal médio $(\mathrm{mm})$ & $2.19 \pm 0.31$ \\
\% diâmetro de estenose & $71.95 \pm 6.49$ \\
Diâmetro de referência $(\mathrm{mm})$ & $2.57 \pm 0.39$ \\
$\quad$ & \\
\hline Pós-procedimento intra-stent & \\
Comprimento do stent $(\mathrm{mm})$ & $23.96 \pm 4.88$ \\
Diâmetro luminal mínimo $(\mathrm{mm})$ & $2.38 \pm 0.36$ \\
Diâmetro luminal máximo $(\mathrm{mm})$ & $3.08 \pm 0.45$ \\
Diâmetro luminal médio $(\mathrm{mm})$ & $2.74 \pm 0.36$ \\
\% diâmetro de estenose & $3.27 \pm 8.58$ \\
Diâmetro de referência $(\mathrm{mm})$ & $2.47 \pm 0.34$ \\
Ganho agudo (mm) & $1.66 \pm 0.31$ \\
$\quad$ Pós-procedimento no segmento tratado & \\
Comprimento da lesão $(\mathrm{mm})$ & $33.26 \pm 4.91$ \\
Diâmetro luminal mínimo $(\mathrm{mm})$ & $2.14 \pm 0.29$ \\
Diâmetro luminal máximo $(\mathrm{mm})$ & $3.14 \pm 0.48$ \\
Diâmetro luminal médio $(\mathrm{mm})$ & $2.69 \pm 0.36$ \\
Diâmetro de referência $(\mathrm{mm})$ & $8.77 \pm 4.90$ \\
Ganho agudo (mm) & $2.34 \pm 0.34$ \\
\hline Dados expressos por média \pm desvio padrão para variáveis contínuas. \\
\end{tabular}


Tabela 4 - Achados sequenciais da tomografia de coerência óptica na região do stent durante o procedimento índice

\begin{tabular}{|c|c|c|c|c|c|}
\hline & Basal & 10 atm & 14-16 atm & Resultado final & $\mathrm{P}^{*}$ \\
\hline Área Luminal total, $\mathrm{mm}^{2}$ & $\begin{array}{l}4.0 \\
(3.1-5.1)\end{array}$ & $\begin{array}{l}5.5 \\
(4.5-7.4)\end{array}$ & $\begin{array}{l}6.0 \\
(4.7-7.7)\end{array}$ & $\begin{array}{l}6.7 \\
(5.5-8.2)\end{array}$ & $<0.001$ \\
\hline Área luminal mínima, $\mathrm{mm}^{2}$ & $\begin{array}{l}1.8 \\
(1.5-2.5)\end{array}$ & $\begin{array}{l}4.5 \\
(3.6-5.4)\end{array}$ & $\begin{array}{l}5.2 \\
(4.2-6.6)\end{array}$ & $\begin{array}{l}6.0 \\
(4.6-6.6)\end{array}$ & $<0.001$ \\
\hline Área do Stent total, $\mathrm{mm}^{2}$ & & $\begin{array}{l}5.2 \\
(4.3-7.0)\end{array}$ & $\begin{array}{l}5.7 \\
(4.5-7.5)\end{array}$ & $\begin{array}{l}6.5 \\
(5.3-7.9)\end{array}$ & $<0.001$ \\
\hline Área mínima do Stent, $\mathrm{mm}^{2}$ & & $\begin{array}{l}4.4 \\
(3.4-5.4)\end{array}$ & $\begin{array}{l}5.0 \\
(3.9-6.5)\end{array}$ & $\begin{array}{l}5.9 \\
(4.6-6.5)\end{array}$ & $<0.001$ \\
\hline $\begin{array}{l}\text { Área de Prolapso de Placa } \\
\text { total, } \mathrm{mm}^{2}\end{array}$ & & $\begin{array}{l}0.09 \\
(0.06-0.12)\end{array}$ & $\begin{array}{l}0.10 \\
(0.06-0.15)\end{array}$ & $\begin{array}{l}0.15 \\
(0.08-0.20)\end{array}$ & 0.001 \\
\hline $\begin{array}{l}\text { Área de Malaposição total, } \\
\mathrm{mm}^{2}\end{array}$ & & $\begin{array}{l}0.04 \\
(0.01-0.06)\end{array}$ & $\begin{array}{l}0.04 \\
(0.02-0.08)\end{array}$ & $\begin{array}{l}0.03 \\
(0.02-0.04)\end{array}$ & 0.4 \\
\hline
\end{tabular}

Os números são medianas (intervalo interquartil); atm = atmosferas; OCT = optical coherence tomography. *Para todas as comparações após o implante do stent.

\subsubsection{Medidas semi-quantitativas e quantitativas dos componentes da placa aterosclerótica.}

A análise semi-quantitativa da placa aterosclerótica na lesão-alvo com a tomografia de coerência óptica evidenciou ser o componente fibrótico o mais frequente, com pouca calcificação associada (fibrótico $=47.0 \pm 15.8 \%$, lipídico $=17.63 \pm 10.2 \%$, calcificado $=4.63 \pm 5.9 \%$ ) como demonstrado na tabela 5 . Apenas uma menor proporção do conteúdo da lesão alvo foi considerada não analisável devido a artefatos causados pelo fio-guia, presença de sangue 
Tabela 6 - Correlação entre as áreas da luz esperada e obtida e os componentes da placa aterosclerótica com as pressões $10 \mathrm{~atm}, 14-16 \mathrm{~atm}$ e ao final do procedimento - análise por artéria.

\begin{tabular}{|c|c|c|c|c|c|c|}
\hline & \multicolumn{2}{|c|}{$\begin{array}{c}\text { Diferença } \\
\text { entre área da } \\
\text { luz esperada } \\
\text { e obtida a } 10 \\
\text { atm }\end{array}$} & \multicolumn{2}{|c|}{$\begin{array}{c}\text { Diferença } \\
\text { entre área da } \\
\text { luz esperada } \\
\text { e obtida a } \\
14-16 \text { atm }\end{array}$} & \multicolumn{2}{|c|}{$\begin{array}{l}\text { Diferença } \\
\text { entre área da } \\
\text { luz esperada } \\
\text { e obtida final }\end{array}$} \\
\hline & $r$ & $\mathrm{P}$ & $r$ & $\mathrm{P}$ & $r$ & $P$ \\
\hline $\begin{array}{l}\text { Componente } \\
\text { Fibrótico }\end{array}$ & 0.23 & 0.31 & 0.17 & 0.44 & 0.09 & 0.70 \\
\hline $\begin{array}{l}\text { Componente } \\
\text { Lipídico }\end{array}$ & 0.07 & 0.75 & 0.12 & 0.59 & 0.12 & 0.58 \\
\hline $\begin{array}{c}\text { Componente } \\
\text { Calcificado }\end{array}$ &,$- 531^{*}$ & 0.01 &,$- 473^{*}$ & 0.03 &,$- 502^{*}$ & 0.02 \\
\hline $\begin{array}{l}\text { Área de } \\
\text { Cálcio }\end{array}$ &,$- 512^{*}$ & 0.01 &,$- 451^{*}$ & 0.04 &,$- 478^{*}$ & 0.02 \\
\hline $\begin{array}{l}\text { Distância } \\
\text { Cálcio-Luz }\end{array}$ &,$- 518^{*}$ & 0.01 &,$- 449^{*}$ & 0.04 &,$- 471^{*}$ & 0.03 \\
\hline $\begin{array}{l}\text { Ângulo de } \\
\text { Cálcio }\end{array}$ &,$- 516^{*}$ & 0.01 &,$- 457^{*}$ & 0.03 &,$- 479^{*}$ & 0.02 \\
\hline
\end{tabular}


Tabela 7- Correlação entre as áreas do stent esperada e obtida e os componentes da placa aterosclerótica com as pressões $10 \mathrm{~atm}, 14-16 \mathrm{~atm}$ e ao final do procedimento - análise por artéria.

\begin{tabular}{|c|c|c|c|c|c|c|}
\hline & \multicolumn{2}{|c|}{$\begin{array}{c}\text { Diferença } \\
\text { entre área } \\
\text { do stent } \\
\text { esperada e } \\
\text { obtida a } 10 \\
\text { atm }\end{array}$} & \multicolumn{2}{|c|}{$\begin{array}{c}\text { Diferença } \\
\text { entre área } \\
\text { do stent } \\
\text { esperada e } \\
\text { obtida a 14- } \\
16 \text { atm }\end{array}$} & \multicolumn{2}{|c|}{$\begin{array}{c}\text { Diferença } \\
\text { entre área } \\
\text { do stent } \\
\text { esperada e } \\
\text { obtida final }\end{array}$} \\
\hline & $r$ & $\mathbf{P}$ & $\mathbf{r}$ & $\mathbf{P}$ & $r$ & $\mathbf{P}$ \\
\hline $\begin{array}{l}\text { Componente } \\
\text { Fibrótico }\end{array}$ & 0.32 & 0.15 & 0.24 & 0.29 & 0.13 & 0.55 \\
\hline $\begin{array}{l}\text { Componente } \\
\text { Lipídico }\end{array}$ & 0.01 & 0.97 & 0.06 & 0.80 & 0.12 & 0.59 \\
\hline $\begin{array}{c}\text { Componente } \\
\text { Calcificado }\end{array}$ &, $578^{* *}$ & 0.00 &,$- 518^{*}$ & 0.01 & -0.42 & 0.05 \\
\hline $\begin{array}{c}\text { Área de } \\
\text { Cálcio }\end{array}$ &, $5 \overline{5} 7^{\star *}$ & 0.01 &,$- 497^{*}$ & 0.02 & -0.39 & 0.07 \\
\hline $\begin{array}{l}\text { Distância } \\
\text { Cálcio-Luz }\end{array}$ &, $563^{* *}$ & 0.01 &,$- 498^{*}$ & 0.02 & -0.38 & 0.08 \\
\hline $\begin{array}{l}\text { Ângulo de } \\
\text { Cálcio }\end{array}$ & $\overline{-}^{-}, 1^{* *}$ & 0.01 &,$- 503^{*}$ & 0.02 & -0.39 & 0.08 \\
\hline
\end{tabular}

Quando esta mesma comparação entre os diferentes componentes da placa aterosclerótica e as áreas da luz e do stent nos diferentes momento pressóricos foi feita considerando os segmentos pareados $(1$ segmento $=3 \mathrm{~mm}$ de comprimento, total de 187 segmentos), o comportamento do cálcio para as medidas da luz e do stent (tabelas 8 e 9) não apresentou correlação expressiva. 
Tabela 8 - Correlação entre as áreas da luz esperadas e obtidas e componentes da placa aterosclerótica com as pressões $10 \mathrm{~atm}, 14-16 \mathrm{~atm}$ e ao final do procedimento - análise por segmentos.

\begin{tabular}{|c|c|c|c|c|c|c|}
\hline & \multicolumn{2}{|c|}{$\begin{array}{l}\text { Diferença entre } \\
\text { área da luz } \\
\text { esperada e } \\
\text { obtida a } 10 \mathrm{~atm}\end{array}$} & \multicolumn{2}{|c|}{$\begin{array}{c}\text { Diferença entre } \\
\text { área da luz } \\
\text { esperada e } \\
\text { obtida a 14-16 } \\
\text { atm }\end{array}$} & \multicolumn{2}{|c|}{$\begin{array}{c}\text { Diferença entre } \\
\text { área da luz } \\
\text { esperada e } \\
\text { obtida final }\end{array}$} \\
\hline & $r$ & $\mathbf{P}$ & $\mathbf{r}$ & $\mathbf{P}$ & $\mathbf{r}$ & $\mathbf{P}$ \\
\hline $\begin{array}{l}\text { Componente } \\
\text { Fibrótico }\end{array}$ & 0.016 & 0.826 & 0.065 & 0.381 & 0.020 & 0.788 \\
\hline $\begin{array}{l}\text { Componente } \\
\text { Lipídico }\end{array}$ & $-.206^{* *}$ & 0.005 & -0.134 & 0.071 & -0.011 & 0.881 \\
\hline $\begin{array}{l}\text { Componente } \\
\text { Calcificado }\end{array}$ & $-.162^{*}$ & 0.028 & $-.151^{*}$ & 0.042 & -0.114 & 0.124 \\
\hline $\begin{array}{c}\text { Área de } \\
\text { Cálcio }\end{array}$ & $-.152^{*}$ & 0.039 & $-.152^{*}$ & 0.041 & -0.105 & 0.154 \\
\hline $\begin{array}{l}\text { Distância } \\
\text { Cálcio-Luz }\end{array}$ & $-.171^{*}$ & 0.021 & $-.149^{*}$ & 0.045 & -0.095 & 0.198 \\
\hline $\begin{array}{l}\text { Ângulo de } \\
\text { Cálcio }\end{array}$ & $-.162^{*}$ & 0.029 & $-.155^{*}$ & 0.036 & -0.120 & 0.105 \\
\hline
\end{tabular}


Tabela 9 - Correlação entre as áreas da stent esperada e obtida e componentes da placa aterosclerótica com as pressões $10 \mathrm{~atm}, 14-16 \mathrm{~atm}$ e ao final do procedimento - análise por segmento

\begin{tabular}{|c|c|c|c|c|c|c|}
\hline & \multicolumn{2}{|c|}{$\begin{array}{l}\text { Diferença entre } \\
\text { área do stent } \\
\text { esperada e } \\
\text { obtida a } 10 \mathrm{~atm}\end{array}$} & \multicolumn{2}{|c|}{$\begin{array}{c}\text { Diferença entre } \\
\text { área do stent } \\
\text { esperada e } \\
\text { obtida a 14-16 } \\
\text { atm }\end{array}$} & \multicolumn{2}{|c|}{$\begin{array}{c}\text { Diferença entre } \\
\text { área do stent } \\
\text { esperada e } \\
\text { obtida final }\end{array}$} \\
\hline & $r$ & $\mathbf{P}$ & $r$ & $\mathbf{P}$ & $r$ & $\mathbf{P}$ \\
\hline $\begin{array}{l}\text { Componente } \\
\text { Fibrótico }\end{array}$ & -0.10 & 0.17 & 0.07 & 0.32 & 0.02 & 0.79 \\
\hline $\begin{array}{l}\text { Componente } \\
\text { Lipídico }\end{array}$ & $-.188^{\star}$ & 0.01 & -0.09 & 0.24 & 0.06 & 0.38 \\
\hline $\begin{array}{l}\text { Componente } \\
\text { Calcificado }\end{array}$ & $-.203^{* *}$ & 0.01 & $-.167^{*}$ & 0.02 & -0.10 & 0.17 \\
\hline $\begin{array}{l}\text { Área de } \\
\text { Cálcio }\end{array}$ & $-.176^{\star}$ & 0.02 & $-.158^{*}$ & 0.03 & -0.08 & 0.28 \\
\hline $\begin{array}{l}\text { Distância } \\
\text { Cálcio-Luz }\end{array}$ & $-.209^{* *}$ & 0.00 & $-.177^{*}$ & 0.02 & -0.08 & 0.28 \\
\hline $\begin{array}{l}\text { Ângulo de } \\
\text { Cálcio }\end{array}$ & $-.199^{\star *}$ & 0.01 & $-.172^{*}$ & 0.02 & -0.11 & 0.14 \\
\hline
\end{tabular}

4.2.4 Composição da placa e seu impacto nos resultados agudos do implante do stent

Para avaliar os efeitos da composição da placa nos resultados agudos do stent coronário, as lesões foram divididas em dois grupos usando a mediana 
de cada tipo de tecido como valores de corte para categorizar as lesões (grupo 1= menos componente da placa; grupo 2= mais componente da placa).

Na linha de base, a área luminal mínima foi semelhante entre as placas com diferentes componentes da placa. No entanto, o comportamento mecânico durante a intervenção foi significativamente modulado pela composição da placa subjacente. Os segmentos com grande conteúdo fibrocalcificado tenderam a menores áreas luminais mínimas durante as dilatações sequenciais da intervenção, em comparação `as lesões com pouco conteúdo fibrocalcificado. Por outro lado, as placas com muito conteúdo lipídico aumentaram as áreas luminal mínimas durante as dilatações sequenciais, em comparação com lesões com pouco conteúdo lipídico. Os segmentos com vaso normal não influenciaram significativamente os resultados (Figura 11). Da mesma forma, a quantidade de prolapso da placa durante as etapas de dilatação foi significativamente influenciada pela composição do tecido basal (Figura 12). 


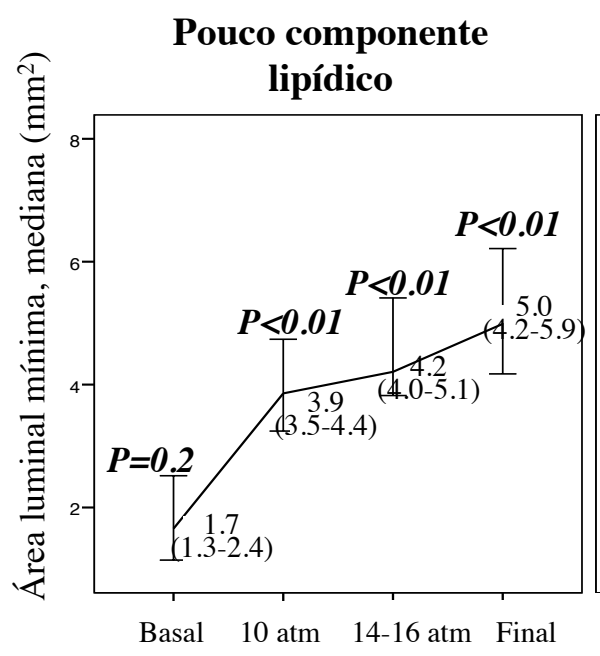

Muito componente
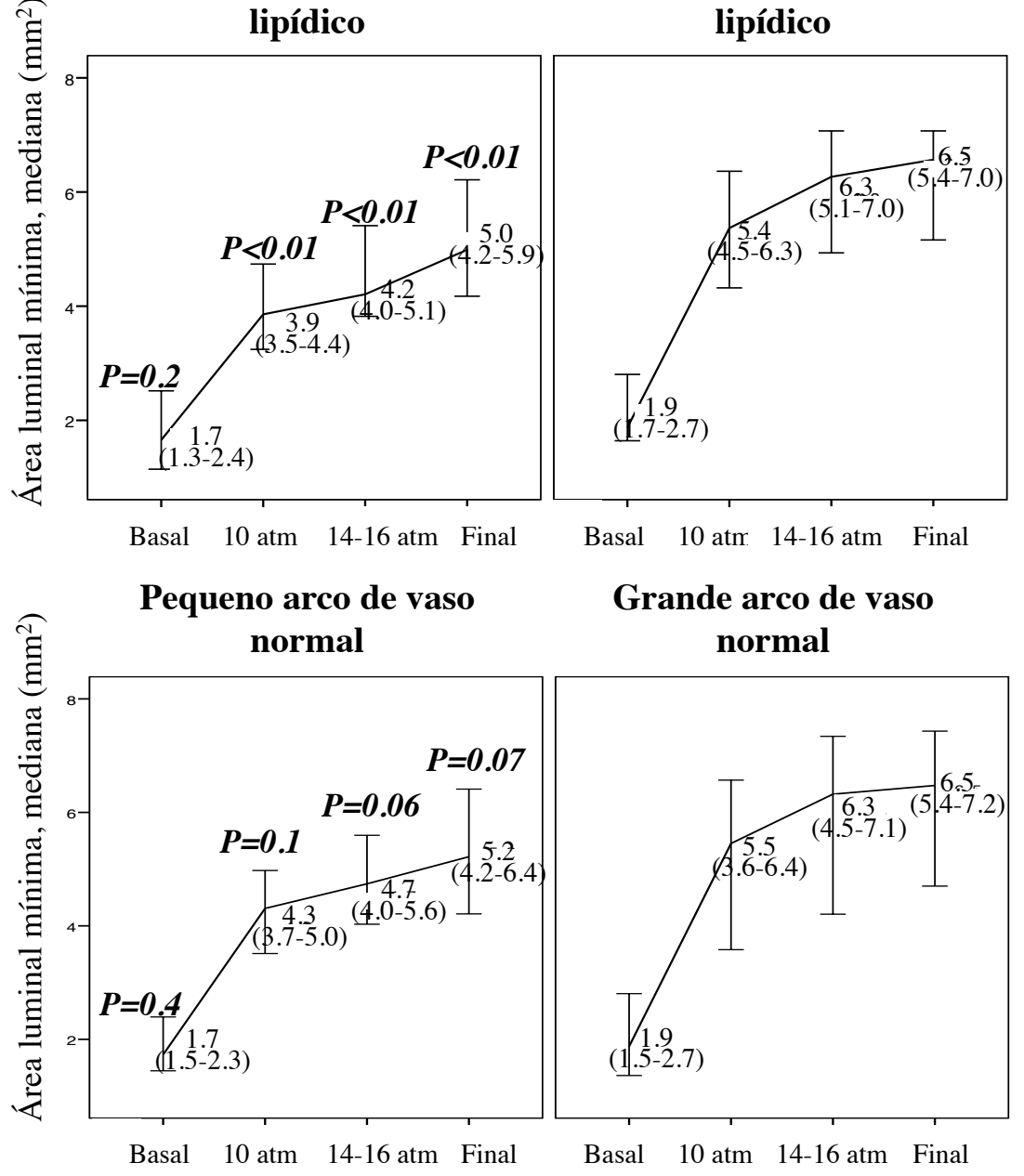

Grande arco de vaso normal

Pouco componente fibrocalcificado

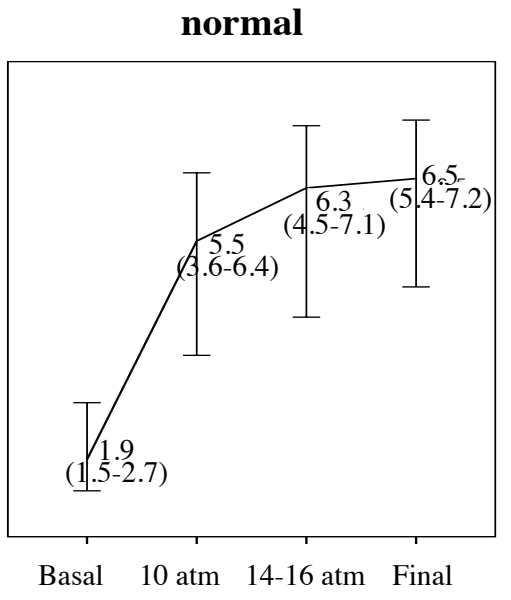

Muito componente fibrocalcificado

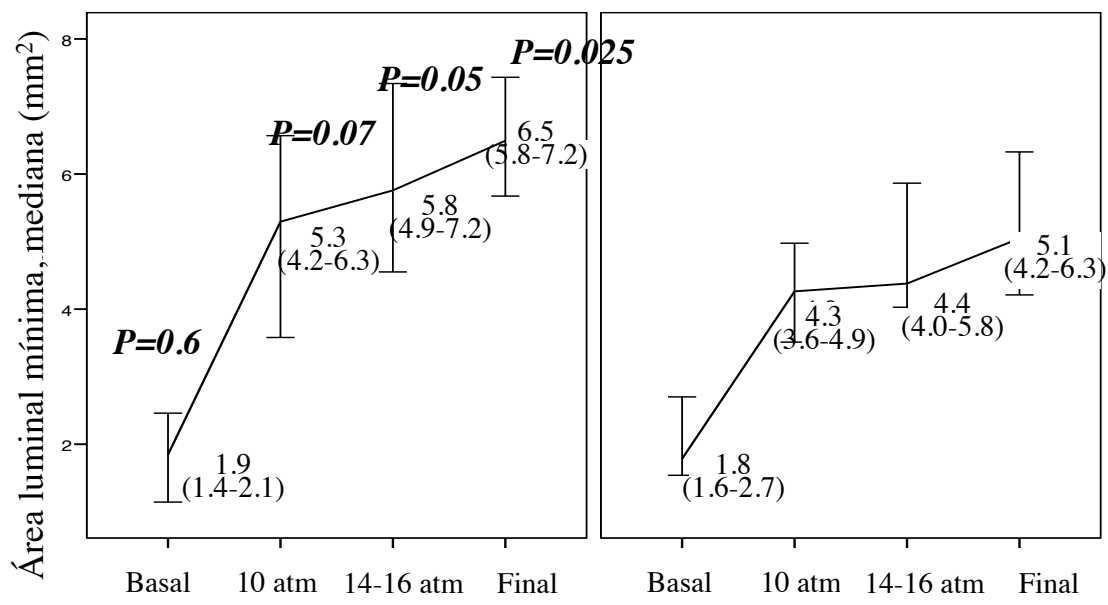


Figura 11- Áreas luminais mínimas nas diferentes etapas do procedimento índice (basal, após o implante do stent a 10 atm, após a pós-dilatação com 1416 atm e ao final do procedimento). Os gráficos mostram o comportamento mecânico das placas com pouco ou muito componente lipídico (painéis superiores), pouco ou muito conteúdo de vaso normal (painéis do meio), e pouco ou muito componente fibrocalcificado (painéis inferiores). As lesões foram divididas em 2 grupos usando a mediana de cada tipo de tecido como valores de corte para categorizar as lesões. Os valores de $\mathrm{P}$ se referem `as comparações da área luminal mínima entre placas com pouco ou muito componente tecidual no mesmo momento do protocolo. Atm = atmosferas; barras de erro são intervalos de confiança 95\%; úmeros são medianas (intervalos interquartis). 

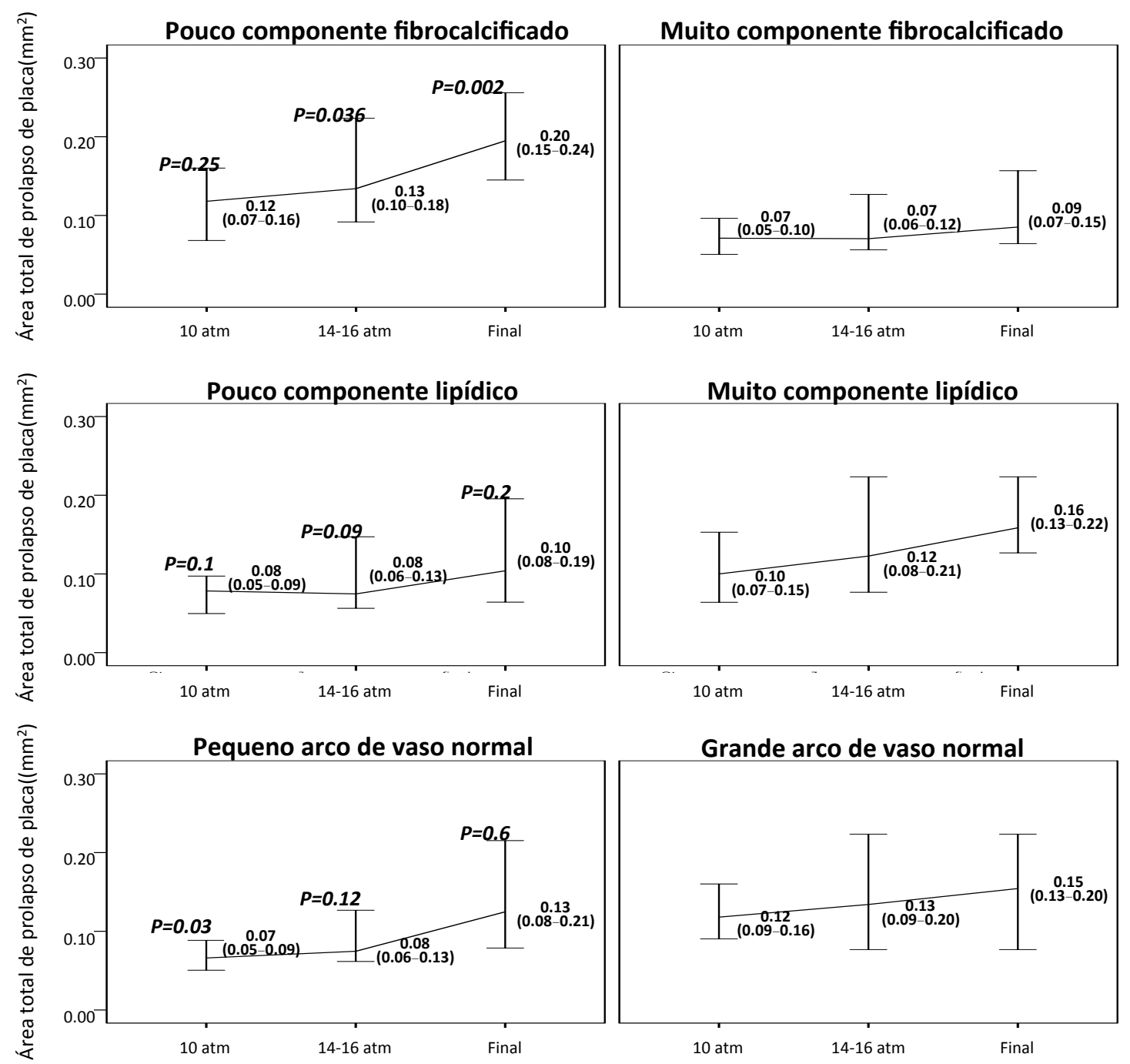

Figura 12 - Área total de prolapso de placa nas diferentes etapas do procedimento índice (após o implante do stent a $10 \mathrm{~atm}$, após a pós-dilatação a 14-16 atm, e ao final do procedimento). Os gráficos mostram a quantidade de prolapso de placa dentro do stent na placa-alvo com pouco ou muito componente fibrocalcificado (painel superior), pouco ou muito componente lipídico (painel do meio), e pequeno ou grande arco de vaso normal (painel inferior). $\mathrm{O}$ valor de $\mathrm{P}$ refere-se à comparação da área luminal mínima entre placas com pouco ou muito componente tecidual na mesma etapa do procedimento. atm = atmosferas; as barras de erro são 95\% dos intervalos de confiança; números são medianas (intervalo interquartil). 


\subsection{Resultados tardios do reestudo por tomografia de coerência óptica}

Foram reestudados por angiografia e tomografia de coerência óptica 17 do total de 20 pacientes (19 de 22 artérias - 86\%) com uma média de 19,7 meses $(591,88 \pm 60,52$ dias) do procedimento índice ( $\min =515$, máx $=697$ dias ). Um paciente apresentou reestenose angiográfica do stent (estenose> $50 \%$ no segmento-alvo) e pela análise da tomografia de coerência óptica o tecido neointimal observado era compatível com neoaterosclerose, ou seja, presença de tecido heterogêneo com áreas de baixa intensidade e infiltrado de lipídios e presença de capa fibrosa fina.

\subsubsection{Análise do stent haste a haste}

A análise haste a haste do stent no reestudo por tomografia de coerência óptica evidenciou uma alta porcentagem de hastes cobertas por tecido neointimal $(99.36 \%)$, com espessura neointimal média de $0.156 \pm$ $0.097 \mathrm{~mm}$ (tabela 10). 
Tabela 10 - Análise da tomografia de coerência óptica no seguimento tardio- análise haste a haste

\section{Análise ao nível da haste do stent}

Total de hastes analisadas $(n)$ 6992.00

Número de hastes por seção transversa (média \pm desvio padrão)

Porcentagem de hastes cobertas (\%)

Porcentagem de hastes malapostas ou desnudas (\%)

\section{Análise ao nível da seção transversa}

Número total de seções transversas analisadas

Espessura máxima da Neoíntima $(\mathrm{mm})$

Espessura mínima da Neoíntima $(\mathrm{mm})$

Espessura média da Neoíntima $(\mathrm{mm})$

Área luminal $\left(\mathrm{mm}^{2}\right)$

Área do stent $\left(\mathrm{mm}^{2}\right)$

Área da neoíntima $\left(\mathrm{mm}^{2}\right)$

Área de malaposição $\left(\mathrm{mm}^{2}\right)$

As medidas estão descritas como frequências, porcentagens e média \pm desvio padrão.

\subsubsection{Relação entre os resultados do procedimento-índice e do reestudo avaliados pela tomografia de coerência óptica}

A área luminal mínima no segmento do stent aumentou nos diferentes momentos pressóricos instituídos no procedimento índice e diminuiu no reestudo $(p<0.01$ para todas as comparações - tabela 11). 
Tabela 11 - Medida quantitativa da área luminal mínima nos diferentes momentos pressóricos e no reestudo tardio - análise por artéria

\begin{tabular}{ll} 
Área Luminal Mínima & \\
\hline Basal & $1.82(1.52-2.47)$ \\
$10 \mathrm{~atm}$ & $4.54(3.64-5.44)$ \\
$14-16 \mathrm{~atm}$ & $5.21(4.17-6.64)$ \\
Final & $6.03(4.59-6.61)$ \\
Reestudo & $4.57(2.96-6.44)$
\end{tabular}

Os resultados são expressos em mediana (intervalo interquartil). Observou-se $\mathrm{P}<0.01$ para todas comparações entre os momentos subsequentes

A composição da placa no procedimento do índice influenciou significativamente a futura formação neointimal no seguimento tardio . As placas com muito tecido fibrocalcificado no momento basal apresentaram crescimento neointimal significativamente menor no seguimento tardio, enquanto que o grau de conteúdo lipídico ou vaso normal tiveram impacto nulo da formação do tecido neointimal (Figura 13). 


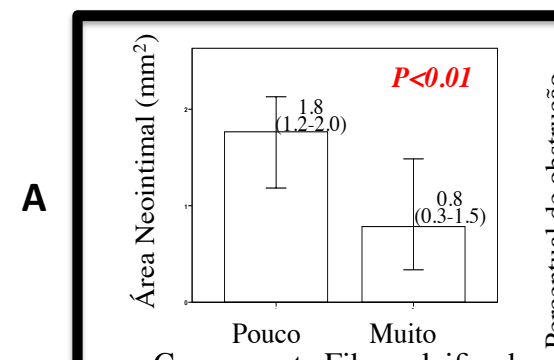

Componente Fibrocalcificado

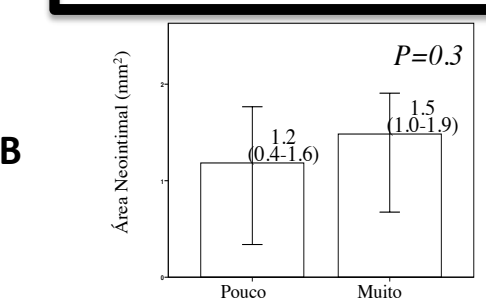

Componente Lipídico

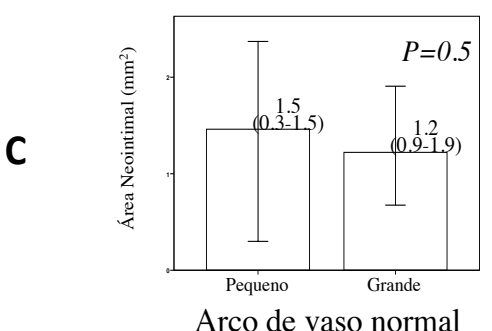

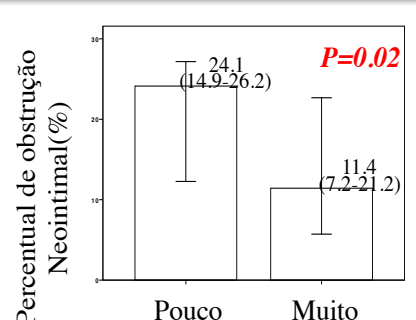

Componente Fibrocalcificado

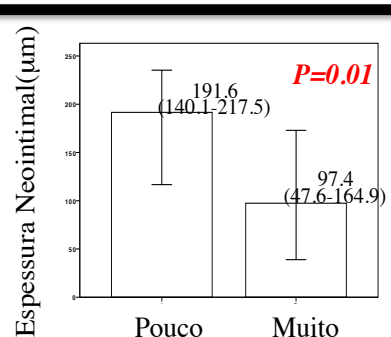

Componente Fibrocalcificado

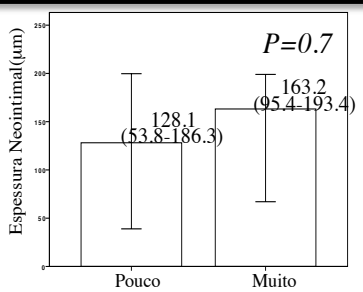

Componente Lipídico

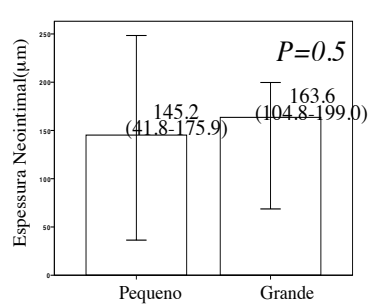

Arco de vaso normal

Figura 13 - Achados da tomografia de coerência óptica no seguimento tardio.

Os gráficos mostram as medidas da área neointimal, percentual de obstrução neointimal e espessura da neointima na placa-alvo com com pouco ou muito componente fibrocalcificado (A), pouco ou muito componente lipídico (B), e pequeno ou grande arco de vaso normal $(\mathrm{C})$. $\mathrm{O}$ valor de $\mathrm{P}$ refere-se às comparações entre a área luminal mínima das placas com pouco ou muito componente tecidual na mesma etapa do procedimento. Barras de erro são 95\% dos intervalos de confiança; números são medianas (intervalo interquartil). 
A análise pareada para os diferentes momentos da angioplastia e no seguimento tardio, considerando os segmentos de forma independentes (1 segmento $=3 \mathrm{~mm}$ de comprimento, total de 154 pares de segmentos), observou-se uma correlação positiva entre a área de protrusão tecidual e a área da neoíntima (figura 14).

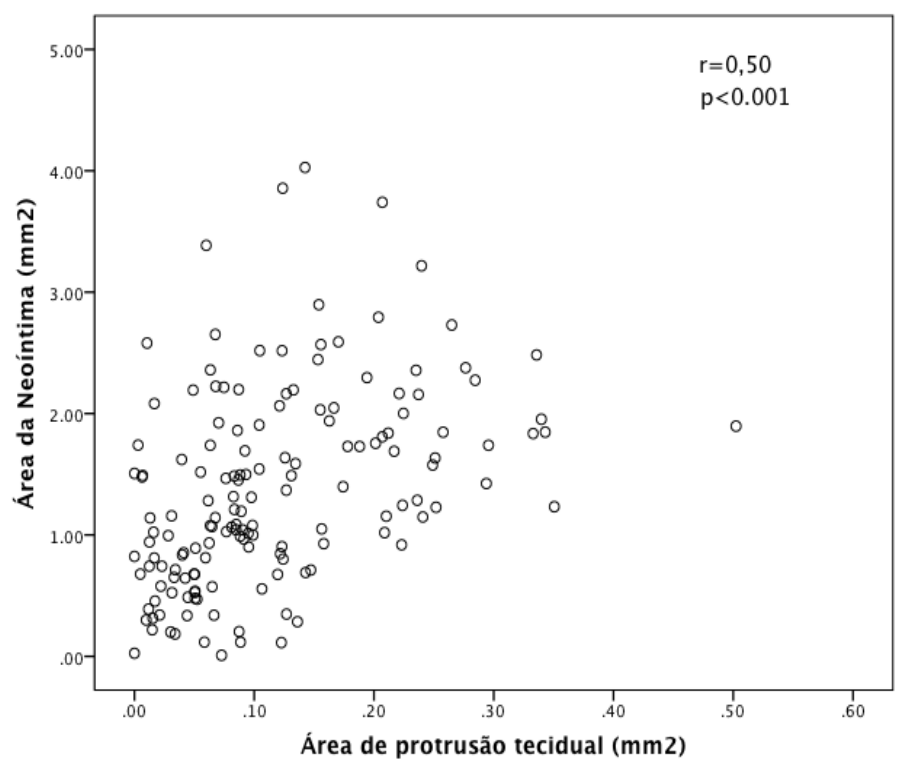

Figura 14 - Correlação entre as medidas da área de protrusão tecidual no procedimento índice e a área da neoíntima no reestudo com tomografia de coerência óptica.

\subsubsection{Injúria vascular no procedimento índice e seu efeito na formação do tecido neointimal}

A mudança na área luminal mínima entre o pré-procedimento e o resultado final (ou seja, o ganho agudo total), bem como a área de prolapso da 
placa no final do procedimento índice foram utilizadas como substitutos da lesão do vaso após o implante do stent coronário. A alteração da área luminal mínima no procedimento índice correlacionou-se significativamente com a área do tecido neointimal (mas não com a porcentagem de obstrução neointimal e espessura neointimal) no seguimento. Além disso, o prolapso da placa no procedimento índice correlacionou-se significativamente com todos os parâmetros de crescimento neointimal no seguimento tardio (Figura 15). 


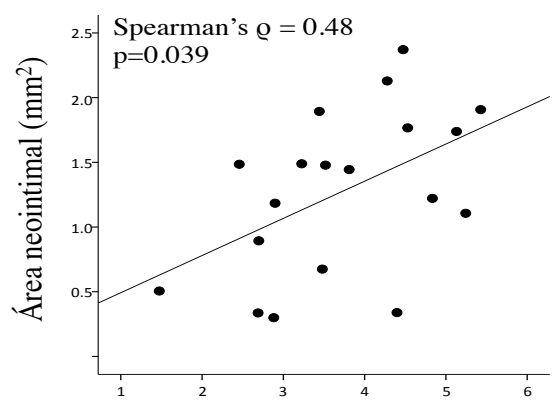

$\triangle$ ALM basal- final $\left(\mathrm{mm}^{2}\right)$

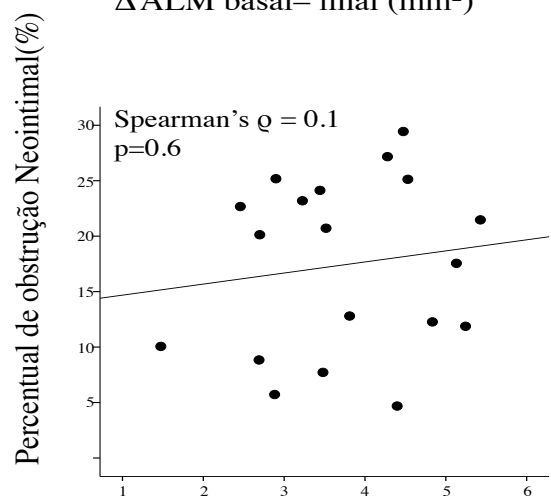

$\triangle$ ALM basal- final $\left(\mathrm{mm}^{2}\right)$

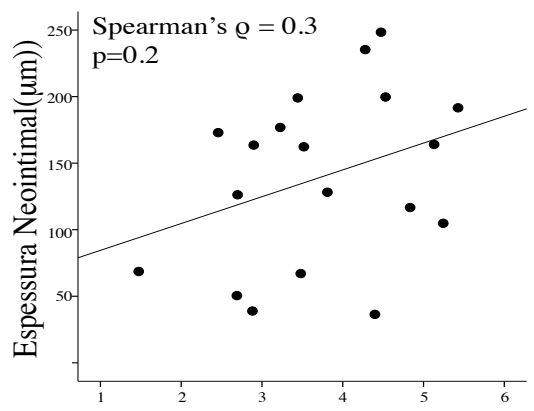

$\triangle$ ALM basal- final $\left(\mathrm{mm}^{2}\right)$

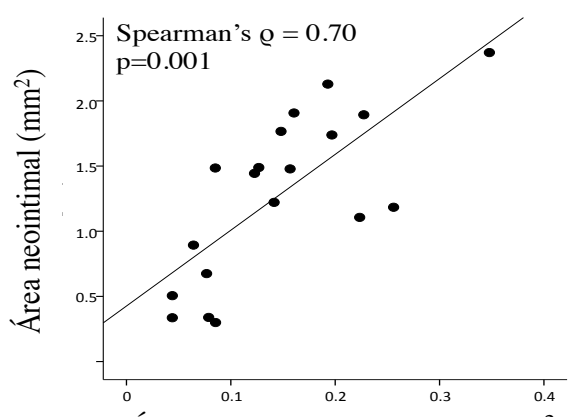

Área de prolapso de placa $\left(\mathrm{mm}^{2}\right)$

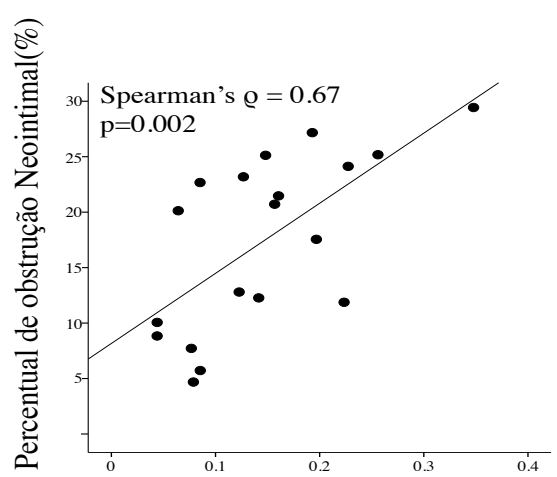

Área de prolapso de $\operatorname{placa}\left(\mathrm{mm}^{2}\right)$

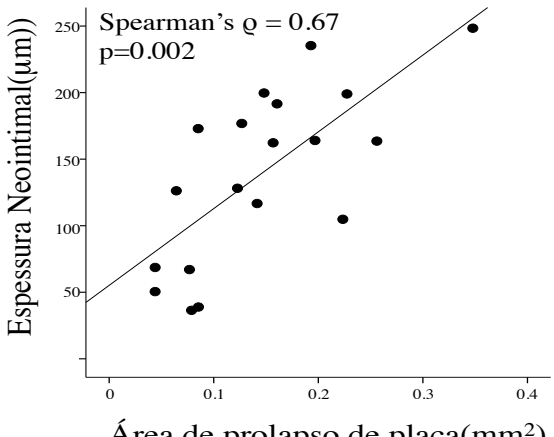

Área de prolapso de placa $\left(\mathrm{mm}^{2}\right)$

Figura 15 - Correlações entre índices de lesão vascular após o implante de stent no procedimento índice (mudanças na área luminal mínima entre o préprocedimento e o resultado final - painéis da esquerda; área de prolapso de placa ao final do procedimento índice - painéis da direita) versus os parâmetros de crescimento neointimal. 


\subsection{Evolução intra-hospitalar e acompanhamento a longo prazo}

$\mathrm{Na}$ evolução intra-hospitalar não ocorreram infarto periprocedimento, piora da função renal ou queda da hemoglobina 24 horas após o procedimento. Não ocorreu morte em geral e de origem cardíaca, infarto agudo do miocárdio, revascularização cirúrgica da lesão-alvo ou do vaso-alvo ou trombose de stent em 12 meses após o procedimento índice. No seguimento tardio, houve a necessidade de revascularização percutânea da lesão-alvo em 01 paciente, no qual foi implantado um novo stent farmacológico. 
Este estudo piloto analisou sistematicamente o impacto da composição basal da placa aterosclerótica sobre os efeitos mecânicos agudos e sobre a cicatrização vascular a longo prazo em resposta ao implante de stent coronário. O presente relatório detalhou in vivo as interações entre lúmen, placa aterosclerótica, parede do vaso e hastes dos stents empregando uma metodologia predefinida de dilatações progressivas no procedimento índice (antes, durante e imediatamente após o implante do stent) e a cicatrização vascular no seguimento tardio. Os principais achados deste estudo foram os seguintes:

1) O aumento sequencial das pressões de dilatação durante o implante dos stents foi associado `a expansão proporcional das áreas do stent, da luz e do prolapso tecidual.

2) A composição da placa basal modulou o comportamento mecânico da lesão tratada durante a intervenção;

3) A composição basal da placa no procedimento índice influenciou a formação do tecido neointimal no seguimento tardio.

4) Os indicadores substitutos de injúria vascular após o implante do stent correlacionaram-se ao posterior crescimento do tecido neointimal.

\subsection{Maior área mínima do stent versus lesão vascular no procedimento índice}

Até o presente momento, a pressão ideal a ser empregada durante o implante do stent para assegurar maior área luminal final e maior expansão do 
stent com menos lesão vascular possível ainda é uma questão em aberto. As principais razões para o uso de altas pressões de insuflação são garantir maior área mínima do stent e evitar a subexpansão, ambas variáveis relacionadas à trombose e à reestenose, tanto para stents convencionais como para stents farmacológicos $12,15,44,50,64,65$. Em estudo recente, Song et al correlacionaram menores áreas mínimas do stent medidas pelo ultrassom intracoronário à reestenose angiográfica no seguimento de 9 meses em 990 stents farmacológicos de segunda geração ${ }^{50}$. Em acordo com estes achados, Prati et al, ao avaliarem o impacto clínico dos achados da tomografia de coerência óptica durante a intervenção coronária percutânea em mais de 800 pacientes, identificaram como um dos preditores independentes de eventos cardíacos maiores a área luminal mínima intra-stent $<4,5 \mathrm{~mm}^{247}$.

Uma série de estudos têm investigado as consequências da pressão de dilatação e da lesão vascular sobre os eventos clínicos ${ }^{14,18}$. Um estudo retrospectivo que avaliou a pressão de insuflação do stent e o resultado clínico de mais de 90.000 stents apresentou maior risco de trombose e de reestenose de stents implantados com pressões baixas ( $\leq 15 \mathrm{~atm})$ ou muito altas ( $\geq 22$ atm), onde a pós-dilatação foi associada ao maior risco de reestenose após o implante do stent ${ }^{18}$. Neste caso, o uso de altas pressões de dilatação podem ter causado dissecção de borda do stent, ruptura das camadas íntima e/ou média levando a maior resposta inflamatória e processo cicatricial vascular mais pronunciado e, consequentemente maior taxa de reestenose. Vários estudos anatomopatológicos e em animais mostraram que a penetração das hastes do stent no núcleo lipídico e lesão vascular da camada média podem 
intensificar a inflamação arterial e aumentar a trombogenicidade, aumentando assim o risco de trombose precoce de stent e reestenose ${ }^{66,67}$.

No nosso estudo, as imagens de tomografia de coerência óptica apresentaram maiores áreas luminal e do stent após cada etapa do protocolo de liberação e de pós-dilatação do stent, com aumento do prolapso tecidual. Embora prolapso tecidual seja um marcador de lesão vascular aguda, seu valor prognóstico permanece incerto, com algumas evidências sugerindo um impacto clínico deletério ${ }^{40,42,47,68}$. Em um registro multicêntrico recente, Soeda et al analisaram 900 lesões por tomografia de coerência óptica após o implante do stent e identificaram o prolapso tecidual como um dos preditores de eventos clínicos em 1 ano ${ }^{42}$. Por outro lado, Qu et al avaliaram mais de 2000 pacientes e os classificaram de acordo com a presença ou ausência de prolapso tecidual baseado em imagens de ultrassom intracoronário após o implante do stent. Neste estudo, apesar de presente com frequência, o prolapso não se relacionou com eventos clínicos em 2 anos ${ }^{68}$. Uma possível explicação para este achado seria o fato dos stents utilizados serem mais calibrosos ou terem recebido pós-dilatação com maior frequência, sendo a área luminal mínima das lesões com prolapso maiores e, deste modo, contrabalanceando o efeito deletério do prolapso ${ }^{68}$.

No entanto, uma intervenção mais agressiva não necessariamente resulta em maior grau de injúria vascular, podendo-se especular que, devido ao seu comportamento mecânico, a placa aterosclerótica subjacente poderia prevenir a ruptura da lâmina elástica interna causada pelos stents, atuando como uma barreira física ao trauma vascular e, portanto, atenuando a formação neointimal. Na era dos stents farmacológicos, outra possível explicação seria 
que seu efeito anti-reestenótico suprimiria a proliferação do tecido neointimal, minimizando o efeito da lesão vascular.

Apesar de ter um papel importante na otimização do implante do stent, a insuflação do balão com alta pressão pode não ser a única opção para se atingir maiores áreas luminais intra-stent. O tempo de insuflação do balão também deve ser levado em conta com o objetivo de equalizar a pressão no sistema de dilatação, conforme descrito em estudos prévios ${ }^{69-71}$. Asano at al, em um estudo empregando ultrassom intracoronário demonstraram que insuflações prolongadas (60 segundos) aumentaram a área e expansão do stent quando comparados `a insuflação de curta duração (10 segundos) ${ }^{70}$. Em situações clínicas em que a insuflação prolongada não é possível, como em lesões de tronco de coronária esquerda não protegido, múltiplas insuflações de curta duração podem resultar em melhor expansão do stent ${ }^{72}$. Hovase et al demonstraram que o implante de stent com insuflação por 25 segundos resultou em melhor expansão do stent, com um aumento médio de no diâmetro mínimo do stent de $8,55 \pm 6,0 \%{ }^{71}$. No nosso estudo as insuflações foram mantidas durante 30 segundos para assegurar a equalização da pressão no sistema de dilatação. 


\subsection{Propriedades mecânicas da placa aterosclerótica e sua interação com o stent}

Estudos biomecânicos in vitro demostraram propriedades mecânicas anormais de placas ateroscleróticas relacionadas ao desenvolvimento e à progressão da doença bem como relacionadas à resposta vascular ao implante de stent $1,73,74$. Possivelmente existam componentes teciduais da placa prontamente dilatáveis nos quais o implante "ótimo" do stent é alcançado com

o emprego de pressões mais baixas ${ }^{23,24}$. Robertson et al investigaram a hipótese de que as placas ateroscleróticas diferiam mecanicamente dos tecidos ao seu redor e este comportamento mecânico estaria na dependência do tipo de placa ${ }^{75}$. Eles identificaram que, regiões com grande carga de placa apresentavam maior variabilidade na complacência e que placas lipídicas eram mais complacentes do que os tecidos ao redor, ao passo que as calcificadas eram menos complacentes ${ }^{75}$. Na nossa análise, os segmentos arteriais ricos em tecido fibrocalcificado apresentaram áreas luminais mínimas menores com menos prolapso da placa ao longo do protocolo de pós-dilatação quando comparados aos segmentos com pouco componente fibrocalcificado. Por outro lado, as placas com muito componente lipídico ou grande arco de artéria normal aumentaram as áreas luminais mínimas durante as dilatações sequenciais do protocolo quando comparadas às lesões com pouco conteúdo dos respectivos componentes. Neste cenário, a pressão de expansão excessiva poderia causar lesão vascular desnecessária, sem nenhum ganho útil ao tamanho final do stent. 
O detalhamento preciso da interação da placa aterosclerótica com o stent no momento do seu implante é crucial para a compreensão das forças mecânicas atuantes na complacência vascular. A informação sobre a composição da placa in situ obtida pela tomografia de coerência óptica poderia guiar o tratamento destas lesões, aplicando-se localmente altas pressões em segmentos da lesão com placas mecanicamente mais resistentes, evitando esta estratégia em placas mecanicamente menos resistentes, sendo possível assim individualizar não só a lesão, mas diferentes segmentos da mesma lesão com características mecânicas distintas. Por conseguinte, a pressão de insuflação do stent necessária para se obter uma alteração relativa na área luminal do vaso variaria de acordo com o componente de placa predominante em cada segmento do vaso. Esse racional é corroborado por informações de estudos prévios de que a distensibilidade da coronária acometida pela doença aterosclerótica apresenta-se como uma função linear da pressão somente a baixas pressões e principalmente em artérias com lesões concêntricas, enquanto que em vigência de pressões mais elevadas a distensibilidade não é previsível $^{76}$.

Os fabricantes dos stents e balões fornecem um gráfico de complacência que informa o diâmetro final obtido como uma função do tamanho nominal do stent ou balão e a pressão de liberação empregada . Em estudo prévio, de Ribamar Costa et al já demonstraram a pouca acurácia desses gráficos de complacência quando comparados com medidas reais durante o tratamento de lesões ateroscleróticas guiadas por ultrassom intracoronário ${ }^{77}$. Estes achados se devem ao fato de que esses gráficos são embasados por resultados de testes in vitro e, por conseguinte, não levam em 
consideração a interação com o vaso e a placa aterosclerótica da lesão a ser tratada. No presente estudo, com o emprego de dilatações sequenciais seguidas de imagens intracoronarianas de tomografia de coerência óptica, foi possível a descrição real das curvas de complacência vascular das lesões ateroscleróticas com diferentes composições teciduais como mostrado na figura 11.

\subsection{Tecido neointimal e sua relação com a composição basal da placa}

O impacto da placa aterosclerótica localizada atrás do stent na formação neointimal durante o processo de cicatrização vascular permanece controverso. Antes do surgimento do stent, em que a angioplastia das lesões ateroscleróticas era realizada apenas com dilatações por balão, estudos com ultrassom intracoronário relacionaram a placa residual à reestenose ${ }^{78}$. Com o surgimento dos stents metálicos esta correlação da placa subjacente com o crescimento do tecido neointimal mostrou-se positiva em alguns estudos e ausente em outros ${ }^{79,80}$. Na era dos stents farmacológicos, evidências apontavam para a ausência da influência da placa residual atrás do stent sobre o impacto na formação do tecido neointimal no longo prazo, fato este que poderia ser atribuido ao efeito anti-proliferativo do fármaco sobre a neointima ${ }^{81}$. No entanto, um estudo recente identificou a placa basal como um preditor independente da área neointimal no seguimento tardio após o implante tanto de stents não farmacológicos como de stents farmacológicos ${ }^{82}$. 
Existem alguns mecanismos possíveis pelos quais a placa aterosclerótica subjacente poderia influenciar o tecido neointimal após o implante do stent ${ }^{48,82}$. É plausível que esta influência possa ser resultado da comunicação da placa subjacente através das hastes do stent, atuando como uma fonte para células inflamatórias e fatores de crescimento, contribuindo para o processo de reestenose. Em estudo recente que avaliou a resposta vascular após o implante de stents convencionais e farmacológicos, Andreou et al observaram uma diminuição na área da placa basal atrás dos stents convencionais que, com a progressão da placa ao longo do tempo, a mesma expandiu através das hastes do stent em direção à neointima, ao passo que o aumento da área de placa após o implante dos stents farmacológicos sugerem que a placa aterosclerótica tenha continuado a progredir em direção `a parede do vaso, similar ao remodelamento positivo observado na fase precoce do processo da doença aterosclerótica ${ }^{82}$.

No presente estudo, demonstramos que o componente fibrocalcificado da placa afeta positivamente a resposta cicatricial tardia, com excelente cobertura das hastes do stent e menores espessura e área neointimais. Por outro lado, pode-se questionar se tal padrão de resposta não tenha sido devido à ausência de características instáveis da placa "não-fibrocalcificada" rica em lipídios a verdadeira causa do melhor perfil de cicatrização. Estudos prévios demonstraram que placas "macias" apresentavam maior área neointimal, sugerindo que as placas ricas em lipídios poderiam representar uma doença mais ativa ${ }^{25,83-85}$. Além disso, a análise histológica de estudos anatomopatológicos em humanos mostraram que a penetração das hastes do stent núcleo lipídico e danos Vasculares poderia aumentar a resposta 
inflamatória local, aumentando a formação do tecido neointimal e, consequentemente o risco de trombose e reestenose precoce do stent ${ }^{67,86}$. De fato, nossos achados mostraram uma correlação positiva entre o prolapso tecidual, marcador de lesão vascular, com a área do tecido neointimal no seguimento a longo prazo.

Do ponto de vista clínico, a apresentação da doença arterial coronariana tem sido relacionada a diferentes padrões de cicatrização após o implante de stent farmacológico, onde pacientes com síndromes coronarianas agudas têm a cicatrização arterial lentificada quando comparados aos pacientes com síndromes estáveis ${ }^{87-89}$. Alguns estudos correlacionaram o tipo de placa aterosclerótica culpada pelo evento agudo com a apresentação clínica e eventos no seguimento à longo prazo, apontando para a morfologia da lesão basal como sendo este elo de ligação ${ }^{58,88,90}$. Alguns mecanismos são apontados como os desencadeadores destes eventos, como o processo de cicatrização retardado com menor crescimento neointimal, maior deposição de fibrina e inflamação local ${ }^{87,88}$.

Alguns estudos têm indicado que a ocorrência da neoaterosclerose está frequentemente relacionada à falência de stent no seguimento tardio, podendo ser o substrato comum entre a reestenose e a trombose muito tardia dos stents 61, 91. Estudos anatomopatológicos evidenciaram algumas características da placa aterosclerótica, como a presença de microvasos, também presentes no processo de neoaterosclerose intra-stent. Essa formação de neovasos, originada dos vasa vasorum da adventícia, na presença de placas com núcleo lipídico e necrótico, comunicam-se por contiguidade com o tecido neointimal e possivelmente contribuem para a formação da 
neoaterosclerose ${ }^{92}$. Desta forma, o tipo de placa basal presente atrás do stent implantado poderia vir a ter uma participação neste processo. Estudos com tomografia de coerência óptica mostraram uma correspondência entre microvasos e neoaterosclerose tanto para stents convencionais como para stents farmacológicos ${ }^{93}$. Neste mesmo estudo, Tian et al também identificaram a presença de placas lipídicas nas bordas do stent com a presença de neoaterosclerose, sugerindo que a progressão da doença basal e, consequentemente da placa basal pré-existente ao implante do stent, estejam envolvidas neste processo ${ }^{93}$.

\subsection{Limitações do estudo}

O presente estudo tem as limitações intrínsecas do seu tamanho amostral relativamente pequeno e deve ser visto como uma pesquisa de fisiopatologia, em vez de um estudo clinicamente orientado. O potencial valor clínico de nossas observações só pode ser explorado em estudos adequadamente desenvolvidos, por exemplo, para avaliar se a classificação da composição da placa pela tomografia de coerência óptica pode ser usada para planejar a estratégia da intervenção.

É importante reconhecer que nossa população excluiu pacientes com lesões altamente calcificadas, vasos cronicamente ocluídos, ou aqueles tratados com pré-dilação com balão ou rotablator, por exemplo. Também excluímos lesões contendo trombo e localizadas em pontos de bifurcação de vasos principais. 
Nossos resultados, portanto, não podem ser diretamente extrapolados para esses cenários. Mesmo que fosse utilizado um stent de libertação de drogas de última geração (doses baixas de sirolimus, revestido com polímeros biodegradáveis na sua face abluminal), não é possível garantir que nossos achados também sejam reproduzidos para outros stents farmacológicos. 


\section{Conclusões}


1. A composição tecidual da placa aterosclerótica analisada pela tomografia de coerência óptica durante o implante de stent farmacológico, influenciou tanto os efeitos mecânicos agudos (em que placas com predomínio do componente fibrocalcificado apresentaram menores ganhos de áreas luminal e do stent), quanto a resposta biológica cicatricial tardia dos vasos (onde as placas com predomínio do componente fibrocalcificado evoluíram com menor crescimento neointimal).

2. A lesão vascular ocorrida durante o implante do stent farmacológico no procedimento índice, esteve potencialmente relacionada ao crescimento do tecido neointimal no seguimento tardio, conforme visualizada pela tomografia de coerência óptica. 


\section{Referências}


1. Edelman ER, Rogers C. Pathobiologic responses to stenting. The American journal of cardiology. 1998 Apr 9;81(7A):4E-6E. PubMed PMID: 9551587.

2. Cheneau E, Satler LF, Escolar E, Suddath WO, Kent KM, Weissman NJ, et al. Underexpansion of sirolimus-eluting stents: incidence and relationship to delivery pressure. Catheterization and cardiovascular interventions : official journal of the Society for Cardiac Angiography \& Interventions. 2005 Jun;65(2):222-6. PubMed PMID: 15900554.

3. Holmes DR, Jr., Kereiakes DJ, Laskey WK, Colombo A, Ellis SG, Henry TD, et al. Thrombosis and drug-eluting stents: an objective appraisal. Journal of the American College of Cardiology. 2007 Jul 10;50(2):109-18. PubMed PMID: 17616294.

4. Luscher TF, Steffel J, Eberli FR, Joner M, Nakazawa G, Tanner FC, et al. Drug-eluting stent and coronary thrombosis: biological mechanisms and clinical implications. Circulation. 2007 Feb 27;115(8):1051-8. PubMed PMID: 17325255.

5. Stefanini GG, Byrne RA, Serruys PW, de Waha A, Meier B, Massberg S, et al. Biodegradable polymer drug-eluting stents reduce the risk of stent thrombosis at 4 years in patients undergoing percutaneous coronary intervention: a pooled analysis of individual patient data from the ISAR-TEST 3, ISAR-TEST 4, and LEADERS randomized trials. European heart journal. 2012 May;33(10):1214-22. PubMed PMID: 22447805. 
6. Serruys PW, Daemen J. Are drug-eluting stents associated with a higher rate of late thrombosis than bare metal stents? Late stent thrombosis: a nuisance in both bare metal and drug-eluting stents. Circulation. 2007 Mar 20;115(11):1433-9; discussion 9. PubMed PMID: 17344323.

7. de Feyter PJ, Kay P, Disco C, Serruys PW. Reference chart derived from post-stent-implantation intravascular ultrasound predictors of 6-month expected restenosis on quantitative coronary angiography. Circulation. 1999 Oct 26;100(17):1777-83. PubMed PMID: 10534464.

8. Uren NG, Schwarzacher SP, Metz JA, Lee DP, Honda Y, Yeung AC, et al. Predictors and outcomes of stent thrombosis: an intravascular ultrasound registry. European heart journal. 2002 Jan;23(2):124-32. PubMed PMID: 11785994.

9. Cheneau E, Leborgne L, Mintz GS, Kotani J, Pichard AD, Satler LF, et al. Predictors of subacute stent thrombosis: results of a systematic intravascular ultrasound study. Circulation. 2003 Jul 8;108(1):43-7. PubMed PMID: 12821553.

10. Sonoda S, Morino Y, Ako J, Terashima M, Hassan AH, Bonneau HN, et al. Impact of final stent dimensions on long-term results following sirolimuseluting stent implantation: serial intravascular ultrasound analysis from the sirius trial. Journal of the American College of Cardiology. 2004 Jun 2;43(11):195963. PubMed PMID: 15172398. 
11. Fujii K, Carlier SG, Mintz GS, Yang YM, Moussa I, Weisz G, et al. Stent underexpansion and residual reference segment stenosis are related to stent thrombosis after sirolimus-eluting stent implantation: an intravascular ultrasound study. Journal of the American College of Cardiology. 2005 Apr 5;45(7):995-8. PubMed PMID: 15808753.

12. Muraoka Y, Sonoda S, Tsuda Y, Tanaka S, Okazaki M, Otsuji Y. Effect of intravascular ultrasound-guided adjuvant high-pressure non-compliant balloon post-dilation after drug-eluting stent implantation. Heart and vessels. 2011 Nov;26(6):565-71. PubMed PMID: 21181171.

13. Stone GW, St Goar FG, Hodgson JM, Fitzgerald PJ, Alderman EL, Yock PG, et al. Analysis of the relation between stent implantation pressure and expansion. Optimal Stent Implantation (OSTI) Investigators. The American journal of cardiology. 1999 May 1;83(9):1397-400, A8. PubMed PMID: 10235100.

14. Dirschinger J, Kastrati A, Neumann FJ, Boekstegers P, Elezi S, Mehilli J, et al. Influence of balloon pressure during stent placement in native coronary arteries on early and late angiographic and clinical outcome: A randomized evaluation of high-pressure inflation. Circulation. 1999 Aug 31;100(9):918-23. PubMed PMID: 10468521.

15. Hoffmann R, Haager P, Mintz GS, Kerckhoff G, Schwarz R, Franke A, et al. The impact of high pressure vs low pressure stent implantation on intimal hyperplasia and follow-up lumen dimensions; results of a randomized trial. European heart journal. 2001 Nov;22(21):2015-24. PubMed PMID: 11603909. 
16. Gerber R, Colombo A. Does IVUS guidance of coronary interventions affect outcome? a prime example of the failure of randomized clinical trials. Catheterization and cardiovascular interventions : official journal of the Society for Cardiac Angiography \& Interventions. 2008 Apr 1;71(5):646-54. PubMed PMID: 18360858.

17. Jang JS, Song YJ, Kang W, Jin HY, Seo JS, Yang TH, et al. Intravascular ultrasound-guided implantation of drug-eluting stents to improve outcome: a meta-analysis. JACC Cardiovascular interventions. 2014 Mar;7(3):233-43. PubMed PMID: 24529934.

18. Frobert O, Sarno G, James SK, Saleh N, Lagerqvist B. Effect of stent inflation pressure and post-dilatation on the outcome of coronary artery intervention. A report of more than 90,000 stent implantations. PloS one. 2013;8(2):e56348. PubMed PMID: 23418560. Pubmed Central PMCID: 3571959.

19. Ahn JM, Kang SJ, Yoon SH, Park HW, Kang SM, Lee JY, et al. Metaanalysis of outcomes after intravascular ultrasound-guided versus angiographyguided drug-eluting stent implantation in 26,503 patients enrolled in three randomized trials and 14 observational studies. The American journal of cardiology. 2014 Apr 15;113(8):1338-47. PubMed PMID: 24685326.

20. Guo N, Maehara A, Mintz GS, He Y, Xu K, Wu X, et al. Incidence, mechanisms, predictors, and clinical impact of acute and late stent 
malapposition after primary intervention in patients with acute myocardial infarction: an intravascular ultrasound substudy of the Harmonizing Outcomes with Revascularization and Stents in Acute Myocardial Infarction (HORIZONSAMI) trial. Circulation. 2010 Sep 14;122(11):1077-84. PubMed PMID: 20805433.

21. Habara M, Nasu K, Terashima M, Kaneda H, Yokota D, Ko E, et al. Impact of frequency-domain optical coherence tomography guidance for optimal coronary stent implantation in comparison with intravascular ultrasound guidance. Circulation Cardiovascular interventions. 2012 Apr;5(2):193-201. PubMed PMID: 22456026.

22. Prati F, Di Vito L, Biondi-Zoccai G, Occhipinti M, La Manna A, Tamburino C, et al. Angiography alone versus angiography plus optical coherence tomography to guide decision-making during percutaneous coronary intervention: the Centro per la Lotta contro I'Infarto-Optimisation of Percutaneous Coronary Intervention (CLI-OPCI) study. Eurolntervention : journal of EuroPCR in collaboration with the Working Group on Interventional Cardiology of the European Society of Cardiology. 2012 Nov 22;8(7):823-9. PubMed PMID: 23034247.

23. Garot P, Pelle G, Teiger E, Belarbi A, Aptecar E, Boudali L, et al. Impact of coronary plaque morphology as assessed by IVUS computer-aided analysis on mechanisms of balloon angioplasty and stenting. Catheterization and cardiovascular interventions : official journal of the Society for Cardiac Angiography \& Interventions. 2001 Apr;52(4):449-56. PubMed PMID: 11285597. 
24. von Birgelen C, Mintz GS, Bose D, Baumgart D, Haude M, Wieneke H, et al. Impact of moderate lesion calcium on mechanisms of coronary stenting as assessed with three-dimensional intravascular ultrasound in vivo. The American journal of cardiology. 2003 Jul 1;92(1):5-10. PubMed PMID: 12842236.

25. Sahara M, Kirigaya H, Oikawa Y, Yajima J, Nagashima K, Hara H, et al. Soft plaque detected on intravascular ultrasound is the strongest predictor of instent restenosis: an intravascular ultrasound study. European heart journal. 2004 Nov;25(22):2026-33. PubMed PMID: 15541839.

26. Fujimoto JG. Optical coherence tomography for ultrahigh resolution in vivo imaging. Nature biotechnology. 2003 Nov;21(11):1361-7. PubMed PMID: 14595364.

27. Kume T, Akasaka T, Kawamoto T, Watanabe N, Toyota E, Neishi Y, et al. Assessment of coronary intima--media thickness by optical coherence tomography: comparison with intravascular ultrasound. Circulation journal : official journal of the Japanese Circulation Society. 2005 Aug;69(8):903-7. PubMed PMID: 16041157

28. Tearney GJ, Jang IK, Bouma BE. Optical coherence tomography for imaging the vulnerable plaque. Journal of biomedical optics. 2006 MarApr;11(2):021002. PubMed PMID: 16674177. Pubmed Central PMCID: 2785459.

29. Schmitt JM, Knuttel A, Yadlowsky M, Eckhaus MA. Optical-coherence tomography of a dense tissue: statistics of attenuation and backscattering. Physics in medicine and biology. 1994 Oct;39(10):1705-20. PubMed PMID: 15551540. 
30. Jang IK, Bouma BE, Kang DH, Park SJ, Park SW, Seung KB, et al. Visualization of coronary atherosclerotic plaques in patients using optical coherence tomography: comparison with intravascular ultrasound. Journal of the American College of Cardiology. 2002 Feb 20;39(4):604-9. PubMed PMID: 11849858.

31. Kume T, Akasaka T, Kawamoto T, Watanabe N, Toyota E, Neishi Y, et al. Assessment of coronary arterial plaque by optical coherence tomography. The American journal of cardiology. 2006 Apr 15;97(8):1172-5. PubMed PMID: 16616021.

32. Kawasaki M, Bouma BE, Bressner J, Houser SL, Nadkarni SK, MacNeill BD, et al. Diagnostic accuracy of optical coherence tomography and integrated backscatter intravascular ultrasound images for tissue characterization of human coronary plaques. Journal of the American College of Cardiology. 2006 Jul 4;48(1):81-8. PubMed PMID: 16814652.

33. Kubo T, Imanishi T, Takarada S, Kuroi A, Ueno S, Yamano $\mathrm{T}$, et al. Assessment of culprit lesion morphology in acute myocardial infarction: ability of optical coherence tomography compared with intravascular ultrasound and coronary angioscopy. Journal of the American College of Cardiology. 2007 Sep 4;50(10):933-9. PubMed PMID: 17765119. 
34. Rieber J, Meissner O, Babaryka G, Reim S, Oswald M, Koenig A, et al. Diagnostic accuracy of optical coherence tomography and intravascular ultrasound for the detection and characterization of atherosclerotic plaque composition in ex-vivo coronary specimens: a comparison with histology. Coronary artery disease. 2006 Aug;17(5):425-30. PubMed PMID: 16845250.

35. Yabushita H, Bouma BE, Houser SL, Aretz HT, Jang IK, Schlendorf KH, et al. Characterization of human atherosclerosis by optical coherence tomography. Circulation. 2002 Sep 24;106(13):1640-5. PubMed PMID: 12270856.

36. Tearney GJ, Regar E, Akasaka T, Adriaenssens T, Barlis P, Bezerra HG, et al. Consensus standards for acquisition, measurement, and reporting of intravascular optical coherence tomography studies: a report from the International Working Group for Intravascular Optical Coherence Tomography Standardization and Validation. Journal of the American College of Cardiology. 2012 Mar 20;59(12):1058-72. PubMed PMID: 22421299.

37. Low AF, Kawase Y, Chan YH, Tearney GJ, Bouma BE, Jang IK. In vivo characterisation of coronary plaques with conventional grey-scale intravascular ultrasound: correlation with optical coherence tomography. Eurolntervention : journal of EuroPCR in collaboration with the Working Group on Interventional Cardiology of the European Society of Cardiology. 2009 Mar;4(5):626-32. PubMed PMID: 19378684. Pubmed Central PMCID: 3425358. 
38. Bouma BE, Tearney GJ, Yabushita H, Shishkov M, Kauffman CR, DeJoseph Gauthier D, et al. Evaluation of intracoronary stenting by intravascular optical coherence tomography. Heart. 2003 Mar;89(3):317-20. PubMed PMID: 12591841. Pubmed Central PMCID: 1767586.

39. Gutierrez-Chico JL, Wykrzykowska J, Nuesch E, van Geuns RJ, Koch $\mathrm{KT}$, Koolen JJ, et al. Vascular tissue reaction to acute malapposition in human coronary arteries: sequential assessment with optical coherence tomography. Circulation Cardiovascular interventions. 2012 Feb 1;5(1):20-9, S1-8. PubMed PMID: 22319063.

40. Gonzalo N, Serruys PW, Okamura T, Shen ZJ, Onuma Y, Garcia-Garcia $\mathrm{HM}$, et al. Optical coherence tomography assessment of the acute effects of stent implantation on the vessel wall: a systematic quantitative approach. Heart. 2009 Dec;95(23):1913-9. PubMed PMID: 19671534.

41. Nakata T, Fujii K, Fukunaga M, Shibuya M, Kawai K, Kawasaki D, et al. Morphological, Functional, and Biological Vascular Healing Response 6 Months After Drug-Eluting Stent Implantation: A Randomized Comparison of Three Drug-Eluting Stents. Catheterization and cardiovascular interventions : official journal of the Society for Cardiac Angiography \& Interventions. 2015 Nov 3. PubMed PMID: 26526816.

42. Soeda T, Uemura S, Park SJ, Jang Y, Lee S, Cho JM, et al. Incidence and Clinical Significance of Poststent Optical Coherence Tomography Findings: One-Year Follow-Up Study From a Multicenter Registry. Circulation. 2015 Sep 15;132(11):1020-9. PubMed PMID: 26162917. 
43. Wijns W, Shite J, Jones MR, Lee SW, Price MJ, Fabbiocchi F, et al. Optical coherence tomography imaging during percutaneous coronary intervention impacts physician decision-making: ILUMIEN I study. European heart journal. 2015 Dec 14;36(47):3346-55. PubMed PMID: 26242713. Pubmed Central PMCID: 4677272.

44. Prati F, Kodama T, Romagnoli E, Gatto L, Di Vito L, Ramazzotti V, et al. Suboptimal stent deployment is associated with subacute stent thrombosis: optical coherence tomography insights from a multicenter matched study. From the CLI Foundation investigators: the CLI-THRO study. American heart journal. 2015 Feb;169(2):249-56. PubMed PMID: 25641534.

45. Kawamori $H$, Shite J, Shinke T, Otake $H$, Matsumoto D, Nakagawa M, et al. Natural consequence of post-intervention stent malapposition, thrombus, tissue prolapse, and dissection assessed by optical coherence tomography at mid-term follow-up. European heart journal cardiovascular Imaging. 2013 Sep;14(9):865-75. PubMed PMID: 23291393. Pubmed Central PMCID: 3738096.

46. Shimamura K, Kubo T, Akasaka T, Kozuma K, Kimura K, Kawamura M, et al. Outcomes of everolimus-eluting stent incomplete stent apposition: a serial optical coherence tomography analysis. European heart journal cardiovascular Imaging. 2015 Jan;16(1):23-8. PubMed PMID: 25342855.

47. Prati F, Romagnoli E, Burzotta F, Limbruno U, Gatto L, La Manna A, et al. Clinical Impact of OCT Findings During PCI: The CLI-OPCI II Study. JACC Cardiovascular imaging. 2015 Nov;8(11):1297-305. PubMed PMID: 26563859. 
48. De Cock D, Bennett J, Ughi GJ, Dubois C, Sinnaeve P, Dhooge J, et al. Healing course of acute vessel wall injury after drug-eluting stent implantation assessed by optical coherence tomography. European heart journal cardiovascular Imaging. 2014 Jul;15(7):800-9. PubMed PMID: 24497520.

49. Liu X, Doi H, Maehara A, Mintz GS, Costa Jde R, Jr., Sano K, et al. A volumetric intravascular ultrasound comparison of early drug-eluting stent thrombosis versus restenosis. JACC Cardiovascular interventions. 2009 May;2(5):428-34. PubMed PMID: 19463466.

50. Song HG, Kang SJ, Ahn JM, Kim WJ, Lee JY, Park DW, et al. Intravascular ultrasound assessment of optimal stent area to prevent in-stent restenosis after zotarolimus-, everolimus-, and sirolimus-eluting stent implantation. Catheterization and cardiovascular interventions : official journal of the Society for Cardiac Angiography \& Interventions. 2014 May 01;83(6):873-8. PubMed PMID: 22815193.

51. Kubo T, Akasaka T, Shite J, Suzuki T, Uemura S, Yu B, et al. OCT compared with IVUS in a coronary lesion assessment: the OPUS-CLASS study. JACC Cardiovascular imaging. 2013 Oct;6(10):1095-104. PubMed PMID: 24011777.

52. Maehara A, Ben-Yehuda O, Ali Z, Wijns W, Bezerra HG, Shite J, et al. Comparison of Stent Expansion Guided by Optical Coherence Tomography Versus Intravascular Ultrasound: The ILUMIEN II Study (Observational Study of Optical Coherence Tomography [OCT] in Patients Undergoing Fractional Flow Reserve [FFR] and Percutaneous Coronary Intervention). JACC Cardiovascular interventions. 2015 Nov;8(13):1704-14. PubMed PMID: 26585621. 
53. Radu MD, Raber L, Heo J, Gogas BD, Jorgensen E, Kelbaek H, et al. Natural history of optical coherence tomography-detected non-flow-limiting edge dissections following drug-eluting stent implantation. Eurolntervention : journal of EuroPCR in collaboration with the Working Group on Interventional Cardiology of the European Society of Cardiology. 2014 Jan 22;9(9):1085-94. PubMed PMID: 24064426.

54. Porto I, Di Vito L, Burzotta F, Niccoli G, Trani C, Leone AM, et al. Predictors of periprocedural (type IVa) myocardial infarction, as assessed by frequency-domain optical coherence tomography. Circulation Cardiovascular interventions. 2012 Feb 1;5(1):89-96, S1-6. PubMed PMID: 22298799.

55. Gonzalo N, Serruys PW, Okamura T, Shen ZJ, Garcia-Garcia HM, Onuma $\mathrm{Y}$, et al. Relation between plaque type and dissections at the edges after stent implantation: an optical coherence tomography study. International journal of cardiology. 2011 Jul 15;150(2):151-5. PubMed PMID: 20466444.

56. Sabate M, Brugaletta S, Cequier A, Iniguez A, Serra A, JimenezQuevedo P, et al. Clinical outcomes in patients with ST-segment elevation myocardial infarction treated with everolimus-eluting stents versus bare-metal stents (EXAMINATION): 5-year results of a randomised trial. Lancet. 2016 Jan 23;387(10016):357-66. PubMed PMID: 26520230.

57. lannaccone M, D'Ascenzo F, Templin C, Omede P, Montefusco A, Guagliumi G, et al. Optical coherence tomography evaluation of intermediateterm healing of different stent types: systemic review and meta-analysis. European heart journal cardiovascular Imaging. 2016 Apr 20. PubMed PMID: 27099274. 
58. Galon MZ, Wang Z, Bezerra HG, Lemos PA, Schnell A, Wilson DL, et al. Differences determined by optical coherence tomography volumetric analysis in non-culprit lesion morphology and inflammation in ST-segment elevation myocardial infarction and stable angina pectoris patients. Catheterization and cardiovascular interventions : official journal of the Society for Cardiac Angiography \& Interventions. 2015 Mar;85(4):E108-15. PubMed PMID: 25178981. Pubmed Central PMCID: 4484583.

59. Gonzalo N, Garcia-Garcia HM, Serruys PW, Commissaris KH, Bezerra $H$, Gobbens $P$, et al. Reproducibility of quantitative optical coherence tomography for stent analysis. Eurolntervention : journal of EuroPCR in collaboration with the Working Group on Interventional Cardiology of the European Society of Cardiology. 2009 Jun;5(2):224-32. PubMed PMID: 19527980.

60. Teramoto T, Ikeno F, Otake H, Lyons JK, van Beusekom HM, Fearon WF, et al. Intriguing peri-strut low-intensity area detected by optical coherence tomography after coronary stent deployment. Circulation journal : official journal of the Japanese Circulation Society. 2010 Jun;74(6):1257-9. PubMed PMID: 20453394.

61. Park SJ, Kang SJ, Virmani R, Nakano M, Ueda $Y$. In-stent neoatherosclerosis: a final common pathway of late stent failure. Journal of the American College of Cardiology. 2012 Jun 5;59(23):2051-7. PubMed PMID: 22651862. 
62. Thygesen K, Alpert JS, White HD, Joint ESCAAHAWHFTFftRoMI. Universal definition of myocardial infarction. Journal of the American College of Cardiology. 2007 Nov 27;50(22):2173-95. PubMed PMID: 18036459.

63. Hsieh FY, Lavori PW. Sample-size calculations for the Cox proportional hazards regression model with nonbinary covariates. Controlled clinical trials. 2000 Dec;21(6):552-60. PubMed PMID: 11146149.

64. Meneveau N, Souteyrand G, Motreff P, Caussin C, Amabile N, Ohlmann P, et al. Optical Coherence Tomography to Optimize Results of Percutaneous Coronary Intervention in Patients with Non-ST-Elevation Acute Coronary Syndrome: Results of the Multicenter, Randomized DOCTORS Study (Does Optical Coherence Tomography Optimize Results of Stenting). Circulation. 2016 Sep 27;134(13):906-17. PubMed PMID: 27573032.

65. Romagnoli E, Sangiorgi GM, Cosgrave J, Guillet E, Colombo A. Drugeluting stenting: the case for post-dilation. JACC Cardiovascular interventions. 2008 Feb;1(1):22-31. PubMed PMID: 19393140.

66. Gunn J, Arnold N, Chan KH, Shepherd L, Cumberland DC, Crossman DC. Coronary artery stretch versus deep injury in the development of in-stent neointima. Heart2002. p. 401-5.

67. Farb A, Weber DK, Kolodgie FD, Burke AP, Virmani R. Morphological predictors of restenosis after coronary stenting in humans. Circulation. 2002 Jun 25;105(25):2974-80. PubMed PMID: 12081990. 
68. Qiu F, Mintz GS, Witzenbichler B, Metzger DC, Rinaldi MJ, Duffy PL, et al. Prevalence and Clinical Impact of Tissue Protrusion After Stent Implantation: An ADAPT-DES Intravascular Ultrasound Substudy. JACC Cardiovascular interventions. 2016 Jul 25;9(14):1499-507. PubMed PMID: 27478119.

69. Trindade IS, Sarmento-Leite R, Santos de Freitas M, Gottschall CA. Determination of the minimum inflation time necessary for total stent expansion and apposition: an in vitro study. The Journal of invasive cardiology. 2008 Aug;20(8):396-8. PubMed PMID: 18688062.

70. Asano T, Kobayashi Y, Fukushima K, Iwata Y, Kitahara H, Ishio N, et al. Effect of balloon inflation time on expansion of sirolimus-eluting stent. Heart and vessels. 2009 Sep;24(5):335-9. PubMed PMID: 19784815.

71. Hovasse T, Mylotte D, Garot P, Salvatella N, Morice MC, Chevalier B, et al. Duration of balloon inflation for optimal stent deployment: five seconds is not enough. Catheterization and cardiovascular interventions : official journal of the Society for Cardiac Angiography \& Interventions. 2013 Feb;81(3):446-53. PubMed PMID: 22109977.

72. Iwamoto $\mathrm{Y}$, Okamoto $\mathrm{M}$, Hashimoto $\mathrm{M}$, Fukuda $\mathrm{Y}$, Iwamoto $\mathrm{A}$, Iwasaki $\mathrm{T}$, et al. Better stent expansion by two-time inflation of stent balloon and its responsible mechanism. Journal of cardiology. 2012 Mar;59(2):160-6. PubMed PMID: 22266460.

73. Akyildiz AC, Speelman L, Gijsen FJ. Mechanical properties of human atherosclerotic intima tissue. Journal of biomechanics. 2014 Mar 03;47(4):77383. PubMed PMID: 24529360. 
74. Maher E, Creane A, Sultan S, Hynes N, Lally C, Kelly DJ. Tensile and compressive properties of fresh human carotid atherosclerotic plaques. Journal of biomechanics. 2009 Dec 11;42(16):2760-7. PubMed PMID: 19766226.

75. Robertson C, Heidari AE, Chen Z, George SC. Mechanical analysis of arterial plaques in native geometry with OCT wall motion analysis. Journal of biomechanics. 2014 Feb 07;47(3):755-8. PubMed PMID: 24388166. Pubmed Central PMCID: 3914757.

76. Frobert $\mathrm{O}$, Schionning J, Gregersen H, Baandrup U, Petersen JA, Bagger JP. Impaired human coronary artery distensibility by atherosclerotic lesions: a mechanical and histological investigation. International journal of experimental pathology. 1997 Dec;78(6):421-8. PubMed PMID: 9516874. Pubmed Central PMCID: 2694552.

77. de Ribamar Costa J, Jr., Mintz GS, Carlier SG, Costa RA, Fujii K, Sano $\mathrm{K}$, et al. Intravascular ultrasonic assessment of stent diameters derived from manufacturer's compliance charts. The American journal of cardiology. 2005 Jul 01;96(1):74-8. PubMed PMID: 15979438.

78. Mintz GS, Popma JJ, Pichard AD, Kent KM, Salter LF, Chuang YC, et al. Intravascular ultrasound predictors of restenosis after percutaneous transcatheter coronary revascularization. Journal of the American College of Cardiology. 1996 Jun;27(7):1678-87. PubMed PMID: 8636553. 
79. Casserly IP, Aronow HD, Schoenhagen P, Tsutsui H, Popovich J, Goormastic $\mathrm{M}$, et al. Relationship between residual atheroma burden and neointimal growth in patients undergoing stenting: analysis of the atherectomy before MULTI-LINK improves lumen gain and clinical outcomes trial intravascular ultrasound substudy. Journal of the American College of Cardiology. 2002 Nov 06;40(9):1573-8. PubMed PMID: 12427408.

80. Moussa I, Moses J, Di Mario C, Busi G, Reimers B, Kobayashi Y, et al. Stenting after optimal lesion debulking (sold) registry. Angiographic and clinical outcome. Circulation. 1998 Oct 20;98(16):1604-9. PubMed PMID: 9778324.

81. Tanabe K, Serruys PW, Degertekin M, Guagliumi G, Grube E, Chan C, et al. Chronic arterial responses to polymer-controlled paclitaxel-eluting stents: comparison with bare metal stents by serial intravascular ultrasound analyses: data from the randomized TAXUS-II trial. Circulation. 2004 Jan 20;109(2):196200. PubMed PMID: 14691036.

82. Andreou I, Takahashi S, Tsuda M, Shishido K, Antoniadis AP, Papafaklis MI, et al. Atherosclerotic plaque behind the stent changes after bare-metal and drug-eluting stent implantation in humans: Implications for late stent failure? Atherosclerosis. 2016 Sep;252:9-14. PubMed PMID: 27494445. Pubmed Central PMCID: 5035643. 
83. Finet G, Weissman NJ, Mintz GS, Satler LF, Kent KM, Laird JR, et al. Mechanism of lumen enlargement with direct stenting versus predilatation stenting: influence of remodelling and plaque characteristics assessed by volumetric intracoronary ultrasound. Heart. 2003 Jan;89(1):84-90. PubMed PMID: 12482801. Pubmed Central PMCID: 1767502.

84. Narula J, Nakano M, Virmani R, Kolodgie FD, Petersen R, Newcomb R, et al. Histopathologic characteristics of atherosclerotic coronary disease and implications of the findings for the invasive and noninvasive detection of vulnerable plaques. Journal of the American College of Cardiology. 2013 Mar 12;61(10):1041-51. PubMed PMID: 23473409. Pubmed Central PMCID: 3931303.

85. Higuma T, Soeda T, Yamada M, Yokota T, Yokoyama H, Nishizaki F, et al. Coronary Plaque Characteristics Associated With Reduced TIMI (Thrombolysis in Myocardial Infarction) Flow Grade in Patients With STSegment-Elevation Myocardial Infarction: A Combined Optical Coherence Tomography and Intravascular Ultrasound Study. Circulation Cardiovascular interventions. 2016 Sep;9(9). PubMed PMID: 27609831.

86. Nakano M, Yahagi K, Otsuka F, Sakakura K, Finn AV, Kutys R, et al. Causes of early stent thrombosis in patients presenting with acute coronary syndrome: an ex vivo human autopsy study. Journal of the American College of Cardiology. 2014 Jun 17;63(23):2510-20. PubMed PMID: 24768883. 
87. Gonzalo N, Barlis P, Serruys PW, Garcia-Garcia HM, Onuma Y, Ligthart $\mathrm{J}$, et al. Incomplete stent apposition and delayed tissue coverage are more frequent in drug-eluting stents implanted during primary percutaneous coronary intervention for ST-segment elevation myocardial infarction than in drug-eluting stents implanted for stable/unstable angina: insights from optical coherence tomography. JACC Cardiovascular interventions. 2009 May;2(5):445-52. PubMed PMID: 19463469.

88. Nakazawa G, Finn AV, Joner M, Ladich E, Kutys R, Mont EK, et al. Delayed arterial healing and increased late stent thrombosis at culprit sites after drug-eluting stent placement for acute myocardial infarction patients: an autopsy study. Circulation. 2008 Sep 09;118(11):1138-45. PubMed PMID: 18725485.

89. Raber L, Zanchin T, Baumgartner S, Taniwaki M, Kalesan B, Moschovitis A, et al. Differential healing response attributed to culprit lesions of patients with acute coronary syndromes and stable coronary artery after implantation of drugeluting stents: an optical coherence tomography study. International journal of cardiology. 2014 May 01;173(2):259-67. PubMed PMID: 24631113.

90. Prati F, Romagnoli E, Gatto L, La Manna A, Burzotta F, Limbruno U, et al. Clinical Impact of Suboptimal Stenting and Residual Intrastent Plaque/Thrombus Protrusion in Patients With Acute Coronary Syndrome: The CLI-OPCI ACS Substudy (Centro per la Lotta Contro L'Infarto-Optimization of Percutaneous Coronary Intervention in Acute Coronary Syndrome). Circulation Cardiovascular interventions. 2016 Dec;9(12). PubMed PMID: 27965297. 
91. Habara M, Terashima M, Nasu K, Kaneda H, Yokota D, Ito T, et al. Morphological differences of tissue characteristics between early, late, and very late restenosis lesions after first generation drug-eluting stent implantation: an optical coherence tomography study. European heart journal cardiovascular Imaging. 2013 Mar;14(3):276-84. PubMed PMID: 22945378.

92. Virmani R, Kolodgie FD, Burke AP, Finn AV, Gold HK, Tulenko TN, et al. Atherosclerotic plaque progression and vulnerability to rupture: angiogenesis as a source of intraplaque hemorrhage. Arteriosclerosis, thrombosis, and vascular biology. 2005 Oct;25(10):2054-61. PubMed PMID: 16037567.

93. Tian J, Ren X, Uemura S, Dauerman H, Prasad A, Toma C, et al. Spatial heterogeneity of neoatherosclerosis and its relationship with neovascularization and adjacent plaque characteristics: optical coherence tomography study. American heart journal. 2014 Jun;167(6):884-92 e2. PubMed PMID: 24890539. 